\title{
Acessos sob demanda em NGN: impactos das trocas dinâmicas entre provedores Wi-Fi para o usuário móvel
}

\author{
Mário Ezequiel Augusto
}




\title{
Acessos sob demanda em NGN: impactos das trocas dinâmicas entre provedores Wi-Fi para o usuário móvel
}

\author{
Mário Ezequiel Augusto
}

Orientador: Prof. Dr. Edson dos Santos Moreira

Tese apresentada ao Instituto de Ciências Matemáticas e de Computação - ICMC-USP, como parte dos requisitos para obtenção do título de Doutor em Ciências - Ciências de Computação e Matemática Computacional. VERSÃO REVISADA.

USP - São Carlos

Fevereiro de 2013 
Ficha catalográfica elaborada pela Biblioteca Prof. Achille Bassi e Seção Técnica de Informática, ICMC/USP, com os dados fornecidos pelo(a) autor(a)

\begin{tabular}{|l} 
A923a Augusto, Mário Ezequiel \\
Acessos sob demanda em NGN impactos das trocas \\
dinâmicas entre provedores Wi-Fi para o usuário móvel \\
/ Mário Ezequiel Augusto; orientador Edson dos \\
Santos Moreira. -- São Carlos, 2012. \\
115 p. \\
Tese (Doutorado - Programa de Pós-Graduação em \\
Ciências de Computação e Matemática Computacional) -- \\
Instituto de Ciências Matemáticas e de Computação, \\
Universidade de São Paulo, 2012. \\
1. acesso sob demanda. 2. gerenciamento de \\
handover. 3. NGN. 4. MIH. 5. simulação de rede. I. \\
Moreira, Edson dos Santos, orient. II. Título. \\
\end{tabular}


À minha esposa, Geane Célia, e meus filhos Marcelo Henrique, André Vinicius e Thiago Ezequiel, razão do meu viver. 


\section{Agradecimentos}

A Deus pela minha vida e pelas oportunidades que nela surgem.

A minha esposa, Geane Célia, e filhos Marcelo Henrique, André Vinicius e Thiago Ezequiel, por compreenderem os momentos de ausência, pelos créditos e confiança depositados nesta empreitada, e pelo carinho de sempre.

Aos meus pais, Gilberto e Fátima, pelo apoio incondicional em todos os momentos de minha vida, e aos meus irmãos, Ricardo e Giovana, pela amizade em família.

Ao meu orientador, Edson Moreira, pela oportunidade, por acreditar no meu trabalho, e pelos direcionamentos no decorrer desta tese.

Ao Hélio Guardia e Renata Vanni pelo tempo cedido nas reuniões relacionadas à montagem da arquitetura MYHand e contribuições para o artigo.

Ao Glenford Mapp e Mahdi Aiash da Universidade de Middlesex, Inglaterra, pelo apoio com alguns artigos.

Aos amigos Roberto Melani, Flávio Santana, Chidambaram, Hermes Irineu, e outros que, em algum momento, expressaram sincera confiança em mim e me deram o apoio moral para eu alcançar este objetivo.

Aos amigos do ICMC, Roberto Rigolin, Roberto Sadao, Bruno Kimura, Renata Vanni, e demais integrantes do Intermídia pela amizade e apoio.

Aos membros da banca de qualificação, professores Edmundo Madeira, Luis Trevelin, e Rodrigo Mello, pelos valiosos direcionamentos do trabalho, e aos membros da banca de defesa pelo tempo dedicado à leitura e análise desta tese.

À Universidade do Estado de Santa Catarina - UDESC por conceder o afastamento durante o período de doutorado.

Ao Programa de Pós-Graduação do ICMC-USP. 


\section{Resumo}

Atualmente tem crescido o uso de aparelhos móveis com mais de uma interface de rede para o acesso à Internet, caracterizando em parte as Redes de Próxima Geração (NGN). Outras características da NGN são o acesso sob demanda, no qual o cliente de acesso não seria, necessariamente, usuário de um único provedor e usaria a rede de outros provedores conforme a necessidade, e o gerenciamento de handover (trocas de rede) centrado no usuário, no qual o usuário é quem decide à qual rede vai se conectar e em que momento. Existem algumas implicações relacionadas ao acesso sob demanda que podem melhorar ou piorar a experiência de acesso do usuário e causar certos impactos relacionados à vazão recebida, valor gasto, número de handovers, entre outros. Para o dispositivo móvel gerenciar os handovers, ele precisa obter informações sobre as redes disponíveis como, por exemplo, preço e incentivos, além das informações já obtidas atualmente como força do sinal recebido e identificador do provedor (SSID). Porém, os provedores não possuem um sistema automatizado para fornecer tais informações aos dispositivos móveis. Esta tese apresenta uma avaliação dos impactos das trocas dinâmicas entre provedores Wi-Fi para o usuário móvel, comparando o acesso sob demanda com o acesso tradicional (como é feito atualmente). Como metodologia para esta avaliação, foram realizadas simulações de redes em um cenário com provedores Wi-Fi com perfis diferentes, nas quais foram analisados o número de handovers realizados, a quantidade de bytes recebidos e o valor gasto com o acesso. Nestas simulações o usuário pôde priorizar o custo da conexão, a força do sinal recebido e a carga de trabalho no ponto de acesso para decidir a troca de rede. Esta tese também apresenta uma arquitetura para provimento de informações adicionais sobre as redes disponíveis em um ambiente de acesso sob demanda com gerenciamento de handover centrado no usuário, chamada MYHand (MIH-based and Y-Comm-based Handover Management). Para isso foi utilizada a arquitetura para acesso sob demanda chamada Y-Comm e o padrão IEEE 802.21 (MIH - Media Independent Handover). Os resultados desta tese contribuem no gerenciamento das trocas de rede e ubiquidade do acesso à Internet em NGN. A arquitetura MYHand auxiliará o dispositivo móvel a obter mais informações necessárias à decisão de handover, podendo otimizá-la. Com os resultados das simulações, o dispositivo móvel poderá prever o quanto determinada decisão poderá beneficiar a experiência do usuário em termos de qualidade da conexão e custo.

Palavras-chave: acesso sob demanda, gerenciamento de handover, NGN, Y-Comm, MIH, simulação 


\section{Abstract}

Currently, the usage of mobile devices with multiple network interfaces for Internet access has been growing, characterizing partially the Next Generation Networks (NGN). Other features of the NGN are access on demand, in which the customer is not, necessarily, user of a single provider and would use the network of other providers as needed, and the user-centric handover management, in which the user decides which network to connect to and at which time. There are some implications related to access on demand which can improve or worsen the user access experience and cause some impacts related to throughput, paid value, number of handovers, among others. The mobile can manage the handovers but he needs to obtain information about available networks as, for example, price and incentives, in addition to the information already obtained currently as received signal strength and provider identifier (SSID). However, providers do not have an automated system to provide such information to mobile devices. This thesis presents an evaluation of the impacts of dynamic switching between Wi-Fi providers for the mobile user, comparing access on demand to the traditional approach (as currently done). As methodology for this evaluation, simulations were performed in a scenario with Wi-Fi providers with different profiles, in which the number of handovers performed, the amount of received bytes, and the paid value were analyzed. In these simulations the mobile user could prioritize the cost of the connection, the received signal strength, and the load on the access point to decide the handover. This thesis also presents an architecture for additional information provisioning about available networks in an access on demand environment with user-centric handover management, called MYHand (MIH-based and Y-Comm-based Handover Management). For this purpose, an architecture for access on demand called Y-Comm and the IEEE 802.21 standard (MIH - Media Independent Handover) were used. The results of this thesis contribute to the handover management and ubiquity of Internet access in NGN. The MYHand architecture will assist the mobile device to obtain more information, necessary to the handover decision, optimizing it. With the results of the simulations, the mobile device can predict how much a particular decision may benefit the user experience in terms of connection quality and cost.

Keywords: access on demand, handover management, NGN, Y-Comm, MIH, simulation 


\section{Sumário}

Lista de Figuras ................................................................................................................................. iii

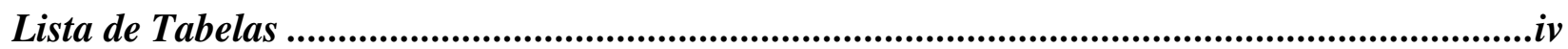

Lista de Abreviaturas e Siglas..................................................................................................

Capítulo 1 Introdução.............................................................................................................. 1

Capítulo 2 Tecnologias de Redes Sem Fio e NGN....................................................... 7

2.1 Tecnologias de rede sem fio .................................................................................................. 7

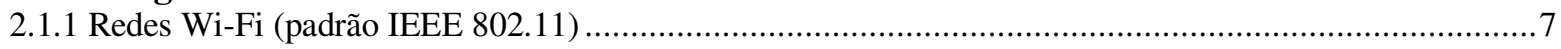

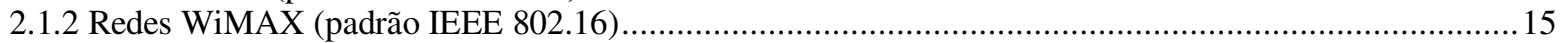

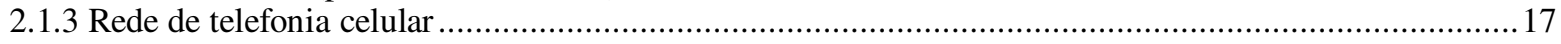

2.2 Redes de Próxima Geração (NGN) ........................................................................................... 23

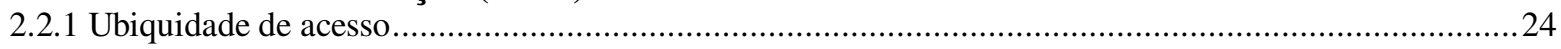

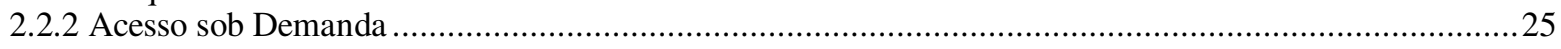

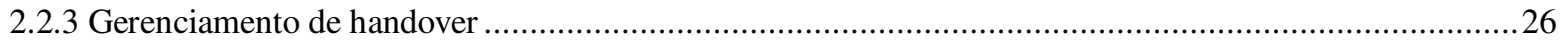

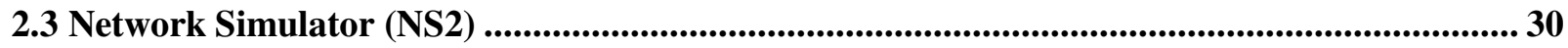

Capítulo 3 Gerenciamento de Mobilidade..................................................................... 32

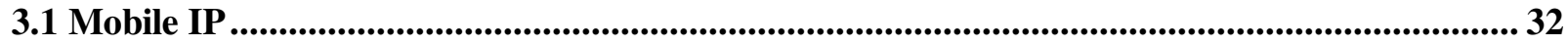

3.2 Arquiteturas para Provimento NGN ................................................................................................ 34

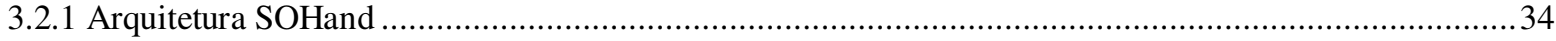

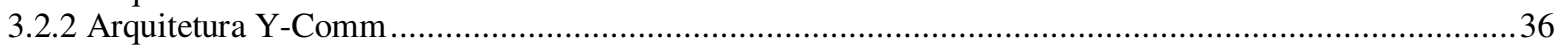

3.3 Handover Independente do Meio (MIH - Media Independent Handover)................................. 38

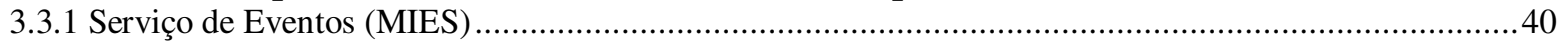

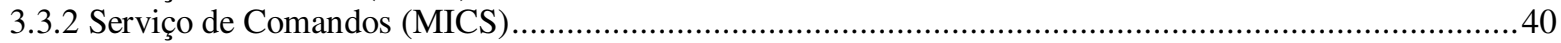

3.3.3 Serviço de Informações (MIIS) ….................................................................................................

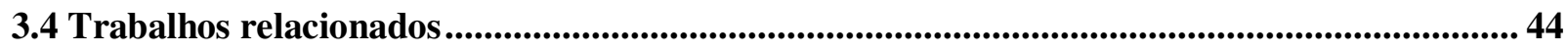

Capítulo 4 Cenários simulados e resultados das simulações................................. 48

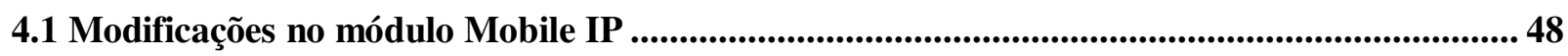

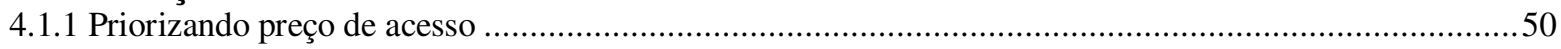

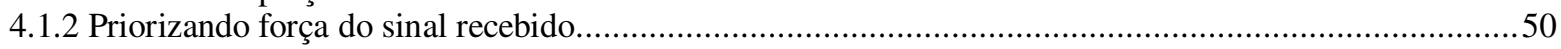

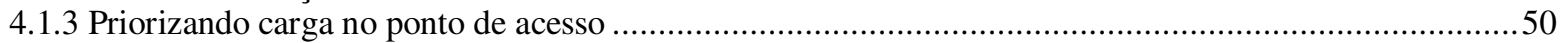

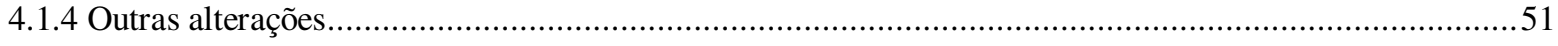

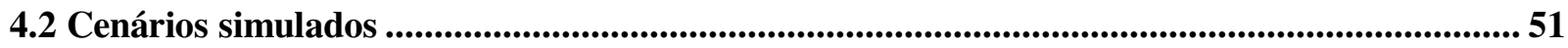

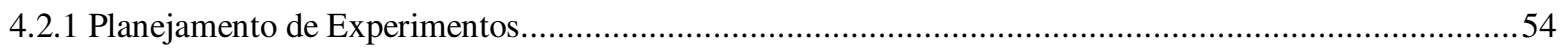

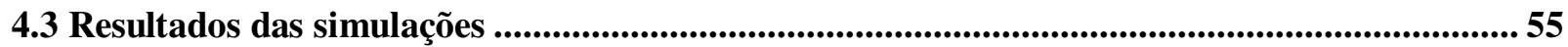

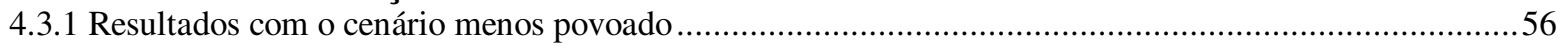

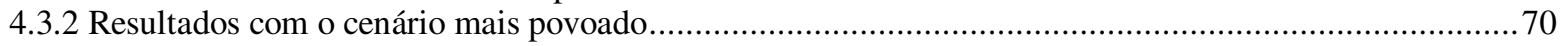

Capítulo 5 Arquitetura MYHand para provimento de informações.............................. 85

5.1 Esquema estendido proposto .................................................................................................................. 86

5.2 Arquitetura MYHand .................................................................................................................... 88

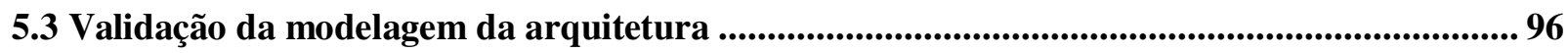




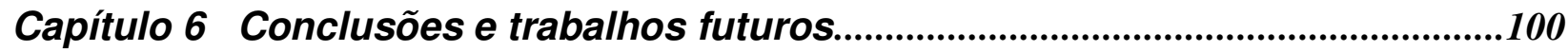

6.1 Contribuições ..................................................................................................................................... 103

6.2 Trabalhos Futuros ...................................................................................................................... 104

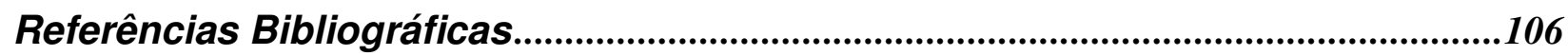

Apêndice $A$ - Resultados do cenário menos povoado à $36 \mathrm{~km} / \mathrm{h}$..............................112

Apêndice $B$ - Resultados do cenário menos povoado à $5 \mathrm{~km} / \mathrm{h}$...............................113

Apêndice $C$ - Resultados do cenário mais povoado à $36 \mathrm{~km} / \mathrm{h}$..................................114

Apêndice $D$ - Resultados do cenário mais povoado à $5 \mathrm{~km} / \mathrm{h}$....................................115 


\section{Lista de Figuras}

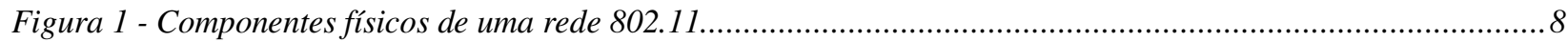

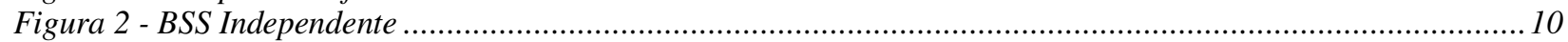

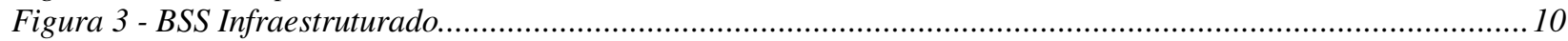

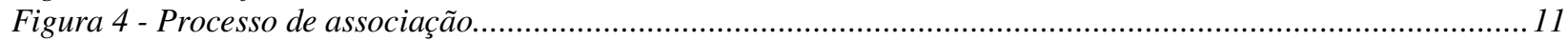

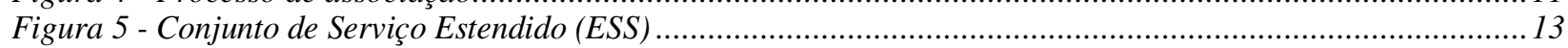

Figura 6 - Arquitetura de um provedor Wi-Fi, adaptada de [Bresil, 2004] ...................................................... 14

Figura 7 - Arquitetura de rede GSM/GPRS, adaptada de [Bresil, 2004] ...........................................................19

Figura 8 - Arquitetura de rede UMTS, adaptada de [Bresil, 2004] ................................................................2

Figura 9 - Classificação de tipos de handover, extraído de [Mapp, 2009] ..........................................................28

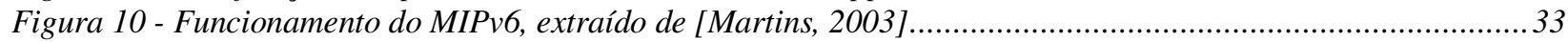

Figura 11 - Arquitetura SOHand, extraída de [Yokoyama, 2008] ........................................................................35

Figura 12 - Arquitetura Y-Comm, extraída de [Mapp, 2007]...........................................................................36

Figura 13 - Modelo de entidade habilitada com MIH, extraído de [IEEE, 2009a] ...............................................39

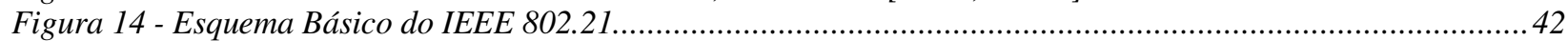

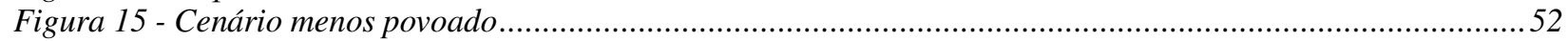

Figura 16 - Cenário mais povoado .........................................................................................................52

Figura 17 - Vazão à $36 \mathrm{~km} / \mathrm{h}$, tráfego VoIP, acesso tradicional, cenário menos povoado .......................................5 57

Figura 18 - Valor gasto, cenário menos povoado, à $36 \mathrm{~km} / \mathrm{h}$, priorizando preço................................................59

Figura 19 - Valor gasto, cenário menos povoado, à $5 \mathrm{~km} / \mathrm{h}$, priorizando preço..................................................5

Figura 20 - Vazão à $36 \mathrm{~km} / \mathrm{h}$, tráfego VoIP, priorizando preço, cenário menos povoado.......................................60

Figura 21 - Bytes recebidos, cenário menos povoado, à $36 \mathrm{~km} / \mathrm{h}$, priorizando força do sinal ................................62

Figura 22 - Bytes recebidos, cenário menos povoado, à $5 \mathrm{~km} / \mathrm{h}$, priorizando força do sinal ................................6 63

Figura 23 - Vazão à $36 \mathrm{~km} / \mathrm{h}$, tráfego VoIP, priorizando RSSI, cenário menos povoado.....................................63

Figura 24 - Valor gasto, cenário menos povoado, à $36 \mathrm{~km} / \mathrm{h}$, priorizando força do sinal ...................................65

Figura 25 - Valor gasto, cenário menos povoado, à $5 \mathrm{~km} / \mathrm{h}$, priorizando força do sinal ........................................65

Figura 26 - Bytes recebidos, cenário menos povoado, à $36 \mathrm{~km} / \mathrm{h}$, priorizando carga no AP ................................66

Figura 27 - Bytes recebidos, cenário menos povoado, à $5 \mathrm{~km} / \mathrm{h}$, priorizando carga no AP ....................................67 67

Figura 28 - Vazão à $36 \mathrm{~km} / \mathrm{h}$, tráfego VoIP, priorizando carga no AP, cenário menos povoado .............................67

Figura 29 - Valor gasto, cenário menos povoado, à $36 \mathrm{~km} / \mathrm{h}$, priorizando carga no AP ......................................69

Figura 30 - Valor gasto, cenário menos povoado, à $5 \mathrm{~km} / \mathrm{h}$, priorizando carga no AP ........................................69

Figura 31 - Vazão à $36 \mathrm{~km} / \mathrm{h}$, tráfego VoIP, acesso tradicional, cenário mais povoado........................................ 72

Figura 32 - Valor gasto, cenário mais povoado, à $36 \mathrm{~km} / \mathrm{h}$, priorizando preço ……......................................... 74

Figura 33 - Valor gasto, cenário mais povoado, à $5 \mathrm{~km} / \mathrm{h}$, priorizando preço …….......................................... 74

Figura 34 - Vazão à $36 \mathrm{~km} / \mathrm{h}$, tráfego VoIP, priorizando preço, cenário mais povoado ..........................................76

Figura 35 - Bytes recebidos, cenário mais povoado, à $36 \mathrm{~km} / \mathrm{h}$, priorizando força do sinal ................................... 77

Figura 36 - Bytes recebidos, cenário mais povoado, à $5 \mathrm{~km} / \mathrm{h}$, priorizando força do sinal....................................... 78

Figura 37 - Vazão à $36 \mathrm{~km} / \mathrm{h}$, tráfego VoIP, priorizando RSS, cenário mais povoado........................................... 78

Figura 38 - Valor gasto, cenário mais povoado, à $36 \mathrm{~km} / \mathrm{h}$, priorizando força do sinal ......................................... 79

Figura 39 - Valor gasto, cenário mais povoado, à $5 \mathrm{~km} / \mathrm{h}$, priorizando força do sinal........................................... 80

Figura 40 - Bytes recebidos, cenário mais povoado, à $36 \mathrm{~km} / \mathrm{h}$, priorizando carga no AP ................................. 81

Figura 41 - Bytes recebidos, cenário mais povoado, à $5 \mathrm{~km} / \mathrm{h}$, priorizando carga no AP..................................... 81

Figura 42 - Vazão à $36 \mathrm{~km} / \mathrm{h}$, tráfego VoIP, priorizando carga no AP, cenário mais povoado............................... 82

Figura 43 - Valor gasto, cenário mais povoado, à $36 \mathrm{~km} / \mathrm{h}$, priorizando carga no AP ..........................................83

Figura 44 - Valor gasto, cenário mais povoado, à $5 \mathrm{~km} / \mathrm{h}$, priorizando carga no AP .......................................... 83

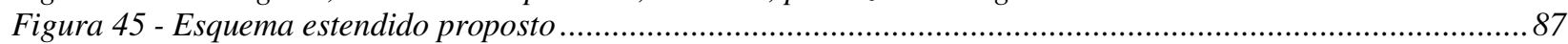

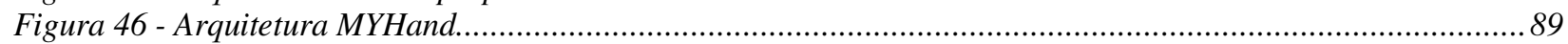

Figura 47 - Procedimento de handover alternativo .........................................................................................92

Figura 48 - Procedimento de handover imperativo reativo..........................................................................95

Figura 49 - Cenário para validação da modelagem da arquitetura .................................................................97 


\section{Lista de Tabelas}

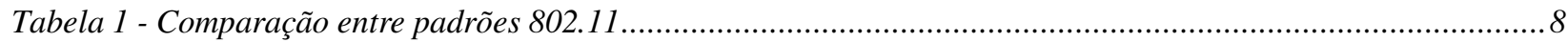

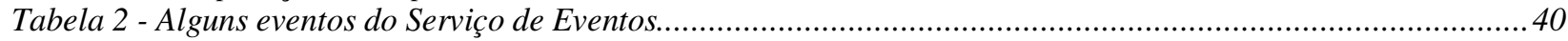

Tabela 3 - Descrição dos elementos da Figura 14 ..........................................................................................

Tabela 4 - Código RDF/OWL para tipo de enlace (link type)...........................................................................4

Tabela 5 - Comparação entre os trabalhos relacionados à política de decisão ..........................................................4 47

Tabela 6 - Comparação entre os trabalhos relacionados à descoberta de redes ..................................................47

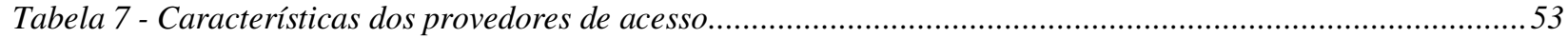

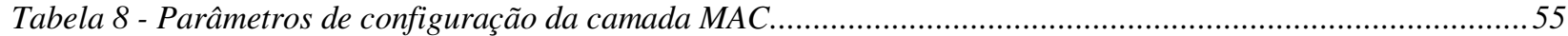

Tabela 9 - Bytes recebidos no cenário menos povoado (TRAD - acesso tradicional)..........................................57

Tabela 10 - Número de handovers feitos no cenário menos povoado (TRAD - acesso tradicional).........................58

Tabela 11 - Bytes recebidos no cenário menos povoado (PREÇO - priorizando preço)..........................................60

Tabela 12 - Número de handovers feitos no cenário menos povoado (PREÇO - priorizando preço) ........................61

Tabela 13 - Número de handovers feitos no cenário menos povoado (RSSI - priorizando força do sinal).................64

Tabela 14 - Número de handovers feitos no cenário menos povoado (CARGA - priorizando carga no AP)..............68

Tabela 15 - Resumo dos resultados - cenário menos povoado.......................................................................... 70

Tabela 16 - Bytes recebidos no cenário mais povoado (TRAD - acesso tradicional) .............................................71

Tabela 17 - Número de handovers feitos no cenário mais povoado (TRAD - acesso tradicional) ............................ 73

Tabela 18 - Bytes recebidos no cenário mais povoado (PREÇO - priorizando preço)........................................... 75

Tabela 19 - Número de handovers feitos no cenário mais povoado (PREÇO - priorizando preço)........................... 76

Tabela 20 - Número de handovers feitos no cenário mais povoado (RSSI - priorizando força do sinal)................... 79

Tabela 21 - Número de handovers feitos no cenário mais povoado (CARGA - priorizando carga no AP).................82

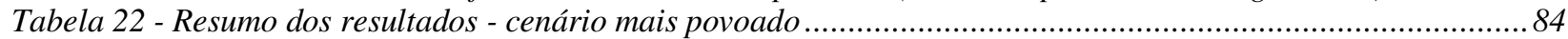

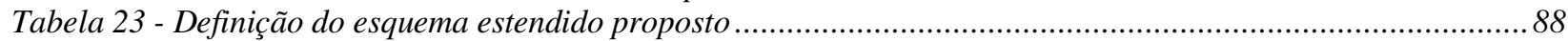

Tabela 24 - Validação da modelagem da arquitetura - parte 1 .........................................................................98

Tabela 25 - Validação da modelagem da arquitetura - parte 2 .............................................................................99 


\section{Lista de Abreviaturas e Siglas}

3GPP Third Generation Partnership Projetct

AAA Authentication, Authorization and Accounting

ACS Ambient Control Space

ADSL Asymmetric Digital Subscriber Line

AN Ambient Networks

AP Access Point

AuC Authentication Center

BSA Basic Service Area

BSC Base Station Controller

BSS Basic Service Set

BTS Base Transceiver Station

CDMA Code Division Multiple Access

CN Core Network, Correspondent Node

COA Care-Of Address

CSMA/CD Carrier Sense Multiple Access with Colision Detection

DNS Domain Name System

DOHand Domain Ontology for Handovers

DS Distribution System

EAP Extensible Authentication Protocol

ESS Extended Service Set

ETSI European Telecommunications Standardizations Institute

FSK Frequency Shift Keying 


\begin{tabular}{|c|c|}
\hline Gbps & Giga bits por segundo \\
\hline GGSN & Gateway GPRS Support Node \\
\hline GMSC & Gateway MSC \\
\hline GPRS & General Packet Radio Service \\
\hline GSM & Global System for Mobile communications \\
\hline HA & Home Agent \\
\hline HLR & Home Location Register \\
\hline HSCSD & High Speed Circuit-Switched Data \\
\hline IEEE & Institute of Electrical and Electronics Engineers \\
\hline IMS & IP Multimedia Subsystem \\
\hline IMSI & International Mobile Subscriber Identity \\
\hline IMT-2000 & International Mobile Telecommunications \\
\hline IP & Internet Protocol \\
\hline ISM & Industrial, Scientific and Medical radio bands \\
\hline ITU & Internation Telecommunication Union \\
\hline Kbps & Kilo bits por segundo \\
\hline LAN & Local Area Network \\
\hline LOS & Light-Of-Sight \\
\hline MAC & Medium Access Control \\
\hline Mbps & Mega bits por segundo \\
\hline MD5 & Message Digest 5 \\
\hline ME & Mobile Equipment \\
\hline MIMO & Multiple Input Multiple Output \\
\hline MIPv4 & Mobile IP version 4 \\
\hline
\end{tabular}




\begin{tabular}{|c|c|}
\hline MIPv6 & Mobile IP version 6 \\
\hline MSC & Mobile Switching Center \\
\hline NLOS & Non-Light-Of-Sight \\
\hline MN & Mobile Node \\
\hline NGN & Next Generation Networks \\
\hline NS2 & Network Simulator 2 \\
\hline PDN & Packet Data Network \\
\hline PKI & Public Key Infrastructure \\
\hline PSTN & Public Switched Telephone Network \\
\hline OFDMA & Orthogonal Frequency-Division Multiple Access \\
\hline OSI & Open Systems Interconnection \\
\hline QoS & Quality of Service \\
\hline RFC & Request For Comments \\
\hline RNC & Radio Network Controller \\
\hline SGSN & Serving GPRS Support Node \\
\hline SLA & Service Level Agreement \\
\hline SNMP & Simple Network Management Protocol \\
\hline SOHand & Service Oriented Handover Management System \\
\hline SSID & Service Set Identifier \\
\hline TCP & Transmission Control Protocol \\
\hline TDMA & Time Division Multiple Access \\
\hline TLS & Transporte Layer Security \\
\hline UDP & User Datagram Protocol \\
\hline $\mathbf{U E}$ & User Equipment \\
\hline
\end{tabular}


UMTS Universal Mobile Telecommunications System

USIM UMTS Subscriber Identity Module

UTRAN UMTS Terrestrial Radio Access Network

VoIP Voice over Internet Protocol

VLR Visitor Location Register

WECA Wireless Ethernet Compatibility Alliance

Wi-Fi Wireless Fidelity

WiMAX Worldwide Interoperability for Macroware Access

WISP Wireless Internet Service Provider

WLAN Wireless Local Area Network

WMAN Wireless Metropolitan Area Network 


\section{Capítulo 1 Introdução}

Desde o surgimento da primeira rede de computadores, há um grande esforço no sentido de aumentar cada vez mais a velocidade de transmissão de dados e melhorar os serviços oferecidos. A velocidade de transmissão das redes cabeadas começou com algumas dezenas de Kbps (kilobits por segundo), passando por $10 \mathrm{Mbps}$ e $100 \mathrm{Mbps}$ até alcançar velocidades atuais de 10 Gbps e 100 Gbps nas redes de fibra óptica.

A evolução das redes sem fio (wireless) tem seguido a mesma tendência, com o aparecimento de novas tecnologias e o gradativo aumento na velocidade de transmissão. As redes sem fio de longa distância utilizadas pela telefonia celular iniciaram com transmissão analógica de voz [DeVriendt, 2002]. Depois o sistema foi digitalizado e apareceram serviços de envio de mensagens curtas de texto, fax e comutação de pacotes (como na Internet). Com o aumento de velocidade e a evolução dos aparelhos, surgiram serviços de envio de correio eletrônico (e-mail), navegação web e outros [DeVriendt, 2002]. As redes sem fio de curta e média distância como, por exemplo, Bluetooth [Bluetooth, 2009], Wi-Fi [IEEE, 2007] e WiMAX [WiMAX, 2009], alcançam velocidades de 1 Mbps a 54 Mbps, e podem chegar até 300 Mbps com o padrão 802.11n [IEEE, 2009b], ou mesmo 1 Gbps com o esperado padrão 802.11ac [Wiki, 2012].

Quase a totalidade das redes sem fio está presente na chamada última milha (last mile), que é o trecho de rede mais próximo do usuário. Com isso, as redes como um todo estão compostas por duas partes: a parte central da rede (núcleo ou core) formada por cabos (geralmente fibra óptica), proporcionando velocidades extremamente rápidas e baixas perdas de pacotes, e a parte periférica da rede (última milha) formada por redes sem fio, caracterizadas por menores taxas de transferência e maiores perdas de pacotes. 
Para o acesso à rede na última milha, tem crescido o uso de aparelhos móveis com várias funções como notebooks, smartphones e tablets, e que utilizam várias tecnologias de comunicação. Por exemplo, os aparelhos denominados smartphones funcionam tanto como um celular quanto como um computador de bolso, podendo usar como meio de comunicação tanto a rede de telefonia celular quanto uma rede local $\mathrm{Wi}-\mathrm{Fi}$, ou até mesmo se comunicar diretamente com outros aparelhos sem a necessidade de uma infraestrutura de rede, compondo as chamadas redes ad-hoc.

Este cenário com dispositivos móveis e várias interfaces de rede por dispositivo caracteriza, em parte, as redes de próxima geração ou NGN (Next Generation Networks). Outras características da NGN são a ubiquidade do acesso à rede, ou seja, um dispositivo se desconecta de uma rede e se conecta a outra de forma transparente para o usuário, a presença de redes heterogêneas, o acesso sob demanda, e o gerenciamento de troca de rede centrado no usuário.

Redes heterogêneas são caracterizadas pela presença de tecnologias diferentes para o acesso. Embora existam tecnologias mais novas para fornecer acesso à Internet usando o meio sem fio como, por exemplo, WiMAX [WiMAX, 2009] [Loa, 2010] e LTE [Loa, 2010], atualmente existem, basicamente, duas formas: por meio dos provedores Wi-Fi (tecnologia IEEE 802.11b/g/n) e das operadoras de telefonia celular (tecnologia 3G). Provedores Wi-Fi oferecem pontos de acesso chamados de hotspots em estabelecimentos comerciais como aeroportos, hotéis, restaurantes e cyber cafés. Embora a conexão seja rápida (em torno de 17 Mbps com 802.11g) e mais barata, o acesso fica limitado à area próxima ao ponto de acesso. As operadoras de celular, através das tecnologias GPRS [Samjani, 2002] e 3G [ITU, 2009], oferecem uma área de cobertura maior, consequentemente maior mobilidade. Por outro lado, este acesso é mais lento (até 2 Mbps na 3G) e mais caro. 
Tendo estas duas formas de acesso, o ideal seria aproveitar as vantagens de ambas, dependendo do ambiente em que o usuário se encontra, ou seja, ter uma cobertura total, com mobilidade real, preço acessível e as melhores taxas de transferência de dados. Para se utilizar tanto a rede celular como as redes Wi-Fi dos vários provedores, torna-se inviável ao usuário ser cliente de vários provedores de acesso, tendo que manter vários contratos, mensalidades, senhas de acesso e configurações das redes. Por este motivo, o acesso sob demanda torna-se imprescindível.

Em um cenário com acesso sob demanda, o usuário seria cliente de um único provedor de acesso, ou de uma entidade que funcionasse como intermediário (broker) entre o cliente e vários provedores, e usaria a rede dos outros provedores quando fosse necessário. No acesso tradicional, como é feito atualmente, o usuário móvel é cliente de um determinado provedor e conecta-se apenas às antenas deste provedor. Diferentemente do acesso tradicional, onde existe uma periodicidade maior de tempo conectado e tráfego do usuário, no acesso sob demanda o usuário ficaria conectado por um tempo aleatório em cada provedor, podendo até utilizar uma única vez um provedor e não mais voltar a usar. O usuário também tem maior liberdade em escolher à qual ponto de acesso vai se conectar (gerenciamento centrado no usuário e não na rede).

Do lado do usuário móvel existem algumas implicações em função do acesso sob demanda que podem melhorar ou piorar a experiência de acesso do usuário e causar alguns impactos relacionados, por exemplo, à vazão recebida, ao valor gasto, e ao número de trocas de rede, dependendo das redes disponíveis e eficiência no gerenciamento das trocas. A quantidade de usuários conectados em cada antena, o tempo de conexão, os serviços utilizados, o perfil de acesso e outras características são mais variáveis no acesso sob demanda, comparado com os acessos de clientes fixos. Isso torna mais difícil para o usuário prever como será sua experiência com o acesso. 
Quando um dispositivo móvel estiver usando uma rede sem fio e se deslocar, ele pode perder o sinal da antena e precisar conectar-se a outra rede disponível para continuar on-line. Neste processo, chamado handover, o dispositivo móvel ou a rede de acesso deve decidir qual rede usar, a fim de dar continuidade à aplicação que é acessada pelo usuário. Para isso, deve-se considerar o tempo necessário para a mudança para a outra rede, a mudança na qualidade de serviço oferecida pela outra rede, entre outros fatores. Atualmente, o provedor de acesso (rede celular ou Wi-Fi) é responsável pelo gerenciamento do handover, ou seja, a rede decide quando e para qual ponto de acesso o dispositivo móvel deve realizar a troca. Esta tese parte do princípio de que este gerenciamento deve ser realizado pelo usuário, ou seja, gerenciamento de handover centrado no usuário, levando em consideração informações de contexto, preferências do usuário e considerando que ele poderá se conectar a uma rede de outro provedor de acesso. Porém os provedores não possuem um sistema automatizado para fornecer maiores informações de conexão a usuários desconhecidos em um ambiente NGN.

Para o dispositivo móvel gerenciar as trocas de rede, ele precisa obter informações sobre as redes disponíveis como, por exemplo, políticas de privacidade e segurança, métricas de Qualidade de Serviço (velocidade de transmissão, atraso de envio dos pacotes, jitter, etc), preço, entre outras informações. Para o usuário obter tais informações das várias redes disponíveis, os provedores de acesso precisam criar mecanismos para oferecer estas informações aos usuários e, desta forma, atrair mais clientes para sua rede de acesso.

Esta tese apresenta dois objetivos principais. O primeiro objetivo é a realização de uma avaliação dos impactos das trocas dinâmicas entre provedores Wi-Fi para o usuário móvel, comparando o acesso sob demanda com o acesso tradicional (como é feito atualmente). Como metodologia para esta avaliação, foram realizadas simulações de rede em um cenário com vários provedores Wi-Fi com perfis diferentes, nas quais foram analisados o número de handovers 
feitos, a quantidade de dados recebidos e o quanto o usuário gastou com a conexão. Para melhor validar os resultados, vários cenários foram simulados, variando-se a quantidade de antenas e usuários, velocidade do usuário móvel, a aplicação em execução no usuário móvel e o tráfego nos outros usuários, totalizando 144 simulações diferentes. O usuário móvel pôde priorizar o custo da conexão, a força do sinal recebido e a carga de trabalho no ponto de acesso para decidir a troca de rede. O segundo objetivo é a criação de uma arquitetura para provimento de informações sobre as redes disponíveis em um ambiente de acesso sob demanda com gerenciamento de handover centrado no usuário. Para isso foi utilizada uma arquitetura para acesso sob demanda chamada YComm e os serviços de informações (MIIS), eventos (MIES) e comandos (MICS) de um protocolo que visa auxiliar o gerenciamento de troca independente do meio (MIH - Media Independent Handover).

É possível encontrar trabalhos relacionados ao gerenciamento de handover como, por exemplo, em [Palazzi, 2007], onde os autores simulam uma versão modificada do protocolo Mobile IP [Perkins, 2002] o qual torna o handover mais transparente em redes sem fio com sobreposição de sinal. Outros trabalhos, comentados no próximo capítulo, propõem novas políticas de decisão de handover [Aust, 2003][Rizvi, 2010][Wang, 1999][Zhu, 2006][Kassar, 2008] e otimização de handover [Sharma, 2004]. Porém, na maioria dos trabalhos há apenas um ou alguns poucos cenários diferentes e as redes geralmente pertencem ao mesmo provedor. Esta tese diferencia-se destes trabalhos com a simulação de 144 configurações diferentes de cenários e as antenas pertencendo a provedores com diferentes características, possibilitando uma melhor validação dos resultados e uma comparação entre acesso tradicional e sob demanda.

Também é possível encontrar alguns trabalhos relacionados à descoberta de rede [Korhonen, 2008][Dutta, 2006][Wu, 2009] [Cicconetti, 2011]. Porém estes trabalhos se preocupam com informações tecnológicas, necessárias ao processo de handover imperativo, no 
qual o dispositivo móvel tem a necessidade de realizar a troca para não haver queda de qualidade e/ou conexão. A arquitetura MYHand, proposta nesta tese, diferencia-se destes trabalhos estendendo a descoberta de redes, embutindo informações extras como as relacionadas, por exemplo, a incentivos, necessárias ao processo de handover alternativo, no qual o dispositivo móvel não é obrigado a realizar por questões tecnológicas mas realiza por preferência do usuário ou incentivo. Também é a primeira arquitetura criada que utiliza Y-Comm em conjunto com o padrão IEEE 802.21 (MIH), além de uma extensão ao esquema básico do 802.21.

Os resultados desta tese contribuem no gerenciamento de handovers e ubiquidade do acesso à Internet na NGN. A arquitetura MYHand poderá auxiliar o dispositivo móvel a obter mais informações necessárias à decisão de handover, podendo otimizá-la. Com os resultados de valor gasto, vazão e número de handovers das simulações, o dispositivo móvel poderá prever o quanto determinada decisão de handover poderá beneficiar a experiência do usuário em termos de qualidade de conexão e custo.

Além deste capítulo introdutório, no capítulo 2 é apresentada uma revisão em abrangência da literatura relacionada a esta tese, mais precisamente, as tecnologias de rede sem fio $\mathrm{Wi}-\mathrm{Fi}$, WiMAX e celular, alguns aspectos das Redes de Próxima Geração, e o simulador de rede NS2. No capítulo 3 é apresentada uma revisão da literatura com maior foco no gerenciamento de mobilidade. Os cenários simulados e os resultados das simulações são descritos no capítulo 4. O capítulo 5 apresenta a arquitetura proposta (MYHand) para fornecimento de informações para tomada de decisão de handover. O capítulo 6 conclui a tese e apresenta as contribuições e trabalhos futuros. 


\section{Capítulo 2 Tecnologias de Redes Sem Fio e NGN}

As redes sem fio (wireless), como o próprio nome diz, são redes formadas sem o uso de cabos. Ao contrário das redes cabeadas (wired), as redes sem fio utilizam ondas de rádio para se comunicar e, devido a esta característica, são mais flexíveis com relação à mobilidade dos usuários. Isso possibilitou o avanço da telefonia móvel (celulares) e, mais recentemente, o conceito de NGN (Redes de Próxima Geração). Algumas das tecnologias de rede sem fio mais conhecidas são Wi-Fi (padrão IEEE 802.11), WiMAX (padrão IEEE 802.16), Bluetooth (padrão IEEE 802.15) e a rede celular.

Este capítulo apresenta uma revisão em abrangência da literatura relacionada a este trabalho, mais precisamente as tecnologias de rede sem fio utilizadas na periferia da rede (última milha), as Redes de Próxima Geração, e o simulador de rede NS2.

\subsection{Tecnologias de rede sem fio}

Quase a totalidade das redes sem fio está presente na chamada última milha, que é o trecho de rede mais próximo do usuário final. Estas redes oferecem menor taxa de transferência e maior perda de pacotes comparados com o núcleo da rede.

\subsubsection{Redes Wi-Fi (padrão IEEE 802.11)}

O funcionamento das redes que seguem o padrão 802.11 [IEEE, 2007] do IEEE (Instituto dos Engenheiros Elétricos e Eletrônicos) é similar às redes Ethernet (IEEE 802.3), com algumas implementações a mais, necessárias ao funcionamento conjunto com redes Ethernet.

O padrão 802.11 é uma parte da família IEEE 802, a qual é uma série de especificações de tecnologia de redes locais focadas nas camadas física e de enlace de dados do modelo OSI [Tanembaum, 2003]. O termo Wi-Fi, do inglês "Wireless Fidelity", foi designado pela WECA 
(Wireless Ethernet Compatibility Alliance) [WiFi, 2009] para certificar produtos compatíveis com o padrão 802.11. Ou seja, produtos com a logomarca Wi-Fi satisfazem às requisições de interoperabilidade exigidas pelo WECA e podem operar com outros produtos com a logomarca Wi-Fi, independente do fabricante. A faixa de rádio frequência utilizada é a banda não licenciada ISM (Industrial Scientific and Medical).

O padrão IEEE 802.11 é dividido em várias especificações que variam principalmente em velocidade e frequência utilizada. Atualmente a maioria das redes Wi-Fi instaladas segue o padrão 802.11g. Uma comparação entre estes padrões é apresentada na Tabela 1.

Tabela 1 - Comparação entre padrões 802.11

\begin{tabular}{|c|c|c|}
\hline Padrão & Velocidade & Freqüência \\
\hline 802.11 & $1 \mathrm{Mbps}$ e $2 \mathrm{Mbps}$ & $2.4 \mathrm{Ghz}$ \\
\hline $802.11 \mathrm{a}$ & Até $54 \mathrm{Mbps}$ & $5 \mathrm{Ghz}$ \\
\hline $802.11 \mathrm{~b}$ & Até $11 \mathrm{Mbps}$ & $2.4 \mathrm{Ghz}$ \\
\hline $802.11 \mathrm{~g}$ & Até $54 \mathrm{Mbps}$ & $2.4 \mathrm{Ghz}$ \\
\hline $802.11 \mathrm{n}$ & Até $300 \mathrm{Mbps}$ & $2.4 \mathrm{e} 5 \mathrm{Ghz}$ \\
\hline
\end{tabular}

Redes padrão 802.11 consistem de 4 componentes físicos principais (ver Figura 1) [Gast, 2002]:

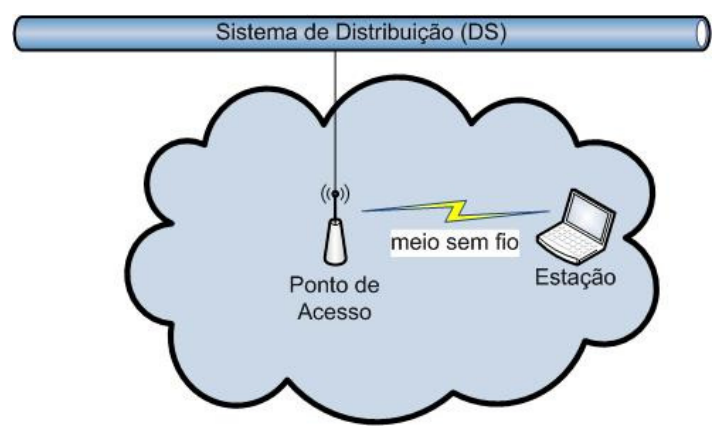

Figura 1 - Componentes físicos de uma rede 802.11 
- $\quad$ Ponto de Acesso (AP - Access Point): o principal objetivo do ponto de acesso é realizar a função de ponte (bridging) entre a rede sem fio e a rede cabeada;

- $\quad$ Sistema de Distribuição (DS - Distribution System): geralmente o DS é formado por uma rede Ethernet (cabeada) e é responsável por fornecer acesso à rede sem fio ao restante da rede (inclusive a outras redes sem fio e à Internet);

- $\quad$ Meio sem fio (wireless medium): é o meio físico usado para a transmissão dos quadros de dados entre estações e pontos de acesso;

- $\quad$ Estações (stations): são os dispositivos computacionais com interfaces de rede sem fio, por exemplo, notebooks, smartphones, tablets ou mesmo computadores de mesa.

O bloco básico de formação de uma rede 802.11 é o chamado conjunto básico de serviço (BSS - Basic Service Set), ou seja, um grupo de estações que se comunicam entre si, utilizando ou não um ponto de acesso. Estas comunicações ocupam uma área com limites não exatos chamada área básica de serviço (BSA - Basic Service Area), definida pela propagação das ondas de rádio. Uma rede típica 802.11 g tem um alcance de aproximadamente 100 metros do ponto de acesso. Quando uma estação está dentro de uma área de serviço, esta pode se comunicar com outras estações do conjunto de serviço. Cada BSS é configurado com um identificador da rede, chamado SSID (Service Set IDentifier). Em um mesmo ponto de acesso, podem ser configurados mais de um SSID formando redes virtuais (VLANs).

Um conjunto de serviço pode ser formado de duas maneiras: um conjunto de serviço independente ou um conjunto infraestruturado, como pode ser visto nas Figuras 2 e 3. 


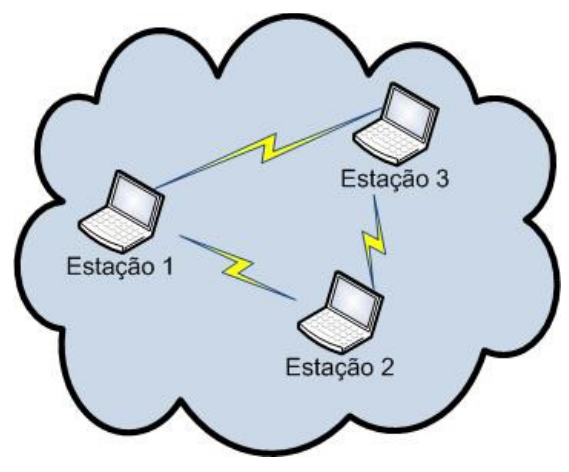

Figura 2 - BSS Independente

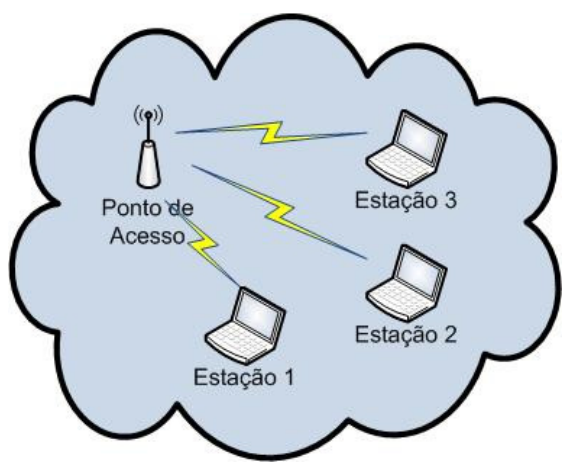

Figura 3 - BSS Infraestruturado

No conjunto de serviço independente, as estações se comunicam diretamente umas com as outras e formam as chamadas redes ad-hoc. Geralmente um BSS independente é composto por poucas estações (normalmente duas) e tem um tempo de vida curto. Um exemplo típico é um BSS composto por duas estações com o objetivo de transferir arquivos de uma para a outra; quando a transferência termina, o BSS é desfeito.

No modo infraestruturado, é utilizado um ponto de acesso para a comunicação entre as estações, ou seja, um pacote de dados com origem na estação 1 e destino na estação 2, primeiramente é transferido para o ponto de acesso e este o retransmite para a estação 2 . A rede infraestruturada tem duas vantagens principais [Gast, 2002]:

- $\quad$ é definida pela distância do ponto de acesso. Todas as estações móveis precisam estar dentro da área de alcance do ponto de acesso, mas não há restrição quanto à distância entre as estações. Na comunicação direta entre estações (modo independente) há economia na transmissão de dados pelo meio sem fio, porém aumenta-se a complexidade na implementação da camada física devido ao fato das estações precisarem manter relacionamentos com todas as estações dentro da área de serviço;

- $\quad$ o ponto de acesso pode ajudar a estação a economizar energia, armazenando pacotes e retransmitindo aos poucos. As estações móveis, para economizar energia, podem 
desligar o transmissor/receptor de sinal quando não estão transmitindo e ligar novamente apenas quando vão transmitir ou receber dados armazenados no ponto de acesso.

Na rede infraestruturada, a estação deve se associar a um, e apenas a um, ponto de acesso para obter o serviço de rede. É como conectar o cabo de rede em uma Ethernet. Este processo é chamado de associação [Cisco, 2008]. A Figura 4 apresenta um processo de associação com o uso de senha pré-compartilhada (Preshared key) ou chave secreta. Este processo é dividido em três partes: scanning, authentication e association.

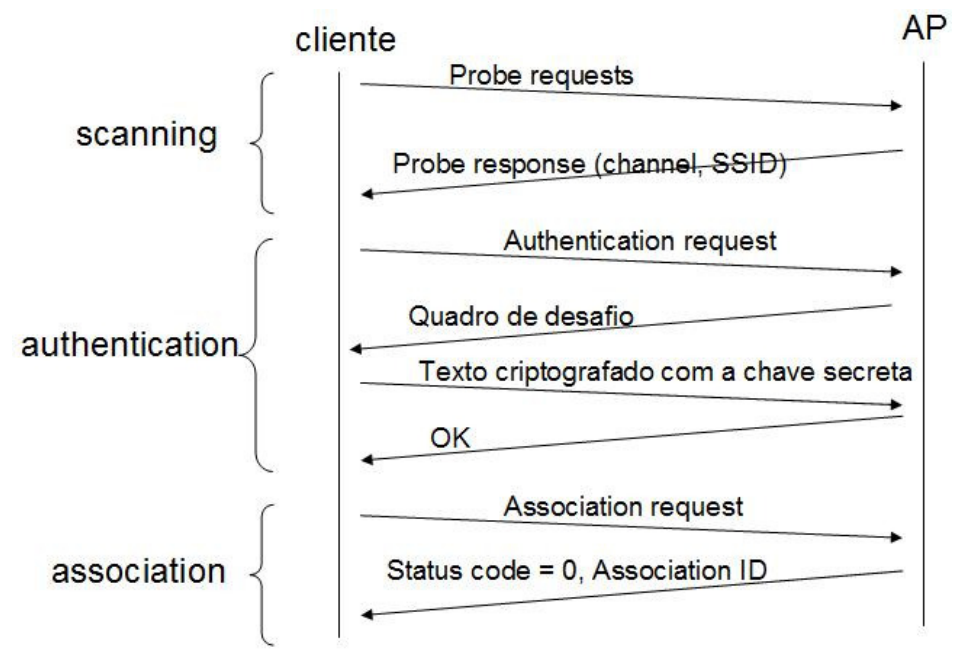

Figura 4 - Processo de associação

Primeiramente o cliente sem fio faz uma varredura por pontos de acesso (active scanning) enviando quadros denominados Probe requests em todos os 11 canais disponíveis no 802.11 (no total são 14 canais, mas no Brasil são usados os 11 primeiros). Os pontos de acesso que receberem estas solicitações enviam uma resposta (Probe response) com informações de canal utilizado, SSID, entre outras informações. O cliente também pode realizar um passive scanning, ou seja, ele não envia Probe requests, apenas aguarda algum ponto de acesso enviar quadros de controle chamados beacons, os quais contêm o SSID da rede.

O cliente sem fio (estação) escolhe um dos APs disponíveis para tentar se conectar baseado em conhecimento pré-existente do SSID, força do sinal, entre outros critérios. Para o AP 
escolhido, o cliente sem fio inicia o processo de autenticação (authentication) enviando quadros de Authentication request. O AP responde com um quadro de desafio, o qual contém um texto que deve ser criptografado pelo cliente utilizando a chave secreta. O cliente envia o texto criptografado para o AP e, caso este confira a autenticidade da chave secreta, aceita o cliente enviando uma resposta confirmando a autenticação.

Por fim, o cliente envia um quadro de pedido de associação (Association request). Ao receber o pedido, o AP insere o endereço MAC do cliente em sua tabela de associação e responde com um OK (status code $=0$ ) e uma identificação da associação (Association ID) ao cliente. Esta associação é necessária ao roteamento de dados entre cliente e o sistema de distribuição.

Um único conjunto de serviço (BSS) pode não conseguir cobrir uma área muito grande, mas a especificação 802.11 permite a interligação entre conjuntos de serviço, criando desta forma um conjunto estendido de serviço (ESS - Extended Service Set), sendo que todos os pontos de acesso são configurados para pertencer ao mesmo ESS, sendo configurados com o mesmo SSID. A Figura 5 ilustra um conjunto estendido formado por três BSSs, cada um com um ponto de acesso fornecendo o sinal de rádio. A formação de um ESS permite maior mobilidade dos usuários sem fio e uma área de cobertura maior, de tal forma que um dispositivo móvel possa sair de uma área BSS e entrar em outra sem perder contato com a rede, supondo que exista uma área de sobreposição de sinal (overlap) dos dois BSS em questão. O padrão 802.11 não especifica uma tecnologia para fazer esta interligação, podendo conectar os pontos de acesso em um mesmo switch/hub ou mesmo usar comunicação sem fio. 


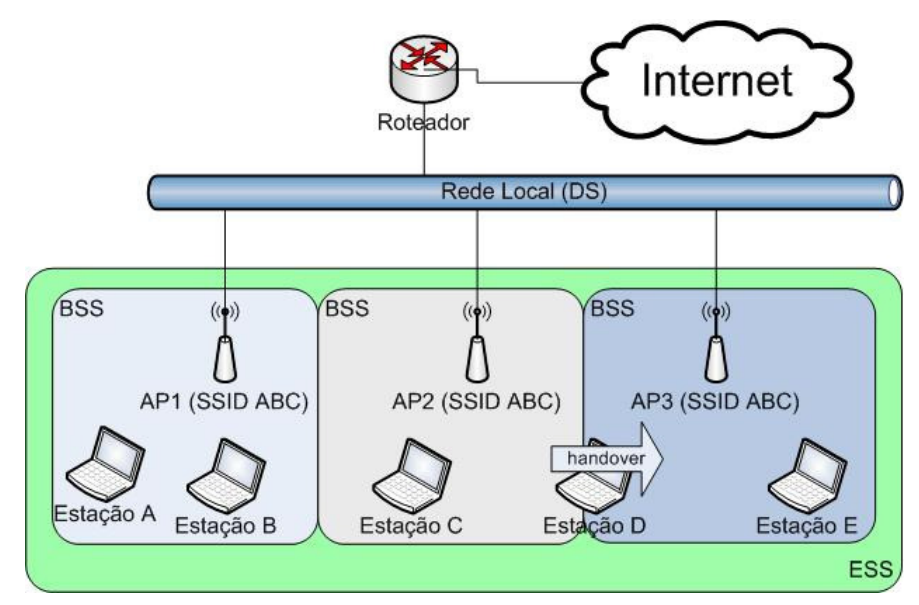

Figura 5 - Conjunto de Serviço Estendido (ESS)

A estação D na Figura 5 está realizando um handover, que é o processo que ocorre quando um dispositivo móvel muda seu ponto de acesso à Internet, e pode ocorrer entre sistemas usando a mesma tecnologia de acesso ou tecnologias diferentes. O gerenciamento de handover é abordado com mais detalhes no capítulo 3 .

O surgimento de novas tecnologias de rádio frequência tem proporcionado um grande aumento no uso das redes sem fio na periferia da rede. Juntamente com a popularização das redes Wi-Fi, cresceu o número de dispositivos móveis como notebooks e celulares com interface 802.11. Estes dois fatores propiciaram o surgimento de provedores Wi-Fi (WISPs - Wireless Internet Service Providers) que disponibilizam os chamados hotspots padrão $802.11 \mathrm{~b} / \mathrm{g} / \mathrm{n}$ instalados em estabelecimentos comerciais como aeroportos, hotéis, restaurantes e cyber cafés.

Um WISP geralmente surge de uma das quatro situações diferentes: uma operadora de telefonia celular que integra WLANs aos seus serviços já existentes [3GPP 22.934], um provedor convencional de acesso à Internet que estende a infraestrutura aos clientes, novas empresas que operam apenas como WISPs ou pontos comerciais como aeroportos e restaurantes, com fornecimento próprio de Internet aos clientes locais. 
A Figura 6 apresenta uma arquitetura típica de fornecimento de acesso Internet de um WISP. Nesta figura estão representados dois estabelecimentos com hotspots do mesmo WISP. Um restaurante, por exemplo, como tem um número menor de usuários conectados, possui apenas um ponto de acesso e uma conexão ADSL à Internet. Em um aeroporto, com uma área de cobertura maior e mais usuários, o provedor possui vários pontos de acesso controlados por um wireless switch e uma conexão Ethernet com a rede do provedor. Todos os APs do mesmo WISP são configurados com o mesmo SSID.

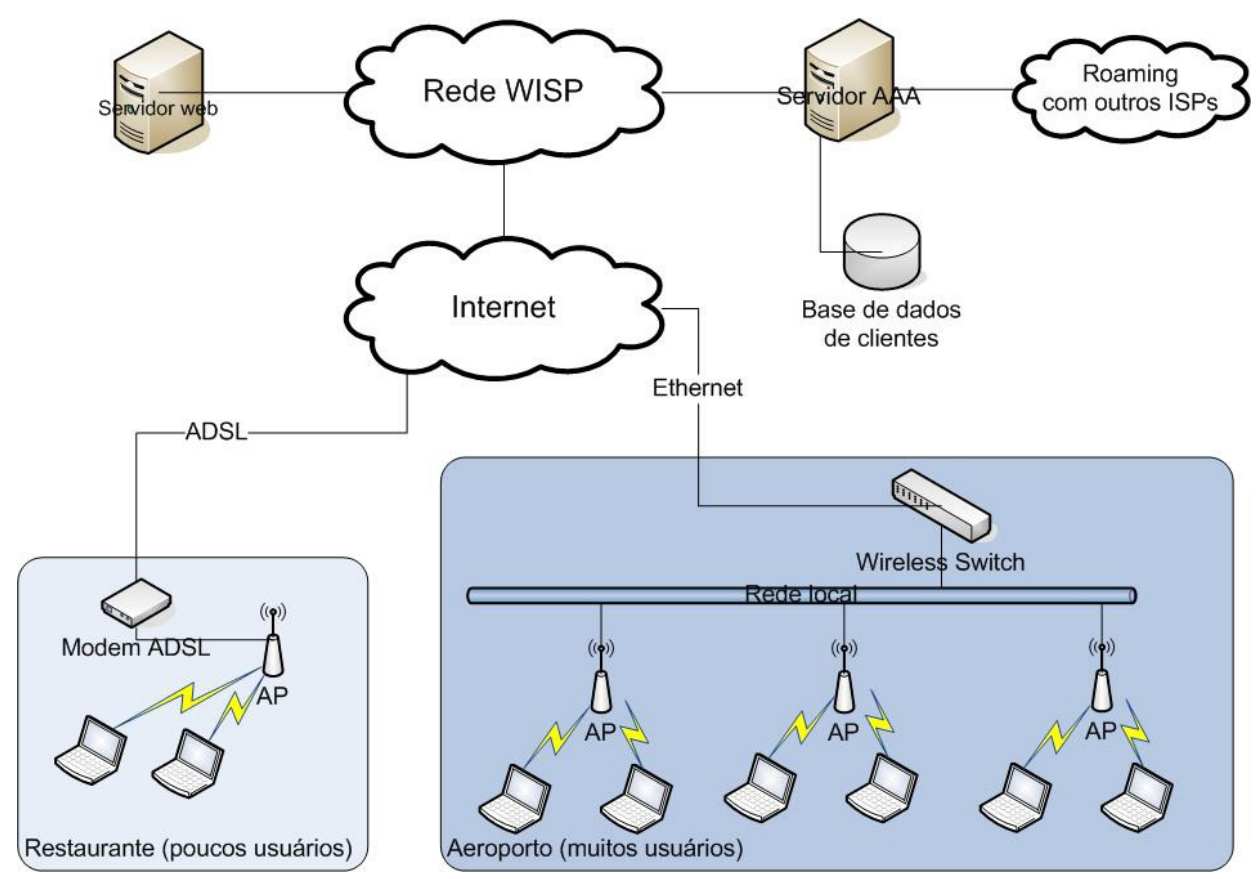

Figura 6 - Arquitetura de um provedor Wi-Fi, adaptada de [Bresil, 2004]

Como ainda pode ser observado na Figura 6, do lado do provedor encontra-se um servidor web que hospeda o portal web e um servidor AAA (Authentication, Authorization and Accounting). O servidor AAA consulta a base de dados local dos seus clientes e um serviço de roaming para autenticar clientes de outros provedores, os quais possuem um acordo de roaming.

Geralmente a autenticação do usuário é feita utilizando-se uma página web chamada captive portal e autenticação 802.1x com protocolo EAP (Extensible Authentication Protocol) 
[Blunk, 1998]. O objetivo do protocolo 802.1x é fornecer autenticação e controle de acesso para um AP por meio do protocolo EAP. Com o 802.1x a autenticação é realizada ao nível de usuário e não por lista de endereços MAC. O EAP é de uso geral para autenticação e suporta vários métodos de autenticação como MD5 (Message Digest 5), TLS (Transport Layer Security) e PKI (Public Key Infrastructure).

Quando o usuário vai acessar algum serviço na Internet, o AP verifica que ele ainda não possui permissões de acesso e apresenta uma página web (captive portal) para o usuário entrar com um nome de usuário e senha. O AP encapsula nome de usuário e senha em mensagens EAP e as envia ao servidor AAA. Este último verifica o nome de usuário, a senha e as permissões de acesso à rede e, se as informações forem validadas, responde ao AP com uma mensagem liberando o acesso ao usuário. A RFC 2869 [Rigney, 2000] detalha este processo utilizando o servidor Radius.

\subsubsection{Redes WiMAX (padrão IEEE 802.16)}

A tecnologia WiMAX (Worldwide Interoperability for Microwave Access) [WiMAX, 2009] segue uma especificação da IEEE denominada IEEE 802.16. Diferentemente das redes Wi-Fi que são redes locais sem fio (WLAN), as redes WiMAX tem um alcance de até $50 \mathrm{Km}$, sendo consideradas redes metropolitanas sem fio (WMAN - Wireless Metropolitan Area Network).

A primeira versão (2001), denominada IEEE 802.16, especificou uma frequência no intervalo de 10-66 GHz [Li, 2007], taxa de tranferência teórica de 120 Mbps e alcance de 50 Km. Porém este padrão apenas suportava transmissão com visada (LOS - Line-Of-Sight) e não era ideal para áreas urbanas. A segunda versão, denominada IEEE 802.16a-2003, não exigia linha de visada (NLOS - non-LOS), suportava frequências no intervalo de 2-11 GHz e incluiu suporte a 
redes mesh (redes em malha). Em 2004 foi definido o padrão 802.16d (IEEE 802.16-2004) para rede fixa, sem mobilidade.

Em 2005 foi oficializada a versão IEEE 802.16e-2005, com suporte à mobilidade e por isso ficou conhecida como Mobile WiMAX. Esta versão apresenta benefícios potenciais em termos de cobertura, consumo de energia, reuso de frequência e eficiência de largura de banda. Este padrão utiliza o intervalo de frequência de 2-6 GHz e não suporta modo mesh, uma vez que redes mesh são configuradas em cenários onde os nós são fixos [Li, 2007].

A topologia de uma rede WiMAX é parecida com a de uma rede $\mathrm{Wi}-\mathrm{Fi}$, com um ponto de acesso chamado estação base (base station), o qual fornece acesso ao sistema de distribuição da rede. Geralmente os clientes seguem um perfil corporativo podendo ser prédios comerciais, condomínios residenciais, casas com uma rede interna Wi-Fi e até mesmo os usuários móveis.

Algumas características suportadas pelo Mobile WiMAX são [WiMAX, 2009]:

- $\quad$ alta taxa de transferência de dados: com a utilização de técnicas de antena MIMO (Múltiplas Entradas Múltiplas Saídas) com esquemas de subcanais flexíveis e codificação e modulação avançadas, obtém taxas de até 63 Mbps para download e até 28 Mbps para upload;

- $\quad$ qualidade de serviço(QoS): define características de fluxo de dados;

- $\quad$ escalabilidade: Mobile WiMAX é desenhada para trabalhar em diferentes faixas de frequência de 1,25 MHz até $20 \mathrm{MHz}$

- $\quad$ segurança: suporta vários tipos de autenticação (EAP, AES-CMM, CMAC e HMAC);

- mobilidade: Mobile WiMAX suporta esquemas de handover otimizados com latências menores que 50 milisegundos para assegurar que aplicações de tempo real sejam executadas sem degradação de serviço. 
Para melhorar o consumo de bateria e o gerenciamento de handovers (duas questões críticas para aplicações móveis), o Mobile WiMAX trabalha com dois modos de consumo de energia (Sleep Mode e Idle Mode) e três métodos de handover (Hard Handoff HHO, Fast Base Station Switching FBSS e Macro Diversity Handover MDHO).

Uma nova padronização do Mobile WiMAX, denominada IEEE 802.16m [Loa, 2010], foi especificada para ser utilizada em telefonia celular.

\subsubsection{Rede de telefonia celular}

As redes sem fio de telefonia celular têm evoluído através de várias gerações [Araujo, 2003]. A primeira geração foi composta pelo sistema de celulares analógicos, que utilizavam modulação em frequência para voz e modulação digital FSK (Frequency Shift Keying) para sinalização. O ponto fraco desta rede era a baixa taxa de dados oferecida e a necessidade de alterações de hardware para qualquer característica nova de serviço.

A segunda geração (2G) foi composta de celulares digitais e serviços de comunicação pessoal. Caracterizou-se pela digitalização do sistema, oferecendo técnicas de codificação digital de voz mais poderosas, maior eficiência espectral, melhor qualidade de voz, maior capacidade de utilização, segurança nas comunicações e transmissão de dados. Entre os principais sistemas $2 \mathrm{G}$ estão [Harte, 2002]: PDC/JDC (Personal Digital Cellular ou Japanese Digital Cellular), TDMA (Time Division Multiple Access), CDMA (Code Division Multiple Access) e GSM (Global System for Mobile Communication). As desvantagens do 2G incluem: largura de banda insuficiente para serviços atuais como multimídia, necessidade de acesso à rede a qualquer instante para uso dos serviços da Internet, e a incapacidade de fornecer serviços que utilizam altas taxas de transmissão oferecidos por transmissão de fibra óptica. 
Uma geração intermediária $(2,5 \mathrm{G})$ entre a segunda e a terceira refere-se aos sistemas celulares com serviços e taxas adicionais àquelas oferecidas pela 2G, baseados no GSM. A 2,5G compreende o GPRS (General Packet Radio Service) e o HSCSD (High Speed Circuit-Switched Data).

A terceira geração $(3 \mathrm{G})$ representa a convergência das tecnologias de Internet (web, email, informações), telefonia (voz, vídeo, fax) e mídia de difusão (TV, rádio, entretenimento, serviços de localização). As principais características dos sistemas 3G são conhecidas como IMT2000 [ITU, 2009] (International Mobile Telecommunications), entre as quais é possível destacar a utilização no mundo todo, utilização em todas as aplicações móveis, suporte à comutação de pacotes e comutação de circuito, e taxas de dados de até 2 Mbps. A proposta mais importante do IMT-2000 é o UMTS [3GPP 23.101] (Universal Mobile Telecommunications System) que foi originado no Japão e adotado para uso na 3G pelo ETSI (European Telecommunications Standardizations Institute). Cada terminal UMTS pode acessar vários serviços ao mesmo tempo.

A quarta geração (4G) foi especificada em março de 2008 pela ITU-R (International Telecommunications Union - Radio communications sector) e é conhecida pelo nome IMTAdvanced (International Mobile Telecommunications Advanced) [Loa, 2010]. Duas tecnologias foram homologadas como sendo complacentes com 4G: Mobile WiMAX (IEEE 802.16m) [Loa, 2010] e LTE Advanced (3GPP) [Loa, 2010].

Atualmente os dois padrões de rede celular sendo utilizados são o GSM/GPRS da 2,5G e seu sucessor, o UMTS da 3G. Algumas redes pré-4G (consideradas 4G mas que ainda não atingem as taxas de dados de $1 \mathrm{Gbps}$ ) funcionam em alguns países, utilizando-se Mobile WiMAX e/ou LTE. Nos Estados Unidos, a rede pré-4G é oferecida via Mobile WiMAX desde 2008 e via LTE desde 2010. No Brasil, a 4G é prevista para estar disponível até abril/2013 em algumas das cidades que sediarão a Copa das Confederações na faixa de frequência de $450 \mathrm{MHz}$ e $2.5 \mathrm{GHz}$, 
segundo o site da Anatel (em http://www.anatel.gov.br/Portal/exibirPortalNoticias.do? acao $=$ carregaNoticia $\&$ codigo $=25255)$.

\subsubsection{Redes GSM/GPRS}

Assim como uma rede Wi-Fi é composta de áreas de cobertura (BSA), a rede GSM é composta por células limitadas pelo alcance da antena (BTS - Base Transceiver Station). As BTSs, ou estações base, são como os pontos de acesso da rede Wi-Fi e se comunicam por meio de rádiofrequência com os aparelhos celulares. A arquitetura de uma rede GSM/GPRS é ilustrada na Figura 7.

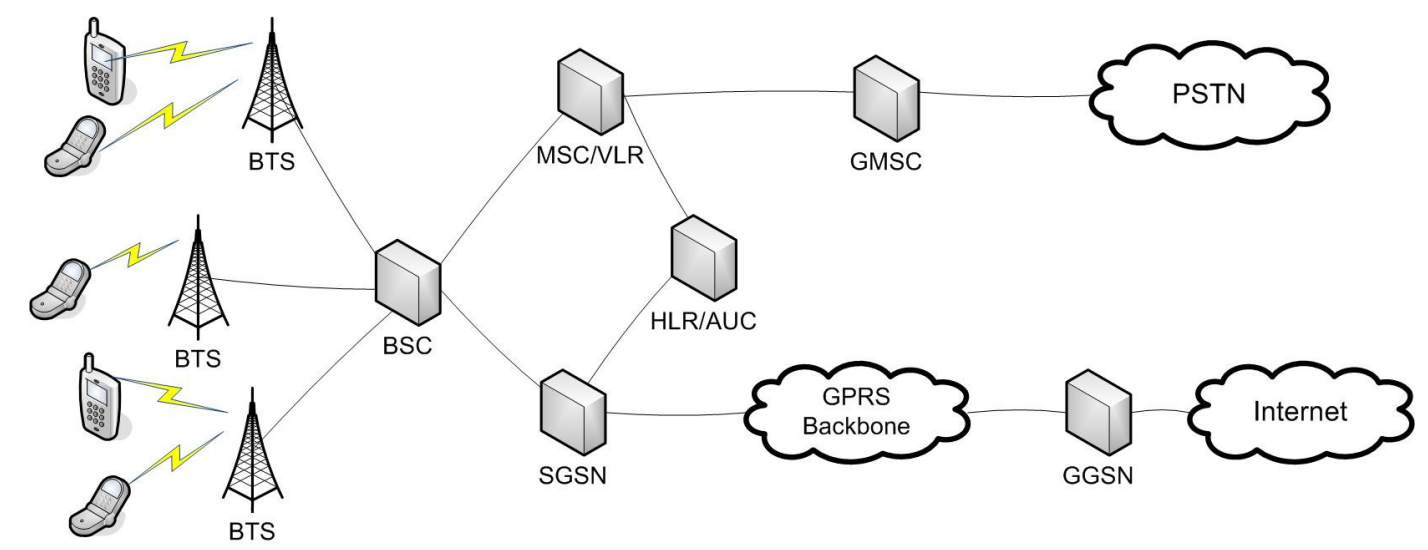

Figura 7 - Arquitetura de rede GSM/GPRS, adaptada de [Bresil, 2004]

Cada estação base está conectada a um BSC (Base Station Controller) sendo que cada BSC pode controlar várias BTSs. O BSC é como o Wireless Switch da rede Wi-Fi. O conjunto de um BSC e suas estações base é chamado de BSS (Base Station Subsystem). Cada BSC é conectado a um MSC (Mobile Switching Center), que é responsável pelo roteamento das ligações dentro da rede GSM. As ligações feitas com destino à rede externa à GSM (PSTN, por exemplo) ou vindas de uma rede externa, passam pelo GMSC (Gateway MSC) que faz a função de ponte entre as duas redes. 
Para armazenar informações de clientes, o sistema possui três bases de dados. A HLR (Home Location Register) contém informações sobre os clientes que residem na região de atuação do MSC. Para cada cliente é atribuída uma única identidade chamada IMSI (Internation Mobile Subscriber Identity). A base de dados VLR (Visitor Location Register) armazena temporariamente a identidade e informações de clientes de outras MSCs que estão visitando a rede local. A base AUC (Authentication Center) manipula as chaves de autenticação e criptografia para cada usuário no HLR e no VLR. Estas bases são equivalentes às bases manipuladas pelo servidor AAA da rede Wi-Fi.

A mobilidade é gerenciada pela rede (centrada na rede) e auxiliada pelo dispositivo móvel, o qual informa as condições de sinal recebido. As trocas de acesso entre antenas (BTSs) gerenciadas pelo mesmo BSC são gerenciadas pelo BSC. Quando ocorre troca entre antenas de diferentes BSCs, o MSC atua no gerenciamento.

O sistema GPRS forma uma rede de dados por pacote, sobreposta à rede GSM. Esta rede transporta dados entre o terminal (aparelho celular) e uma rede externa de dados (PDN - Packet Data Network). Como é uma rede de sobreposição, dois novos elementos foram necessários para possibilitar o tráfego de dados na infraestrutura existente GSM: o SGSN e o GGSN.

O SGSN (Serving GPRS Support Node) realiza a comutação de pacotes na rede GPRS. Suas principais funções são rotear e direcionar os pacotes, gerenciar a mobilidade, gerenciar localização, atribuir canais, autenticação e tarifação de chamadas. O GGSN (Gateway GPRS Support Node) é a interface entre um SGSN e uma outra rede de pacotes GPRS ou uma rede externa de pacotes de dados, ou seja, converte pacotes GPRS vindos da rede GPRS para pacotes IP da rede externa e vice-versa. 


\subsubsection{Redes UMTS}

O sistema UMTS pode ser dividido em três domínios lógicos, além das redes externas, como pode ser visto na Figura 8. O núcleo da rede (CN - Core Network) é o mesmo do sistema GPRS, porém uma nova interface de acesso por rádio é utilizada, chamada UTRAN (UMTS Terrestrial Radio Access Network).

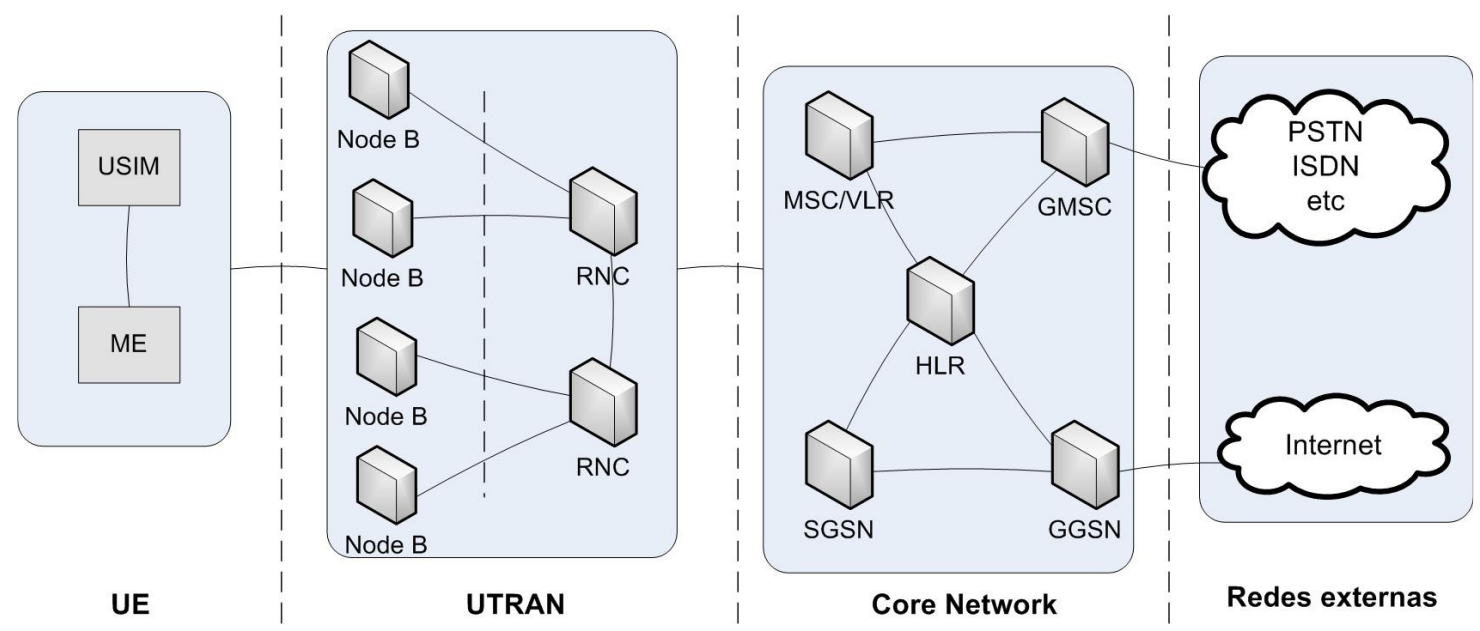

Figura 8 - Arquitetura de rede UMTS, adaptada de [Bresil, 2004]

O domínio lógico UE (User Equipment) é composto pelo dispositivo de rádio do aparelho do cliente (ME - Mobile Equipment) e o cartão USIM (UMTS Subscriber Identity Module). O cartão USIM armazena chaves de autenticação e códigos criptográficos. No domínio UTRAN estão o Node B e o RNC (Radio Network Controller) que têm a mesma função do BTS e BSC, respectivamente, do sistema GSM/GPRS. Os elementos do domínio CN são os mesmos do sistema GSM/GPRS.

\subsubsection{Comparação com o acesso à Internet via provedor Wi-Fi}

Nos últimos anos vários provedores Wi-Fi têm disponibilizado pontos de acesso para provimento sem fio em estabelecimentos comerciais. A tecnologia é disponível para qualquer aparelho com interface $\mathrm{Wi}-\mathrm{Fi}$, incluindo notebooks, tablets e smartphones. As principais vantagens desta forma 
de acesso são a velocidade de conexão rápida (em torno de 17 Mbps com 802.11g) e o custo barato, comparando-se com o acesso pela rede de telefonia celular. Serviços de chamada de voz podem ser realizados utilizando-se Voz sobre IP (VoIP). Porém o acesso é limitado a algumas dezenas de metros da antena. A mobilidade fica prejudicada pois, entre uma antena e outra, o cliente Wi-Fi pode perder a conexão e, consequentemente, a sessão que estava aberta com um provedor de conteúdo. Para conseguir maior área de cobertura da rede, o cliente sem fio teria que ter contrato com vários provedores $\mathrm{Wi}-\mathrm{Fi}$, o que se torna uma prática inviável devido à manutenção de vários contratos, mensalidades e senhas de acesso.

A outra forma de acesso, através da rede de telefonia celular, também está disponível tanto para aparelhos celulares modernos quanto para notebooks equipados com um modem apropriado. As operadoras de celular, através de GPRS e 3G, oferecem uma área de cobertura maior que os provedores Wi-Fi. Consequentemente, o cliente tem disponível uma mobilidade real, sem interrupções de sessão, e o horário para acesso é ininterrupto. Por outro lado, as tecnologias GPRS e 3G não oferecem um acesso rápido como na Wi-Fi, ficando limitado a taxas de transferência entre $60 \mathrm{Kbps}$ e $2 \mathrm{Mbps}$. Esta forma de acesso também é mais cara que Wi-Fi, apesar do custo ter diminuído com relação às outras gerações de celular.

\subsubsection{Redes $4 G$}

Duas tecnologias foram homologadas para a implantação da 4G: Mobile WiMAX (IEEE 802.16m) [Loa, 2010] e LTE Advanced (3GPP) [Loa, 2010]. Independente da tecnologia utilizada, algumas características são comuns, conforme definido na especificação IMTAdvanced.

Diferentemente das redes $3 \mathrm{G}$ e anteriores que implementam chaveamento por circuito (circuit-switched), na 4G é especificado apenas chaveamento por pacote IP com um núcleo 
comum entre as várias redes (all-IP packet switched network). A taxa de dados especificada é de 100 Mbps para usuários em alta velocidade, como usuários no interior de veículos, e de até 1 Gbps para usuários com pouca mobilidade, como usuários caminhando ou estacionados. A transmissão de dados é feita por multi-portadora OFDMA e as comunicações são feitas através de múltiplas-entradas múltiplas-saídas (MIMO). A largura de banda dos canais é escalável de 5 a 20 $\mathrm{MHz}$ e, opcionalmente, $40 \mathrm{MHz}$. As trocas de rede devem ser feitas de forma transparente entre redes heterogêneas.

\subsection{Redes de Próxima Geração (NGN)}

As redes de próxima geração não são, na verdade, novas tecnologias de rede, e sim, um conceito. O conceito de NGN (Next Generation Network), segundo o Projeto NGN 2004 [ITU, 2004], surgiu em função da nova situação em telecomunicações, caracterizado por fatores como: competição entre operadores devido à não regulamentação do mercado, aumento de tráfego digital, por exemplo, devido ao crescente uso da Internet, aumento da demanda por novos serviços multimídia, aumento na demanda por mobilidade, etc. O objetivo maior do Projeto NGN é facilitar a convergência de redes e serviços.

A definição de NGN, segundo o Projeto NGN 2004 [ITU, 2004], é “uma rede baseada em pacotes capaz de fornecer serviços inclusive de telecomunicação e capaz de fazer uso de várias comunicações banda larga, tecnologias de transporte que suportam QoS e cujas funções relacionadas aos serviços sejam independentes da tecnologia de transporte. Esta rede oferece acesso irrestrito a usuários de vários provedores de serviço, e suporta mobilidade generalizada a qual permitirá o provisionamento consistente e ubíquo de serviços aos usuários”.

As várias redes que compõem a NGN utilizam diversas tecnologias (Wi-Fi, WiMAX, Bluetooth, celular, etc) e apresentam sobreposição de sinal umas com as outras. Este fato 
permitirá o handover transparente entre as várias tecnologias, possibilitando ao usuário a mobilidade e estar sempre conectado (always-on). Os núcleos das redes de computadores e celulares serão convergidos em um núcleo IP de comutação de pacotes.

Devido à definição de NGN, de que o usuário móvel terá acesso irrestrito a vários provedores de serviço de tecnologias diferentes, tornando o acesso à rede ubíquo e transparente ao usuário, faz-se necessária a implementação de acesso sob demanda e de gerenciamento de handover feito pelo usuário (centrado no usuário).

As seções seguintes abordam algumas das características relacionadas ao conceito de NGN como a ubiquidade do acesso, o acesso sob demanda, e o gerenciamento de handover.

\subsubsection{Ubiquidade de acesso}

A ideia da computação ubíqua surgiu por volta de 1991, quando Mark Weiser [Weiser, 1991] descreveu um cenário no qual os computadores estariam "invisíveis" aos humanos. Estes computadores acompanhariam os usuários para onde eles fossem e formariam diferentes modelos computacionais dependendo do ambiente onde estivessem inseridos.

Este cenário está se concretizando graças à evolução da telecomunicação sem fio, aumento do poder de processamento e miniaturização de equipamentos, evolução de baterias para dispositivos portáteis e arquiteturas de programas de computador mais flexíveis [Lyytinen, 2002].

A computação ubíqua envolve dois conceitos: a computação móvel e a computação pervasiva. A tecnologia da computação móvel permite que serviços computacionais se movam fisicamente conosco. Uma limitação atual da computação móvel é que o modelo computacional permanece o mesmo enquanto em movimento, ou seja, os dispositivos e configurações não se alteram em função de mudanças do ambiente. 
A computação pervasiva implica que o computador está embarcado no ambiente de forma invisível para o usuário [Araujo, 2003]. Nesta concepção, o computador também consegue obter informações de outros dispositivos presentes no ambiente ao qual ele está embarcado, podendo desta forma, construir modelos computacionais diferentes dinamicamente para melhor atender às necessidades do usuário e serviço sendo utilizado. Os dispositivos presentes no ambiente não são necessariamente dispositivos móveis.

Desta forma, é possível dizer que a computação móvel tem uma alta capacidade de mobilidade e baixa capacidade de embarcamento. Por outro lado, a computação pervasiva tem baixa capacidade de mobilidade e alta capacidade de embarcamento. A computação ubíqua baseia-se na integração da mobilidade da computação móvel com a funcionalidade da computação pervasiva. Na NGN, o principal emprego da computação ubíqua está na ubiquidade do acesso à rede, de forma que o handover seja feito de forma transparente ao usuário.

\subsubsection{Acesso sob Demanda}

Atualmente as operadoras de telefonia celular oferecem aos seus clientes o serviço de roaming. Com este serviço, um cliente de uma operadora pode utilizar os serviços de outra operadora quando se encontrar fora da sua área de cobertura. Para este serviço funcionar, as operadoras precisam firmar acordos de nível de serviço (SLAs) umas com as outras. Quando um usuário vai utilizar o serviço, a operadora visitante autentica as credenciais na operadora do usuário e faz a contabilização dos serviços utilizados. Posteriormente esta contabilização é enviada para a operadora do usuário. Nas redes de computadores e provedores Wi-Fi o cenário é um pouco diferente. A quantidade de provedores de acesso é muito grande, tornando-se impraticável que todos firmem acordos entre si para oferecer roaming aos usuários. 
Em um cenário com acesso sob demanda, o usuário seria cliente de um único provedor de acesso, ou de uma entidade que funcionasse como intermediário (broker) entre o cliente e os vários provedores de acesso, e usaria a rede dos outros provedores quando fosse necessário. Diferentemente do acesso tradicional onde existe uma periodicidade maior de tempo de acesso e tráfego do usuário, no acesso sob demanda o usuário ficaria conectado por um tempo aleatório em cada provedor de acesso, podendo até utilizar uma única vez um provedor e não mais voltar a usar. O usuário também tem maior liberdade em escolher à qual ponto de acesso vai se conectar (gerenciamento centrado no usuário e não na rede).

Do lado do provedor de acesso há várias implicações para o fornecimento de acessos sob demanda. A quantidade de usuários, o tempo de conexão, os serviços utilizados, o perfil de acesso e outras características são mais variáveis que os acessos dos clientes fixos. Isso torna mais difícil para o provedor dimensionar sua infraestrutura em termos de largura de banda, quantidade de pontos de acesso, capacidade dos servidores, segurança ao fornecer acesso a usuários desconhecidos, etc. Outras questões de controle de acesso, qualidade de serviço e tarifação são levantadas por Hecker [Hecker, 2005].

\subsubsection{Gerenciamento de handover}

A NGN será baseada no uso de várias tecnologias diferentes de rede. Neste ambiente, os dispositivos móveis, com várias interfaces de rede, poderão se mover entre redes diferentes sem perder a conexão e o serviço sendo acessado. Uma das questões em desenvolvimento para a NGN é o gerenciamento do handover. Este pode ser feito pela rede (network-centric ou networkcontrolled) com ou sem auxílio do dispositivo móvel, ou pode ser feito pelo usuário (user-centric ou client-based) com ou sem auxílio da rede. Segundo [Mapp, 2009], o gerenciamento centrado no usuário é a melhor solução, sendo mais escalável, pois o usuário pode facilmente monitorar os 
parâmetros necessários de suas interfaces de rede e permite ao dispositivo móvel considerar fatores locais como, por exemplo, o estado de suas conexões TCP.

Handover, ou handoff, é o processo que ocorre quando um dispositivo móvel muda seu ponto de acesso à Internet, ou seja, desconecta-se de um ponto de acesso e conecta-se a outro. Geralmente a troca de ponto de acesso ocorre devido à queda na intensidade do sinal do ponto de acesso atual. Algumas variáveis estão envolvidas em um processo de handover como, por exemplo, o provedor de acesso (com diferentes políticas de qualidade de serviço, privacidade, segurança, preço), a tecnologia de rede (802.11, GPRS, UMTS, WiMAX), o ambiente no qual o usuário se encontra (um túnel, um congestionamento, claridade, ruído), etc.

Um handover pode ser classificado de várias formas, segundo [Vanni, 2006]. Do ponto de vista do sistema, o handover é classificado como intrassistema (ocorre dentro do mesmo provedor de acesso) ou inter-sistema (quando muda de um provedor para outro). Do ponto de vista da cobertura de sinal (overlay), o handover é classificado como vertical (de uma rede para outra com diferentes coberturas e larguras de banda) ou horizontal (se mesma cobertura). O handover vertical ainda pode ser classificado em upward handover (quando a cobertura aumenta) ou downward handover (quando a cobertura diminui). Do ponto de vista da tecnologia de acesso à rede utilizada, o handover pode ser homogêneo (troca entre redes de mesma tecnologia) ou heterogêneo (troca entre tecnologias diferentes).

Os handovers também podem ser classificados como hard handover, que ocorre quando a conexão atual é perdida antes de uma nova conexão ser estabelecida, e soft handover, quando a conexão atual é finalizada após uma nova conexão ter sido estabelecida.

Mapp [Mapp, 2009] ainda classifica os handovers verticais segundo a Figura 9. Handovers imperativos ocorrem apenas devido a razões tecnológicas nas quais pode haver queda no desempenho ou perda da conexão caso o handover não ocorra. Ao contrário, handovers 
alternativos ocorrem devido a outras razões como, por exemplo, incentivos da rede, preferência do usuário, contexto ou oferta de outros serviços, casos em que não haverá perda de desempenho ou conexão caso o handover não ocorra. O handover imperativo é dividido em reativo (reactive) e pró-ativo (proactive). O reativo responde a mudanças nas interfaces de rede sem fio como, por exemplo, disponibilidade ou não de uma rede. O handover reativo ainda pode ser dividido entre antecipado (anticipated), no qual há pontos de acesso alternativos para o dispositivo móvel conectar, e não antecipado (unanticipated), no qual o dispositivo móvel perde a conexão e não há outro ponto de acesso disponível para conectar. No handover pró-ativo, técnicas de soft handover são utilizadas para saber a condição das várias redes disponíveis em certa localidade antes que o dispositivo móvel alcance aquela posição. No pró-ativo baseado em conhecimento (knowledgebased) o dispositivo móvel tenta conhecer a situação das redes através de medição prévia da força do sinal recebido e consulta a bases de dados. O pró-ativo baseado em modelo (model-based) utiliza modelos matemáticos que calculam o ponto no qual o handover deve ocorrer e o tempo que o usuário levará para alcançar determinado ponto em função de sua velocidade e direção.

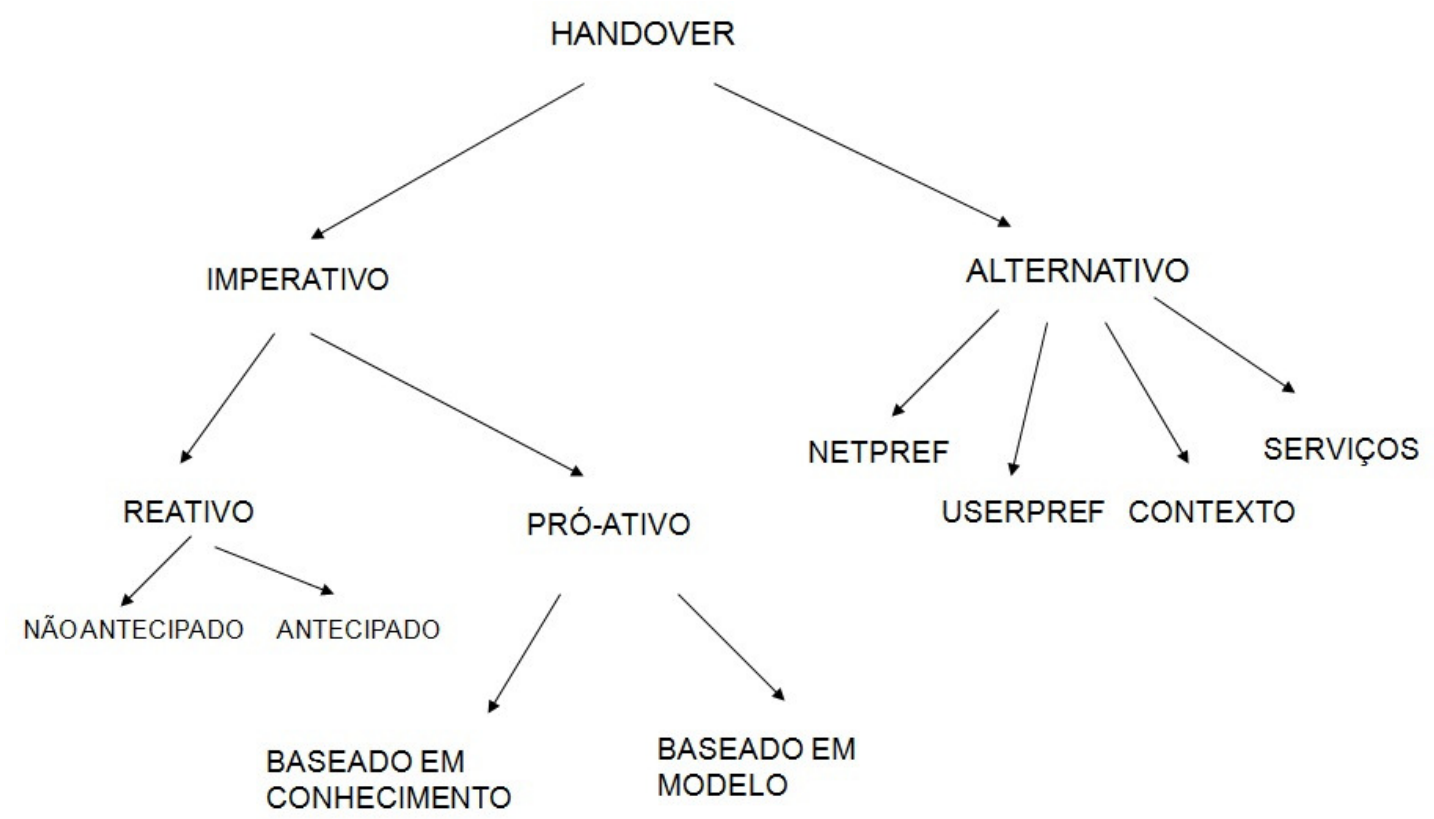

Figura 9 - Classificação de tipos de handover, extraído de [Mapp, 2009] 
Alguns trabalhos têm sido realizados com o objetivo de auxiliar o gerenciamento de handovers. Em [Vanni, 2006] os autores propõem o uso de uma Ontologia de Domínio para Handover (DOHand - Domain Ontology for Handovers) para facilitar decisões envolvidas no processo de handover. A ontologia fornece significado semântico para conceitos comuns que são essenciais no gerenciamento de infraestrutura de rede integrada e ubíqua.

Em [Moreira, 2007] e [Yokoyama, 2008] os autores propõem uma arquitetura chamada SOHand (Service Oriented Handover Management System) que acrescenta ao processo de handover informações sobre o ambiente no qual o evento está inserido. Desta forma, o dispositivo móvel terá mais autonomia nas decisões de handover, diferentemente do sistema atual de telefonia móvel onde o gerenciamento e a escolha do ponto de acesso são feitos pelo provedor de acesso. Esta arquitetura é vista com mais detalhes no capítulo 3.

Em [Mapp, 2007] e [Mapp, 2009] os autores apresentam uma nova arquitetura para redes heterogêneas dividida em camadas (como no modelo OSI), denominada Y-Comm. Do lado do cliente, a camada de handover vertical é responsável por realizar o handover e a camada de gerenciamento de política avalia as circunstâncias em que um handover deve ocorrer (queda do sinal recebido ou vazão, por exemplo). A arquitetura é vista com mais detalhes no capítulo 3.

Em [Su, 2007] os autores apresentam uma arquitetura de rede sem camadas chamada Haggle, diferenciando-se do atual modelo OSI (Open Systems Interconnection) que pressupõe uma infraestrutura fixa. O objetivo desta arquitetura é facilitar a comunicação de dispositivos móveis num ambiente ubíquo, tornando os dispositivos e aplicações não dependentes da atual infraestrutura de rede e possibilitando a formação de redes ad-hoc e comunicação direta entre os dispositivos móveis. 
O projeto MMQoS [Hecker, 2005] é uma arquitetura global que fornece ao usuário mobilidade com suporte à QoS fim-a-fim em um contexto com várias redes sem fio heterogêneas de vários provedores e gerenciadas por diferentes autoridades. Um cartão SIM-IP [Urien, 2002] é utilizado para fornecer aos usuários a mesma experiência de ambiente computacional independentemente da rede usada. Este cartão fornece armazenamento de identidade, acesso controlado à rede e implementa mecanismos necessários para os serviços do núcleo da rede como, por exemplo, controle de acesso, provisionamento dinâmico de QoS e acesso aos serviços.

Ambient Networks (AN) [Kappler, 2004] [Niebert, 2004] é um projeto colaborativo em larga escala da União Européia que envolve operadores de serviço, vendedores e fabricantes de aparelhos e instituições de pesquisa. Este projeto visa a composição automática de redes heterogêneas, sem necessidade de configuração prévia e sem negociação prévia dos operadores das redes envolvidas. O processo de composição das redes é realizado sob demanda e fica transparente aos usuários. É introduzido o conceito de espaço de controle de ambiente (ACS Ambient Control Space), o qual engloba todas as funções de controle em determinado domínio de rede. O ACS juntamente com a conectividade de rede é denominado de Ambiente Network (AN).

\subsection{Network Simulator (NS2)}

Para ser possível prever e estudar os impactos do acesso sob demanda torna-se inviável a experimentação através de infraestrutura real de provimento de acesso com várias antenas e redes de provedores diferentes. Por isso faz-se necessário o uso de simulação.

O NS2 (Network Simulator - versão 2) é um simulador de rede amplamente utilizado por pesquisadores. Seu código fonte é aberto e pode ser copiado do site oficial [NS2, 2012], possibilitando sua alteração para necessidades específicas. 
A arquitetura do simulador segue o modelo de referência OSI. Isso significa que um pacote de rede precisa passar pela camada de rede, camada de enlace e MAC, e camada física. Nas camadas mais baixas, o NS2 suporta redes locais cabeadas (LANs), redes sem fio (WLANs) e redes de satélite. Roteamentos estático, dinâmico, unicast e multicast são suportados. Os protocolos da camada de transporte suportados são TCP (Transport Control Protocol), UDP (User Datagram Protocol) e RTP (Real-Time Transport Protocol).

A implementação do simulador é dividida em duas partes. A parte principal é implementada em linguagem $\mathrm{C}++$, a qual fornece velocidade maior de execução. A parte de configuração é implementada em linguagem Tcl orientado a objetos, chamado OTcl, a qual fornece mais facilidade para o programador pois não é necessário compilação.

Para realizar uma simulação, um cenário precisa ser implementado utilizando-se a linguagem Tcl. Este cenário define as informações necessárias para executar uma simulação como, por exemplo, a topologia da rede e protocolos utilizados, geração de tráfego de rede e eventos controlados por tempo, criação dos nós da rede e enlaces, movimento dos nós móveis, além de monitoramento de filas, tráfego, movimento, taxas de erro e vazão, etc.

Embora o NS2 siga um modelo de simulação determinístico, ou seja, se o mesmo script for simulado várias vezes, os resultados serão os mesmos, é possível alterar a semente (seed) usada para gerar os números aleatórios, gerando assim resultados diferentes.

As simulações apresentadas nesta tese utilizaram o simulador NS2 com algumas modificações no código-fonte, principalmente relacionadas ao módulo Mobile IP [Perkins, 2002] e gerenciamento da troca de rede. Estas modificações estão descritas no capítulo 4. 


\section{Capítulo 3 Gerenciamento de Mobilidade}

Em um ambiente NGN onde há várias redes de tecnologias diferentes e sobreposição de sinal, e usuários móveis com várias interfaces de rede sem fio e maior exigência de QoS, faz-se necessário haver um melhor gerenciamento da mobilidade para possibilitar o handover transparente. Este capítulo apresenta uma revisão mais aprofundada da literatura, abordando algumas questões relacionadas ao gerenciamento de mobilidade como o Mobile IP, arquiteturas SOHand e Y-Comm, o protocolo de handover independente do meio (MIH), e alguns trabalhos relacionados a esta tese.

\subsection{Mobile IP}

Um problema decorrente das trocas entre redes de acesso é a troca do endereço IP do dispositivo móvel, pois cada rede possui um prefixo de endereço diferente. Com a troca do endereço IP, o dispositivo móvel perde a conexão com a aplicação. Para resolver este problema, foram implementadas as versões móveis do protocolo IP: o Mobile IPv4 [Perkins, 2002][ Perkins, 2010] e o Mobile IPv6 [Johnson, 2004][ Johnson, 2011]. Na NGN, a tendência é utilizar o Mobile IPv6 devido à grande quantidade de endereços disponíveis e maior suporte à mobilidade.

O Mobile IPv6, assim como na versão 4, permite ao dispositivo móvel, chamado de nó móvel (MN - Mobile Node), se mover entre redes sem perder uma conexão, pois o endereço IP original (home address) não se modifica. Independente de onde o nó móvel esteja, os pacotes serão roteados para ele, tornando a troca da rede transparente à camada de transporte e às aplicações.

É por meio do endereço original que um nó correspondente ( $\mathrm{CN}$ - Correspondent Node) irá se comunicar com o nó móvel. Quando o nó móvel se conecta a uma rede externa (rede 
estrangeira), ele mantém seu endereço original e recebe um outro (endereço COA - Care-Of Address) pertencente à rede estrangeira. Para o nó correspondente encontrar o nó móvel, o móvel precisa associar (binding) seu home address ao COA. Esta associação é feita no home agent (HA) pelo nó móvel, onde o nó móvel envia mensagens chamadas Binding Update para o home agent, que responde com uma mensagem Binding Acknowledgement. O Home Agent é um roteador da rede de origem (à qual o móvel se conectou inicialmente) que encapsula pacotes de rede para entregar ao nó móvel quando este está conectado a uma rede estrangeira, e mantém informação atual de localização do nó móvel.

Na implementação do Mobile IPv6, os nós correspondentes podem otimizar a rota até o nó móvel, armazenando bindings entre o home address e o COA. Para isso, o nó móvel pode fornecer informações sobre sua localização para os nós correspondentes utilizando o procedimento de associação correspondente (correspondent binding procedure). Neste procedimento, um mecanismo de autorização de estabelecimento de binding é realizado, chamado return routability procedure. O Mobile IPv4 não implementa esta otimização de rota, de tal forma que os pacotes enviados pelo $\mathrm{CN}$ são encaminhados para a rede de origem e esta repassa os pacotes para o endereço COA. Um cenário de mobilidade IPv6 é mostrado na Figura 10.

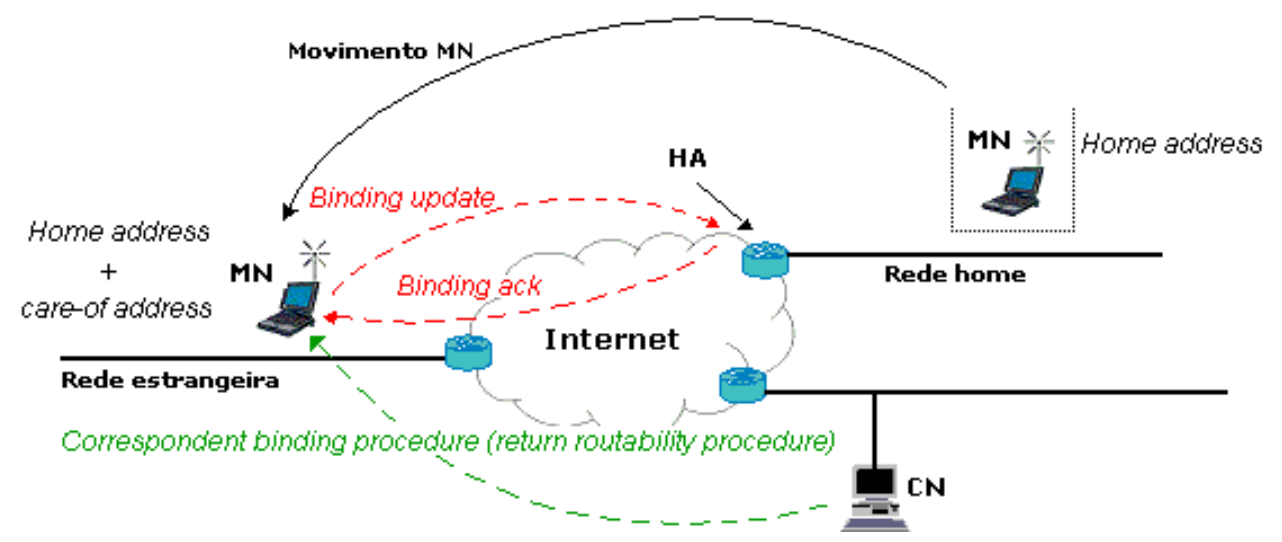

Figura 10 - Funcionamento do MIPv6, extraído de [Martins, 2003] 
A comunicação entre o nó móvel e o nó correspondente pode ocorrer de duas formas:

- Tunelamento bidirecional: não é necessário que o nó correspondente implemente o MIPv6. Neste caso, os pacotes são roteados do $\mathrm{CN}$ para o home agent e do home agent são encapsulados e tunelados para o nó móvel, utilizando o COA como endereço destino. Em seguida, o nó móvel responde diretamente ao nó correspondente;

- Otimização de rota: o nó correspondente precisa implementar MIPv6 e o nó móvel precisa se registrar com o nó correspondente. Neste caso, antes do nó correspondente enviar pacotes ao nó móvel, ele procura em um repositório temporário (cache) alguma associação entre o endereço home address e um COA do nó móvel. Se encontrar, o pacote é roteado para o COA, eliminando congestionamento na rede de origem do nó móvel.

\subsection{Arquiteturas para Provimento NGN}

Algumas arquiteturas foram propostas para fornecer acesso sob demanda para a NGN e encontram-se em implementação. Esta subseção apresenta as arquiteturas SOHand e Y-Comm, as quais apresentam algumas características (uso de informações de contexto, gerenciamento centrado no usuário, entre outras) que foram consideradas para a montagem dos cenários simulados (Capítulo 4) e montagem da arquitetura MYHand (Capítulo 5).

\subsubsection{Arquitetura SOHand}

A arquitetura SOHand (Service Oriented Handover Management System) [Moreira, 2007][Yokoyama, 2008] tem como objetivo auxiliar no gerenciamento de handovers, baseandose no gerenciamento de informações de contexto com suporte de uma ontologia compartilhada entre provedores e clientes. As informações de contexto são provenientes do usuário (localização, 
data e hora, preferências), da rede (IP, Gateway, DNS, SSID, canal, qualidade do sinal) e do dispositivo (interfaces de rede, tempo restante de bateria).

SOHand prevê o gerenciamento de handover sob duas abordagens: o lado cliente e o lado provedor. O lado cliente captura informações de contexto e as utiliza para negociar com os provedores disponíveis e escolher um que se adeque às preferências do usuário. O lado provedor armazena e sincroniza as informações contextuais fornecidas pelos clientes em um broker e permite o acesso por meio de um NAAA (Negotiation AAA), além de personalizar serviços. Diferentemente do sistema de telefonia celular, o gerenciamento de handover no SOHand é centrado no usuário com auxílio da rede, a qual fornece informações como as citadas acima.

A arquitetura SOHand é composta por três entidades: cliente, provedor e broker, como pode ser visto na Figura 11.

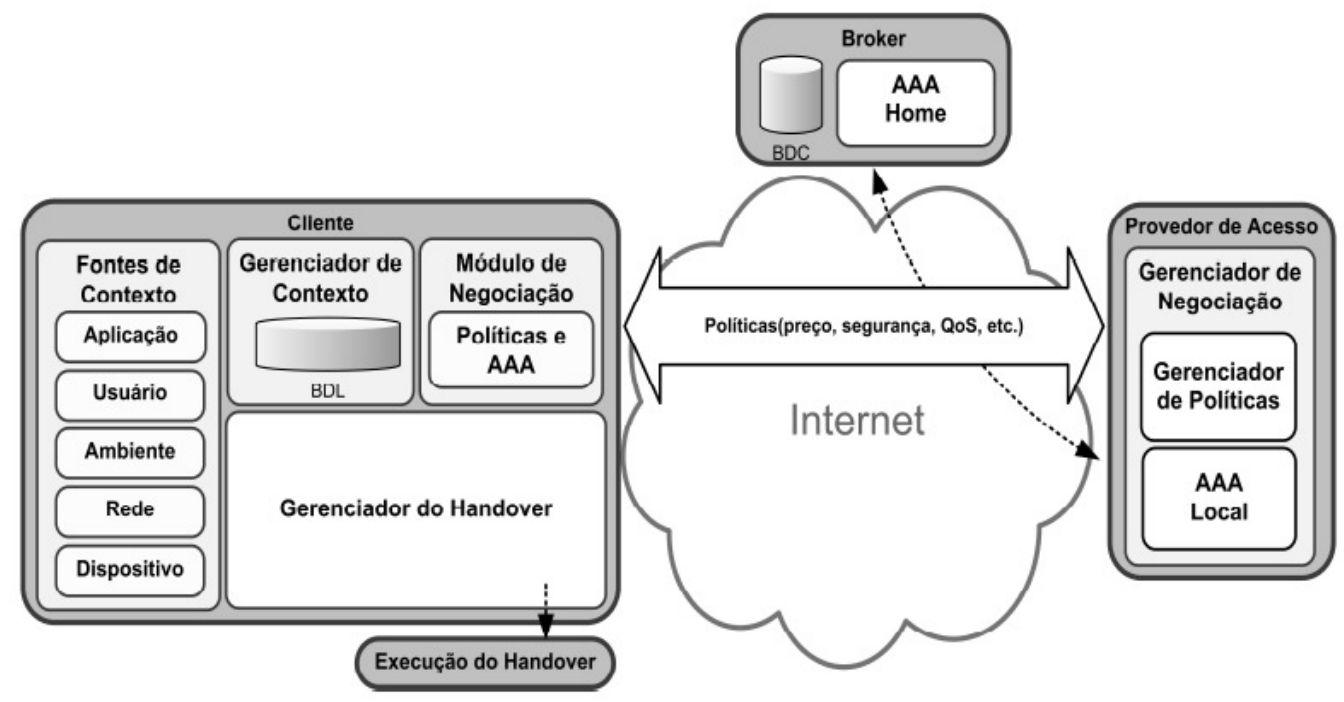

Figura 11 - Arquitetura SOHand, extraída de [Yokoyama, 2008]

No cliente há diversas Fontes de Contexto que fornecem informações capturadas pelo dispositivo móvel. O Gerenciador de Contexto é responsável por processar estas informações, armazená-las em uma Base de Dados Local (BDL) e monitorar as condições da rede atual, do dispositivo e das preferências do usuário. O Módulo de Negociação utiliza os serviços dos 
provedores de acesso para negociar o acesso baseado em políticas pré-definidas e em informações de contexto. O Gerenciador de Handover pode decidir qual a melhor rede para a troca baseada, por exemplo, nas preferências do usuário.

O provedor de acesso possui um Gerenciador de Negociação formado pelos módulos Gerenciador de Políticas, que informa as políticas de acesso de acordo com a posição geográfica do cliente, e o AAA Local, que é responsável por autenticar, autorizar e tarifar o cliente. O Broker é o responsável por disponibilizar informações de negociação de diferentes provedores e as centralizar em um AAA Home.

\subsubsection{Arquitetura Y-Comm}

Y-Comm [Mapp, 2007][Mapp, 2009] apresenta-se como uma nova arquitetura global para redes heterogêneas. Esta arquitetura é dividida em camadas como no modelo OSI mas, separa a rede em duas estruturas pois estas apresentam características distintas: a rede periférica (Peripheral Network), composta pelas redes sem fio presentes na última milha, e o núcleo da rede (Core Network). A divisão de camadas pode ser observada na Figura 12.

PERIPHERAL NETWORK

CORE NETWORK

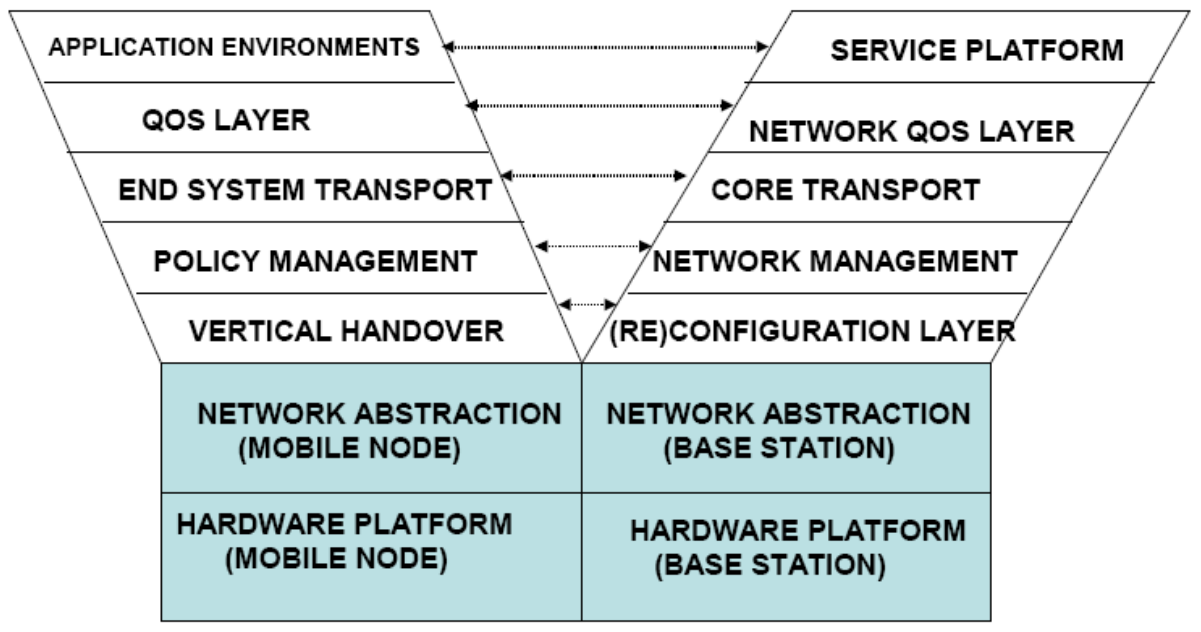

Figura 12 - Arquitetura Y-Comm, extraída de [Mapp, 2007] 
$\mathrm{Na}$ rede periférica, a camada física (Hardware Platform) define os componentes de hardware e tecnologias necessárias para suportar uma rede sem fio particular. A camada de abstração de rede (Network Abstraction) especifica uma interface de rede comum, à qual todas as redes que aderem a esta arquitetura devem suportar. A camada de handover vertical (Vertical Handover) é responsável por adquirir recursos da rede estrangeira e, de fato, realizar o handover. A camada de gerenciamento de política (Policy Management) avalia as circunstâncias em que um handover deve ocorrer, baseado em informações do dispositivo móvel e da rede de acesso. Esta camada pode ser implementada definindo-se certas regras relacionadas a todos os parâmetros relevantes que são avaliados para a decisão do handover. A camada de transporte (End System Transport) é correspondente às camadas de rede e de transporte do modelo OSI. A camada de Qualidade de Serviço (QoS Layer) assegura que a QoS necessária às aplicações seja mantida enquanto o dispositivo móvel troca de rede. A camada de aplicação (Application Environments) especifica mecanismos e rotinas que permitam às aplicações utilizarem as camadas da arquitetura Y-Comm.

No núcleo da rede, as camadas físicas e de abstração de rede (Hardware Platform e Network Abstraction) têm as mesmas funções que as equivalentes na rede periférica. A camada de reconfiguração (Reconfiguration Layer) preocupa-se com a reconfiguração dos recursos de rede no núcleo. A implementação desta camada também será usada pela camada de handover vertical da rede periférica para obter recursos de rede para um handover vertical quando este ocorrer. A camada de gerenciamento de rede (Network Management) fornece o sistema de AAA e interage com a camada de gerenciamento de política para informar sobre os recursos de rede disponíveis e negocia a alocação de recursos para o usuário móvel. A camada de transporte (Core Transport) implementa mecanismos de transporte e endereçamento. Os autores acreditam que o conjunto de protocolos TCP/IP deve continuar sendo usado nesta camada. A camada de QoS 
(Network QoS Layer) é responsável por questões de QoS no núcleo da rede. A camada de serviço (Service Platform) permite que diferentes agentes instalem e operem vários serviços de forma segura e controlada.

Nesta arquitetura, assim como na SOHand, o gerenciamento do handover é centrado no usuário.

\subsection{Handover Independente do Meio (MIH - Media Independent Handover)}

O padrão MIH é um arcabouço especificado pelo Grupo de Trabalho IEEE 802.21 [IEEE, 2009a] que fornece uma interface genérica aos seus usuários, chamados MIH Users, para as camadas físicas e de enlace de diferentes tecnologias de rede. Os MIH Users são programas das camadas mais altas do modelo OSI (rede, transporte e aplicação) que utilizam os serviços do MIH. Basicamente, um módulo chamado MIHF (MIH Function) fornece informações da camada de enlace e mapas das redes próximas para os MIH Users. Tais informações permitem ao dispositivo móvel melhor selecionar uma rede à qual vai se conectar (descoberta e seleção de redes) e trocar de rede de forma mais transparente em um ambiente heterogêneo.

No modelo MIH, existem três diferentes entidades habilitadas com MIH:

- dispositivo móvel (MN - Mobile Node): dispositivo com uma ou mais interfaces de rede e que realiza handovers verticais;

- ponto de conexão (PoA - Point of Attachment): ponto de acesso de uma rede WiFi ou estação base de uma rede celular;

- ponto de serviço (PoS - Point of Service): entidade da rede que pode trocar informações com outras entidades habilitadas com MIH. 
O processo de handover em si não é tratado pelo MIH, apenas o processo de descoberta de rede e tomada de decisão. Portanto, após o dispositivo móvel decidir à qual rede se conectar, algum protocolo de gerenciamento de mobilidade como, por exemplo, o Mobile IPv6 [Johnson, 2011] deve ser utilizado para que a conexão na camada de transporte (UDP ou TCP) não seja perdida.

O protocolo MIH segue um modelo inter-camadas. Neste modelo, informações gerenciadas por diferentes camadas são obtidas destas camadas através de interfaces bem definidas [Srivastava, 2005]. Uma entidade habilitada com MIH é mostrada na Figura 13, a qual mostra seus componentes e lugares devidos. Um MIH User precisa se registrar com o módulo MIHF para poder utilizar seus diferentes serviços. Os serviços oferecidos pelo MIHF são: Serviço de Eventos (MIES), Serviço de Comandos (MICS) e Serviço de Informações (MIIS). LLC_SAP e MIH_LINK_SAP (Service Access Points) são as interfaces específicas para cada meio (WiMAX e Wi-Fi, por exemplo) e MIH_SAP é a interface padrão entre o MIHF e os MIH Users.

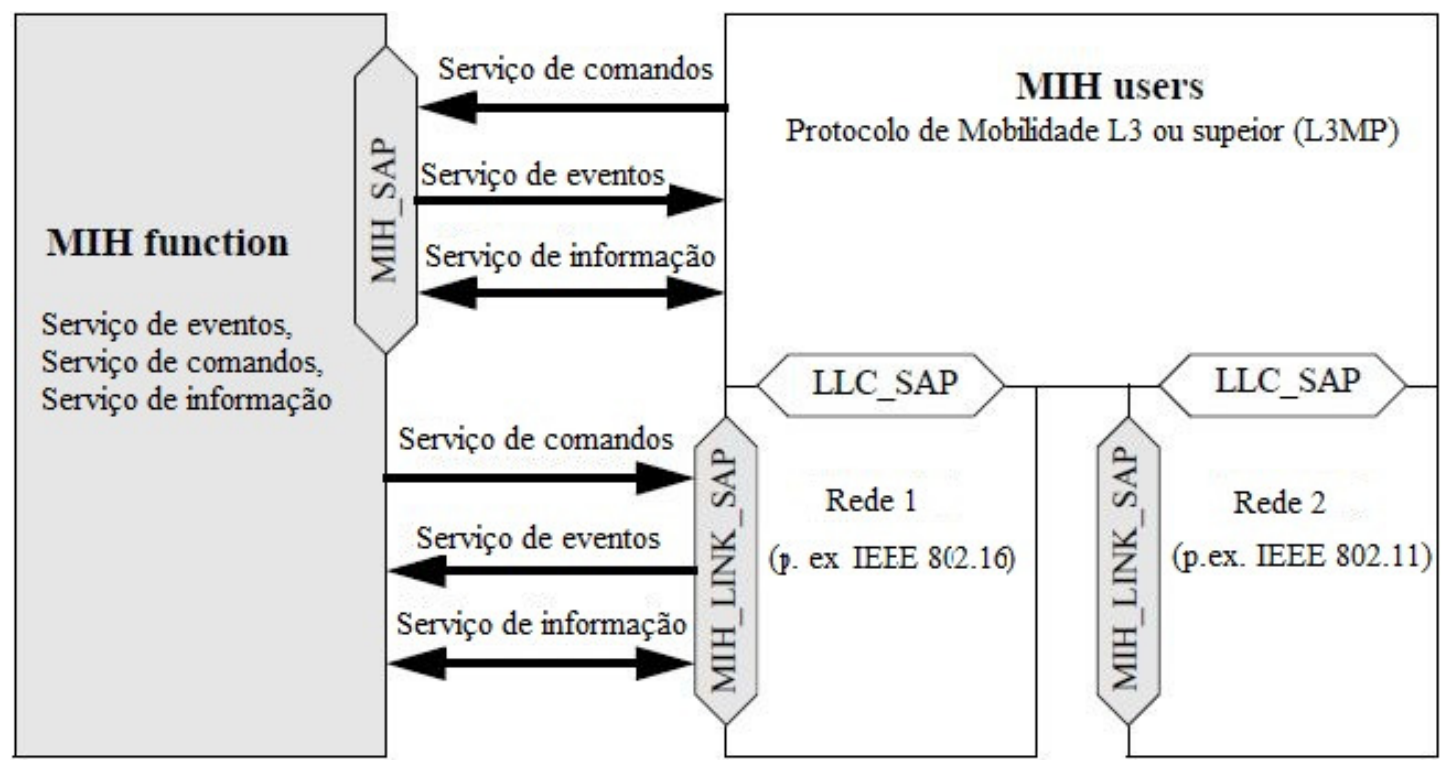

Figura 13 - Modelo de entidade habilitada com MIH, extraído de [IEEE, 2009a] 


\subsubsection{Serviço de Eventos (MIES)}

Quando uma alteração ocorre nas camadas mais baixas do dispositivo móvel ou de uma entidade remota e o MIH User está inscrito no evento específico, um aviso de evento na forma de gatilho (trigger) é enviado para o MIHF do dispositivo móvel. Por sua vez, o MIHF notifica o MIH User, o qual pode tomar alguma providência com relação ao evento. Alguns exemplos de gatilho são descritos na Tabela 2.

Tabela 2 - Alguns eventos do Serviço de Eventos

\begin{tabular}{|c|c|c|}
\hline Nome do evento & Tipo do evento & Descrição \\
\hline Link_Detected & Mudança de estado & $\begin{array}{c}\text { Enlace de uma nova rede foi detectado. } \\
\text { Este evento não é gerado quando outros } \\
\text { PoAs da mesma rede são descobertos }\end{array}$ \\
\hline Link_Up & Mudança de estado & $\begin{array}{c}\text { Conexão L2 estabilizado e enlace pronto } \\
\text { para uso }\end{array}$ \\
\hline Link_Down & Mudança de estado & $\begin{array}{c}\text { Conexão L2 foi quebrada e enlace não } \\
\text { está disponível para uso }\end{array}$ \\
\hline Link_Parameters_Report & Parâmetros de enlace & $\begin{array}{c}\text { Parâmetros do enlace ultrapassaram } \\
\text { limites pré-definidos }\end{array}$ \\
\hline Link_Going_Down & Previsão & $\begin{array}{c}\text { Condições do enlace estão se degradando, } \\
\text { perda da conexão é iminente }\end{array}$ \\
\hline Link_Handover_Complete & Handover de enlace & $\begin{array}{c}\text { Handover L2 para um novo PoA está } \\
\text { completo }\end{array}$ \\
\hline
\end{tabular}

\subsubsection{Serviço de Comandos (MICS)}

O MIH User envia comandos ao MIHF, o qual repassa-os (se for o caso) às camadas mais baixas do dispositivo móvel ou a um MIH remoto. Alguns exemplos de comandos são: o comando MIH_Event_Subscribe, o qual providencia a inscrição em um evento, e os comandos MIH_Link_Configure_Thresholds e MIH_Link_Get_Parameters utilizados para, 
respectivamente, configurar e obter informação de limites (thresholds) de diferentes parâmetros da camada de enlace.

\subsubsection{Serviço de Informações (MIIS)}

Este serviço é utilizado para se obter um mapa das redes próximas. Este mapa é proveniente de um Servidor de Informação (IS - Information Server), de tal forma que a melhor rede possa ser selecionada antes mesmo de o dispositivo móvel detectar o sinal da antena. Este mapa das redes é composto por partes de informações chamadas de Elementos de Informação (IE - Information Elements) que são encapsulados em pacotes TCP ou UDP para serem entregues a um MIHF remoto. Para cada rede de acesso, um conjunto de IEs é chamado de mapa da rede.

O MIIS define dois métodos para representar os Elementos de Informação: representação binária e representação RDF/OWL. No método de representação binária, os Elementos de Informação são representados e codificados no formato TLV (Type-Length-Value). O campo Type indica o tipo/código do Elemento de Informação, o campo Length indica o tamanho em octetos do campo Value, e o campo Value contém o valor do Elemento de Informação.

A arquitetura MYHand utiliza o segundo método de representação de IEs. A representação em esquema RDF/OWL [OWL2, 2012] é utilizada no Serviço de Informação do IEEE 802.21 para definir a estrutura de cada Elemento de Informação, bem como o relacionamento entre eles. A definição do esquema RDF/OWL para o MIIS consiste de duas partes: o Esquema Básico e o Esquema Estendido. O método de representação RDF/OWL pode ser expandido usando um Esquema Estendido. A Figura 14 mostra os Elementos de Informação que compõem o Esquema Básico, segundo o Anexo H de [IEEE, 2009a]. Uma breve descrição de cada elemento é mostrada na Tabela 3. 


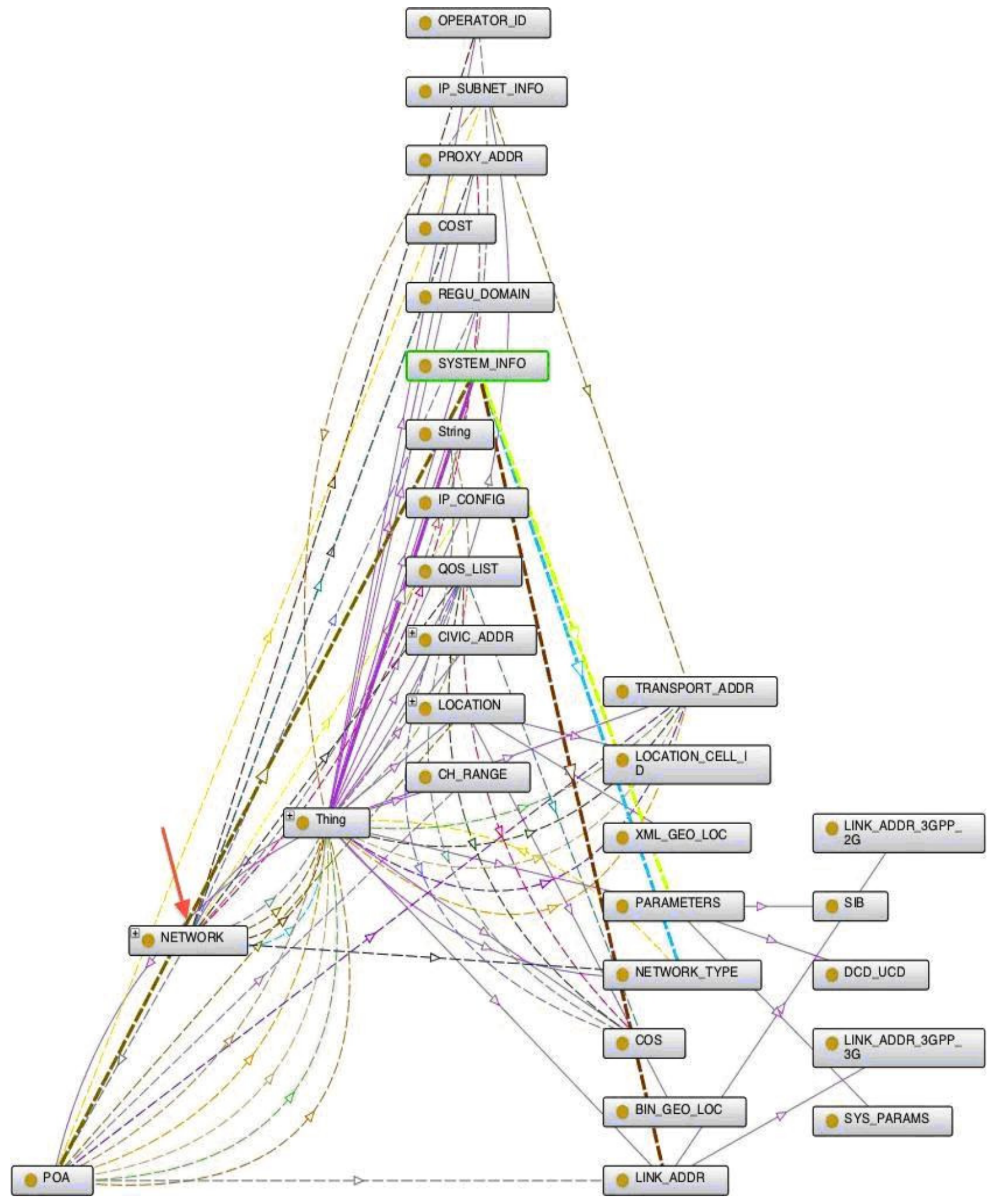

Figura 14 - Esquema Básico do IEEE 802.21 
Tabela 3 - Descrição dos elementos da Figura 14

\begin{tabular}{|c|c|}
\hline Elemento & Descrição \\
\hline Thing & Define o tipo básico para um elemento \\
\hline NETWORK & $\begin{array}{l}\text { Elemento que agrega informações de outros elementos } \\
\text { relacionados à determinada rede }\end{array}$ \\
\hline NETWORK_TYPE & $\begin{array}{l}\text { Tipos de enlace das redes de acesso que estão disponíveis } \\
\text { em uma área geográfica }\end{array}$ \\
\hline Operator_ID & Identificador do operador \\
\hline IP_SUBNET_INFO & Informação sobre subnets suportadas por um PoA \\
\hline PROXY_ADDR & Endereço do servidor proxy \\
\hline COST & Indicação de custo para uso do serviço ou rede \\
\hline REGU_DOMAIN & Classes reguladoras suportadas pela rede de acesso \\
\hline SYSTEM_INFO & $\begin{array}{l}\text { Informação de sistema suportado pela camada de enlace de } \\
\text { um PoA }\end{array}$ \\
\hline IP_CONFIG & Métodos de configuração de IP suportados pela rede \\
\hline QOS_LIST & Características de QoS da camada de enlace \\
\hline POA & $\begin{array}{l}\text { Ponto de Acesso: informação de endereçamento, } \\
\text { localização, taxas de dados, tipo das camadas PHY e MAC, } \\
\text { e parâmetros do canal }\end{array}$ \\
\hline CH_RANGE & Canal utilizado pelo PoA \\
\hline $\begin{array}{l}\text { CIVIC_ADDR, LOCATION, } \\
\text { LOCATION_CELL_ID }\end{array}$ & $\begin{array}{l}\text { Localização geográfica do PoA (endereço civil, coordenada } \\
\text { geográfica, ou ID da célula) }\end{array}$ \\
\hline TRANSPORT_ADDR & $\begin{array}{l}\text { Endereço de transporte (endereço IPv4 ou IPv6, por } \\
\text { exemplo) }\end{array}$ \\
\hline XML_GEO_LOC, BIN_GEO_LOC & $\begin{array}{l}\text { Endereço geográfico definidos, respectivamente, em } \\
\text { [Peterson, 2005] e [Polk, 2004] }\end{array}$ \\
\hline LINK_ADDR & Endereço de enlace de um tipo específico de rede \\
\hline LINK_ADDR_3GPP_2G e LINK_ADDR_3GPP_3G & Endereço de enlace de redes 3GPP e 3GPP2 \\
\hline SIB & Bloco de informação de sistema \\
\hline DCD_UCD & Descritor dos canais downlink (DCD) e uplink (UCD) \\
\hline COS & Classe de Serviço \\
\hline PARAMETERS & $\begin{array}{l}\text { Informações de sistema, dependente do tipo da rede. Por } \\
\text { exemplo: DCD_UCD: IEEE 802.16, SIB: UMTS }\end{array}$ \\
\hline String & Define dados do tipo string \\
\hline SYS_PARAMS & Parâmetros de sistema CDMA2000 \\
\hline
\end{tabular}

O esquema básico em RDF/OWL para o tipo de enlace (propriedade de NETWORK_TYPE), por exemplo, é mostrado na Tabela 4. 
Tabela 4 - Código RDF/OWL para tipo de enlace (link type)

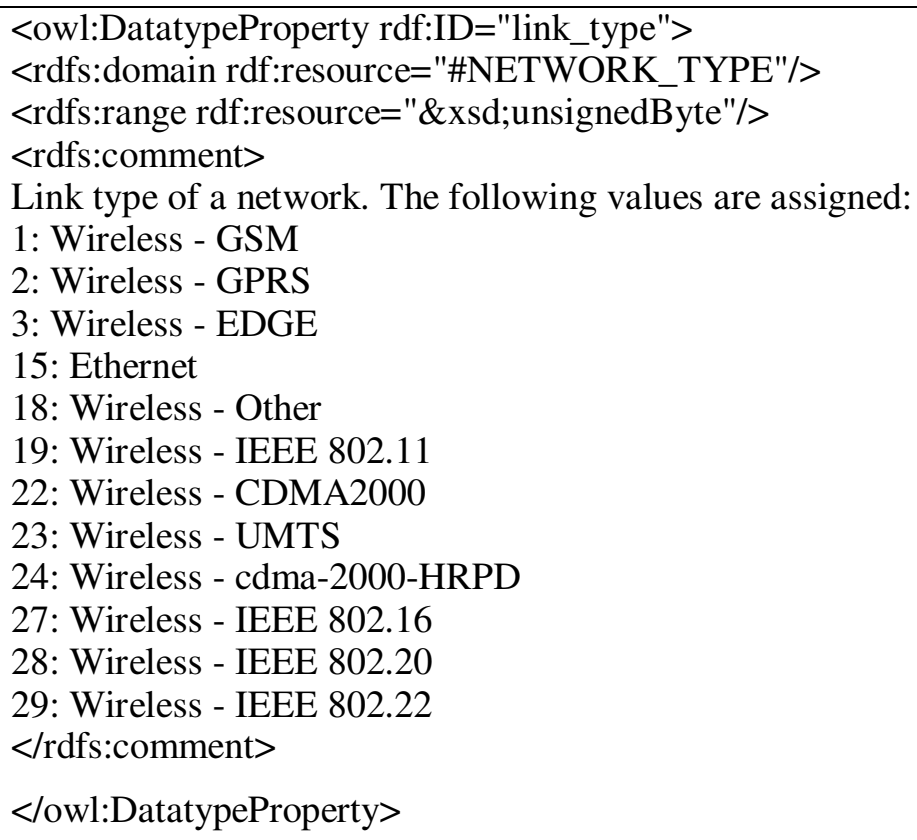

O protocolo 802.21 e os serviços oferecidos pelo MIHF foram utilizados nesta tese para modelar a arquitetura MYHand, a fim de prover informações adicionais para o gerenciamento de handover.

\subsection{Trabalhos relacionados}

Há vários trabalhos relacionados a políticas de decisão. Rizvi [Rizvi, 2010] apresenta um algoritmo de decisão de handover vertical inteligente e cita outros trabalhos. Em [Kassar, 2008] os autores apresentam uma visão geral das estratégias de decisão de handover, as quais são classificadas em cinco categorias (funções de custo, centrada no usuário, Lógica Fuzzy e baseada em Redes Neurais, multi-critérios, e cientes de contexto) e apresentam uma nova abordagem que considera ciência de contexto e políticas, auxiliada por um sistema de Lógica Fuzzy. Em [Wang, 1999] os autores apresentam uma função custo para auxiliar na tomada de decisão e pode ser aplicada em qualquer rede. Em [Zhu, 2006] os autores apresentam um algoritmo de decisão de 
handover vertical multi-serviço (MUSE-VDA) e também uma função de custo geral usada para escolher uma rede alvo. Em [Aust, 2003] os autores descrevem um algoritmo de decisão de handover baseado em política (POLIMAND) e citam vários parâmetros da camada de enlace em redes heterogêneas que podem ser usados na tomada de decisão.

Em [Wu, 2009], os autores propõem um esquema de decisão de handover vertical controlado pelo terminal e baseado em tomada de decisão de múltiplos atributos. O esquema proposto é comparado com os esquemas de tomada de decisão baseado em função de custo e baseado em força do sinal recebido, no qual os autores demonstram que o esquema proposto fornece tempos menores de handover e menor perda na taxa de dados quando comparado com os esquemas baseados em força do sinal e função de custo. Porém, os autores focam em tomada de decisão na integração entre redes Wi-Fi e WiMAX.

Nos trabalhos relacionados à política de decisão de handover, alguns autores validam a proposta através de simulação, na qual são avaliados os impactos das trocas de rede por meio de medição de vazão e perda de pacotes, por exemplo. Porém, é criado apenas um ou alguns poucos cenários diferentes e as redes usualmente pertencem ao mesmo provedor. Um diferencial desta tese é a configuração e simulação de 144 cenários diferentes, com as antenas pertencentes a provedores distintos com diferentes características, possibilitando uma melhor validação dos resultados e, diferentemente dos demais trabalhos, é feita uma comparação entre acesso tradicional e acesso sob demanda, não apenas uma validação da nova proposta.

Em [Sharma, 2004] os autores propõem um esquema de handover Mobile IP de baixa latência que pode reduzir a latência do handover para menos de 100ms, minimizando os impactos da troca de rede. Nas simulações realizadas nesta tese, o tempo de 100ms foi adotado como tempo de handover. 
Há vários trabalhos relacionados à descoberta de rede utilizando o protocolo 802.21. Em [Korhonen, 2008] os autores tratam basicamente de questões relacionadas à descoberta e seleção de redes $\mathrm{Wi}-\mathrm{Fi}$, bem como questões de seleção de identificador do usuário e roteamento AAA (Authentication, Authorization and Accounting). Porém a descoberta de redes considerada utiliza scanning de beacons (modo ativo ou passivo) que é custoso para o dispositivo móvel em termos de tempo e bateria.

Em [Dutta, 2006] os autores propõem uma nova arquitetura para descoberta de rede com solução para construção da base de dados e métodos para os dispositivos móveis conseguirem informações, principalmente, relacionadas à realização de handover pró-ativo (auxiliado pelo móvel e pela rede) e pré-autenticação. Nesta arquitetura, as informações contidas nos servidores de informações ficam restritas às informações que os dispositivos móveis registraram de redes visitadas e às informações que Agentes de Relatório (Reporting Agents), presentes em cada rede, capturam via SNMP e enviam ao servidor de informações. Na arquitetura MYHand, o Gerenciador de Handover pode capturar informações de vários lugares diferentes como, por exemplo, de sua base de dados local, de servidores de informação (MIIS), e até de outros serviços de informações como, por exemplo, o WirelessFootPrinting [Lopes, 2007].

O protocolo 802.21 não especifica como as informações das redes disponíveis são preenchidas nas bases de dados. Em [Mateus, 2010] os autores propõem um mecanismo para este propósito. Desta forma, este trabalho pode ser usado como um complemento à arquitetura MYHand.

Em [Cicconetti, 2011], os autores propõem uma arquitetura de um servidor MIIS e os procedimentos para otimização de handover, os quais evitam a necessidade de scanning e reduzem o consumo de energia. Porém, a arquitetura foca em handover reativo e o gerenciamento das trocas é centrado na rede. 
Os trabalhos relacionados à descoberta de redes e à otimização de handover encontrados na literatura se preocupam com informações tecnológicas, necessárias ao processo de handover imperativo, no qual o dispositivo móvel tem a necessidade de realizar a troca de rede para não haver queda de qualidade e/ou conexão. Nesta tese, a arquitetura MYHand estende a descoberta de redes, embutindo informações extras como as relacionadas, por exemplo, a incentivos, necessárias ao processo de handover alternativo, no qual o dispositivo não é obrigado a realizar por questões tecnológicas, mas realiza por preferência ou incentivo. As Tabelas 5 e 6 mostram uma comparação dos trabalhos relacionados e esta tese. Na Tabela 5, em todos os trabalhos o gerenciamento de troca de rede é feito pelo usuário.

Tabela 5 - Comparação entre os trabalhos relacionados à política de decisão

\begin{tabular}{|c|c|c|c|c|}
\hline Referência & Política de decisão & Validação & $\begin{array}{l}\text { Tipo de } \\
\text { handover }\end{array}$ & $\begin{array}{l}\text { Antenas pertencem a } \\
\text { provedores diferentes }\end{array}$ \\
\hline [Rizvi, 2010] & $\begin{array}{l}\text { Métricas: velocidade, } \\
\text { banda e RSSI }\end{array}$ & Não realizada & Imperativo & $\begin{array}{ll}\text { Validação } & \text { não } \\
\text { realizada } & \end{array}$ \\
\hline [Kassar, 2008] & $\begin{array}{l}\text { Métricas: velocidade, } \\
\text { cobertura e localização }\end{array}$ & Não realizada & $\begin{array}{l}\text { Imperativo } \\
\mathrm{e} \\
\text { alternativo }\end{array}$ & $\begin{array}{l}\text { Validação } \\
\text { realizada }\end{array}$ \\
\hline [Wang, 1999] & $\begin{array}{l}\text { Função custo, métricas: } \\
\text { banda, consumo de } \\
\text { energia e custo }\end{array}$ & $\begin{array}{l}\text { Testbed: Infrared } \quad \mathrm{X} \\
\text { WaveLAN X Ricochet X } \\
\text { GSM }\end{array}$ & $\begin{array}{l}\text { Imperative } \\
\text { e } \\
\text { alternativo }\end{array}$ & Não \\
\hline [Zhu, 2006] & $\begin{array}{l}\text { Algoritmo multiserviço } \\
\text { e função custo }\end{array}$ & $\begin{array}{l}\text { MATLAB, cenário } 3 \mathrm{G} \mathrm{X} \\
\text { WLAN }\end{array}$ & $\begin{array}{l}\text { Imperativo } \\
\text { e } \\
\text { alternativo }\end{array}$ & Sim \\
\hline [Aust, 2003] & $\begin{array}{ll}\text { Métrica: } & \text { relação } \\
\text { sinal/ruído } & \end{array}$ & $\begin{array}{lll}\text { Testebed } & \text { WLAN } & \mathrm{x} \\
\text { GPRS } & & \end{array}$ & Imperativo & Não cita \\
\hline [Wu, 2009] & Múltiplos atributos & $\begin{array}{ll}\text { Simulador } & \text { próprio } \\
\text { comparando com função } \\
\text { custo e RSSI }\end{array}$ & Imperativo & Não cita \\
\hline Nesta tese & $\begin{array}{l}\text { Métricas: preço, RSSI e } \\
\text { carga no AP }\end{array}$ & $\begin{array}{l}\text { Simulação com } \quad \text { NS2, } \\
\text { redes Wi-Fi }\end{array}$ & $\begin{array}{l}\text { Imperativo } \\
\text { e } \\
\text { alternativo }\end{array}$ & Sim \\
\hline
\end{tabular}

Tabela 6 - Comparação entre os trabalhos relacionados à descoberta de redes

\begin{tabular}{|l|l|l|l|l|}
\hline Referência & Utiliza 802.21 & Método de descoberta & Tipo de handover & $\begin{array}{l}\text { Handover gerenciado } \\
\text { pelo(a) }\end{array}$ \\
\hline$[$ Korhonen, 2008] & Não & Scanning de beacons & Imperativo & Usuário \\
\hline$[$ Dutta, 2006] & Não & Servidor de informações & Imperativo & Usuário \\
\hline$[$ Cicconetti, 2011] & Sim & Servidor MIIS & Imperativo & Rede \\
\hline Nesta tese & Sim & Servidor MIIS & $\begin{array}{l}\text { Imperativo } \\
\text { alternativo }\end{array}$ & Usuário \\
\hline
\end{tabular}




\section{Capítulo 4 Cenários simulados e resultados das simulações}

Este capítulo apresenta os resultados de avaliação de desempenho de um ambiente com redes WiFi com acesso sob demanda comparado ao acesso tradicional (como é feito atualmente, ou seja, não sob demanda) no qual foram analisados o número de handovers feitos, a quantidade de bytes recebidos pelo usuário móvel, e o quanto o usuário móvel gastou com o acesso. Para avaliar tal cenário e estudar os impactos das trocas de rede, foi utilizado o simulador de rede NS2 versão 2.34 [NS2, 2012] com modificações na implementação do módulo Mobile IP responsável pelas trocas de rede. Os resultados mostram que nem sempre o acesso sob demanda é benéfico e os resultados nem sempre são previsíveis.

Para melhor validar os resultados, dois cenários foram criados na versão modificada do NS2, um menos e um mais povoado em termos de antenas e usuários, com variações na velocidade do usuário móvel, na aplicação usada e no tráfego de dados dos outros usuários, totalizando 144 simulações diferentes. Com relação à política de decisão de handover para o acesso sob demanda, o usuário móvel pôde priorizar o acesso em função do preço, da força do sinal recebido (RSSI) ou da carga de trabalho no ponto de acesso.

\subsection{Modificações no módulo Mobile IP}

Originalmente o handover no NS2 ocorre em duas situações de acordo com a especificação do Mobile IP [Perkins, 2002]. A primeira situação ocorre quando um aviso de presença de outra rede, denominado ADV (Advertisement), é recebido. Esta é uma indicação de que o usuário móvel alcançou a área de cobertura de uma nova antena. Cada ADV recebido é inserido (ou atualizado) em uma lista de agentes Mobile IP mantida pelo dispositivo móvel, chamada agent_list. 
A segunda situação ocorre quando o tempo de vida (lifetime) do ADV pertencente ao atual ponto de acesso (coa - Care Of Address) expira. Uma função chamada timeout frequentemente percorre a lista de agentes procurando por ADVs com tempo de vida expirado. Quando um é encontrado, o agente é removido da lista. Se o agente removido é o AP ao qual o dispositivo móvel está conectado, o dispositivo móvel realiza um handover para o primeiro AP encontrado na agent_list, independente de qualquer informação de contexto. Entretanto, estas duas situações não refletem o que é esperado em um acesso sob demanda em NGN.

As plataformas SOHand e Y-Comm habilitam o usuário móvel a utilizar informação de contexto tais como custo, força do sinal recebido, carga no AP, identificador do provedor (SSID), entre outras para decidir se um handover deve ocorrer. As três primeiras informações citadas acima foram utilizadas nas simulações de acesso sob demanda como uma política simples de decisão de handover permitindo ao usuário móvel priorizar preço, força do sinal recebido, ou carga no AP.

Para este propósito, uma função executada a cada 0,5 segundos foi criada. Esta função checa a lista de agentes (agent_list) e decide se o dispositivo deve realizar um handover baseado em uma das políticas de decisão mencionadas acima. Também, a informação de SSID foi inserida para cada antena para identificar o provedor de acesso.

Para simular o acesso tradicional, no qual o usuário apenas conecta-se a APs que pertencem ao seu provedor home, ou seja, o provedor o qual o usuário tem contrato de acesso, o dispositivo checa sua lista de agentes procurando por antenas com o mesmo SSID de seu provedor. Se encontrar outra antena com mesmo SSID e melhor força do sinal recebido, então um handover é realizado para este AP.

A força do sinal recebido é obtida no recebimento dos beacons (pacotes de aviso de presença) e a média dos últimos cinco foi considerada para evitar o efeito ping-pong [Pollini, 
1996]. Este efeito ocorre porque a força do sinal recebido pode variar, mesmo quando o dispositivo móvel está estacionado. E quando o usuário está no meio entre dois pontos de acesso, logo após uma troca de antena, a força do sinal do AP anterior à troca pode voltar a ser maior e o dispositivo reconecta ao AP anterior.

Os algoritmos de decisão de handover utilizados nas simulações de acesso sob demanda estão descritos a seguir.

\subsubsection{Priorizando preço de acesso}

Para esta política, cujo objetivo é minimizar o valor gasto, se o dispositivo móvel encontra alguma antena, em sua lista de agentes, com preço menor ou com o mesmo preço mas com melhor força do sinal recebido, então um handover é feito para esta antena.

\subsubsection{Priorizando força do sinal recebido}

Para esta política, cujo objetivo é maximizar a vazão, se o dispositivo móvel encontra alguma antena, em sua lista de agentes, com melhor força do sinal recebido, então um handover é feito para esta antena.

\subsubsection{Priorizando carga no ponto de acesso}

Para esta política, o objetivo também é maximizar a vazão, mas através da escolha do ponto de acesso com a menor carga e, consequentemente, maior banda disponível para novas conexões. Nesta política, se o dispositivo móvel encontra alguma antena, em sua lista de agentes, com menor carga que a antena atual, então um handover é feito para esta antena. Esta informação é prevista para ser fornecida pelo broker, como definido nas arquiteturas SOHand e Y-Comm. Neste caso, o dispositivo móvel não considera a vazão que está sendo utilizada pela aplicação. Desta forma, entre uma antena com 1Mbps disponível e outra com 2Mbps, o dispositivo 
escolherá aquela com 2Mbps mesmo que a aplicação do usuário irá utilizar apenas 100Kbps, por exemplo.

\subsubsection{Outras alterações}

A especificação do Mobile IP implementada no simulador NS2 [Perkins, 2002] recomenda um tempo de intervalo entre os ADVs como sendo um terço do tempo de vida do ADV. Entretanto, o tempo de vida no simulador é igual ao tempo de intervalo entre os ADVs. Esta versão do Mobile IP também especifica que não mais de um handover pode ser feito por segundo, mas este requisito não é respeitado no NS2. Por isso, estas duas características foram modificadas na implementação do simulador para respeitar a especificação do Mobile IP.

Devido ao fato de que os handovers no NS2 não tem um tempo decorrido (relacionado à autenticação de usuário, por exemplo), nas simulações apresentadas nesta tese foi inserido um tempo de 100ms em cada troca de rede, considerando os resultados obtidos em [Sharma, 2004].

Considerando as mudanças apresentadas nesta seção, um dispositivo móvel pode realizar um handover em duas situações: se encontrar uma antena mais atraente (considerando cada política de decisão) ou se o ADV da antena atual expirar e existir outra antena disponível.

\subsection{Cenários simulados}

Para avaliar os resultados de acesso sob demanda, dois cenários foram criados no simulador, um menos povoado, em termos de antenas e usuários, e outro mais povoado. Estes dois cenários são mostrados nas Figuras 15 e 16, e ambos diferem entre si pelo número de antenas e distância entre elas de acordo com a Tabela 7. Há três provedores de acesso denominados P1, P2 e P3, cada um com pontos de acesso Wi-Fi ao longo de uma avenida de 1200 metros. Estes pontos de acesso realizam o acesso ao meio (L2) e o roteamento (L3), embora a figura mostre apenas o desenho de 
uma antena. P1r, P2r e P3r representam roteadores de borda (edge routers) pertencentes a cada um dos três provedores, respectivamente, e que separam o núcleo da rede e a periferia, segundo a arquitetura Y-Comm. Os pontos de acesso são representados por PxAy (y-ésima antena do provedor Px), e suas posições podem ser observadas ao longo da avenida nas Figuras 15 e 16 . A velocidade dos enlaces é de $20 \mathrm{Mbps}$ na rede periférica (entre antena e roteador de borda) e 100Mbps no núcleo e servidores.

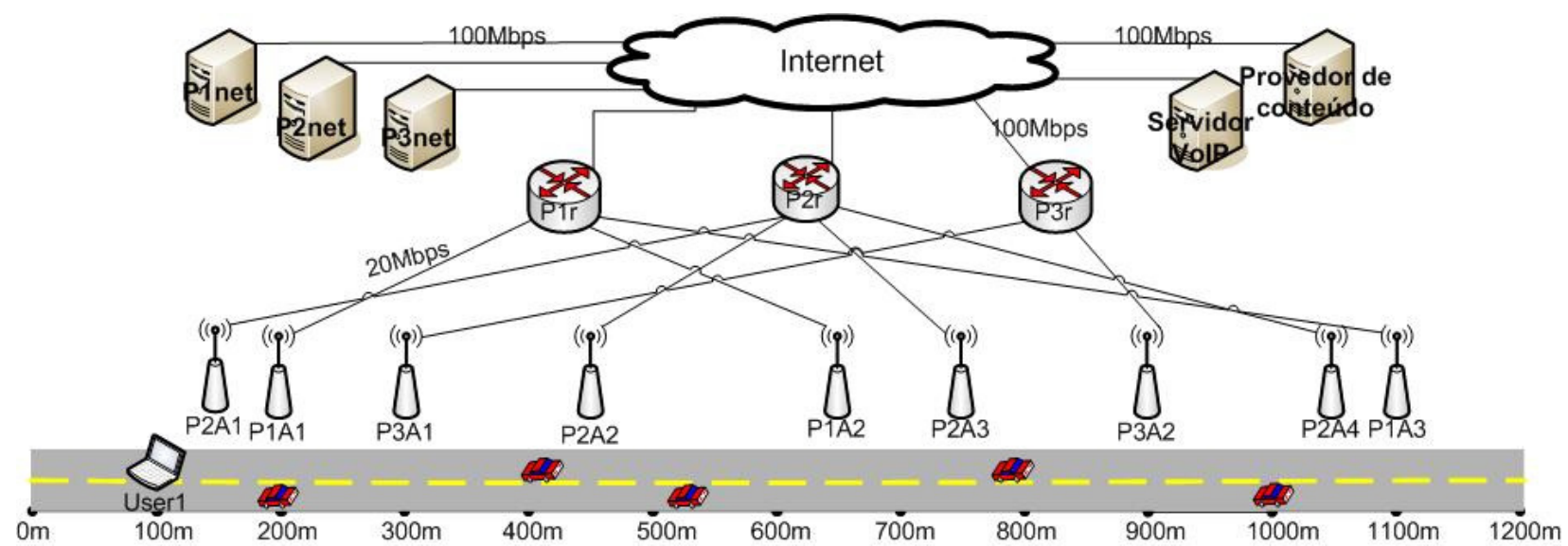

Figura 15 - Cenário menos povoado

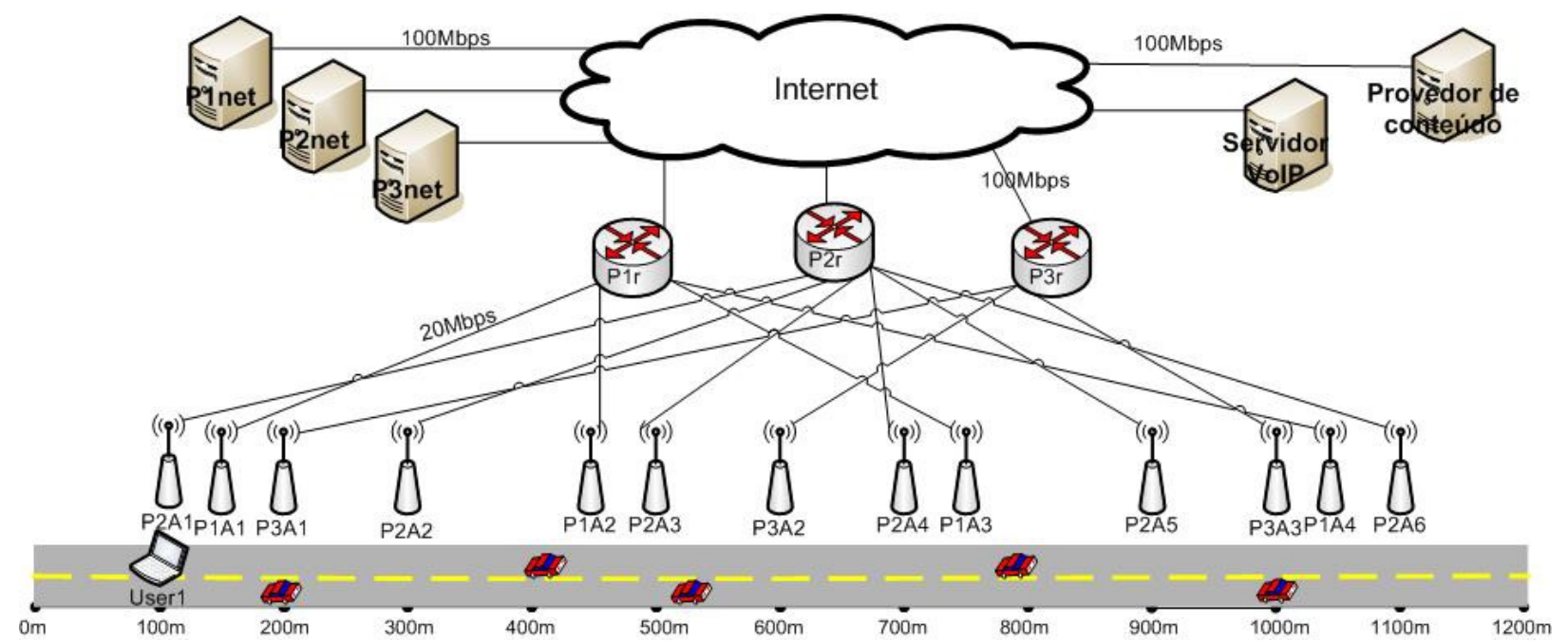

Figura 16 - Cenário mais povoado 
Tabela 7 - Características dos provedores de acesso

\begin{tabular}{|c|c|c|c|c|c|c|}
\hline Cenário & \multicolumn{3}{|c|}{ Menos povoado } & \multicolumn{3}{c|}{ Mais povoado } \\
\hline Provedor & P1 & P2 & P3 & P1 & P2 & P3 \\
\hline Número de antenas & 3 & 4 & 2 & 4 & 6 & 3 \\
\hline Distância entre as antenas (metros) & 450 & 300 & 600 & 300 & 200 & 400 \\
\hline Usuários conectados em cada antena & 3 & 2 & 5 & 3 & 2 & 5 \\
\hline Preço por hora & $\$ 5$ & $\$ 7$ & $\$ 3$ & $\$ 5$ & $\$ 7$ & $\$ 3$ \\
\hline
\end{tabular}

Ainda nas Figuras 15 e 16, é ilustrado o usuário móvel User1, cliente do provedor P1, que irá percorrer a avenida iniciando na posição 100 metros e estacionando na posição 1150 metros, período em que irá realizar vários handovers de acordo com uma das políticas de decisão descritas na seção anterior. Foram simuladas duas velocidades diferentes para este usuário: 36 $\mathrm{km} / \mathrm{h}(10 \mathrm{~m} / \mathrm{s})$ e $5 \mathrm{~km} / \mathrm{h}(1,39 \mathrm{~m} / \mathrm{s})$.

Para cada cenário e velocidade do usuário móvel, três diferentes aplicações foram executadas no dispositivo móvel: um fluxo VoIP consistindo de dois fluxos UDP unidirecionais com taxa constante de bit (CBR) de 64Kbps (segundo codificação G.711) entre o usuário e o servidor VoIP; um fluxo de vídeo MPEG1 de 1,5Mbps cujo servidor é o computador Provedor de Conteúdo; e um download FTP cujo servidor também é o computador Provedor de Conteúdo.

Também foi variado o tráfego nos outros usuários conectados às outras antenas. Estes usuários não estão mostrados nas Figuras 15 e 16. Para cada cenário, velocidade do usuário móvel e aplicação, foram simulados estes outros usuários com fluxos UDP de 100Kbps, 200Kbps e 400Kbps, fluxos tais oriundos do computador Provedor de Conteúdo. Estes usuários são fixos, distantes das antenas por até 20 metros.

Os três provedores possuem diferentes perfis em termos de preço e qualidade (melhor cobertura em função do número de antenas e maior banda disponível em função do número de usuários por antena), de acordo com as características da Tabela 7. O provedor P1 tem infraestrutura e preços medianos, oferecendo uma qualidade de acesso média. O provedor P2 é 
mais caro, tem mais antenas e menos usuários por antena. Com isso, tem carga menor de trabalho nos APs, oferece melhor cobertura de sinal e mais banda disponível para novas conexões comparado ao provedor P1. O provedor P3 é mais barato, tem menos antenas (cobertura pior que P1) e mais usuários conectados por antena (maior carga de trabalho no AP). Embora diferentes provedores possam ter diferentes métodos de cobrança (por hora, por dia, mensalidade, por MByte), nesta tese foi utilizado o mesmo método para uma melhor comparação entre os provedores, ou seja, cobraça por hora conectado.

\subsubsection{Planejamento de Experimentos}

Esta seção descreve o motivo pelo qual alguns parâmetros forma escolhidos nos cenários simulados. As duas velocidades diferentes para o usuário móvel definem as velocidades normalmente encontradas na prática: $36 \mathrm{~km} / \mathrm{h}$ caracteriza um usuário dentro de um ônibus, e 5 $\mathrm{km} / \mathrm{h}$ caracteriza um usuário caminhando.

As três aplicações (VoIP, fluxo de vídeo, e FTP) também definem aplicações bastante utilizadas e que caracterizam diferentes vazões, o que permitiu avaliar melhor a influência da quantidade de tráfego nas simulações. Da mesma forma o tráfego nos outros usuários: foi observado que $100 \mathrm{Kbps}$ não congestionava a rede, $200 \mathrm{Kbps}$ apresentava influência nos fluxo do usuário móvel, e 400 Kbps apresentava congestionamentos.

A simulação de várias quantidades de antenas e a distância entre elas teve como objetivo diferenciar a qualidade do sinal em termos de cobertura e força. As várias quantidades de usuários conectados por antena teve como objetivo diferenciar a carga em cada AP e a banda disponível. Os diferentes preços entre os provedores tiveram como objetivo diferenciar quanto o usuário poderia gastar escolhendo um ou outro provedor. Desta forma, o usuário móvel User1 pôde gastar mais ou menos, e baixar mais ou menos bytes, dependendo da política de handover 
escolhida.

O modelo de propagação utilizado foi o shadowing. Os parâmetros de perda de sinal (loss exponent) e desvio (shadowing deviation) foram, respectivamente, 3,2 e 4, caracterizando um ambiente externo de uma área urbana, de acordo com [NS2, 2012]. Com estes valores, o raio de alcance da antena ficou configurado para 100 metros, porém a força do sinal continuava caindo e chegava a alcançar aproximadamente 250 metros. A camada MAC (Mac/802_11Ext do NS2) foi configurada para o padrão IEEE 802.11g segundo os parâmetros utilizados em [Medepalli, 2004] e [Symington, 2009], e encontram-se na Tabela 8. O protocolo de roteamento utilizado foi o NOAH [NOAH, 2012], adequado para simulações de redes Wi-Fi em modo infraestruturado. O tempo de intervalo entre o envio de ADVs seguiu o tempo recomendade de 1 segundo e o tempo de vida foi configurado para 3 segundos. Em todas as simulações, a mesma semente (padrão do NS2) para gerar números aleatórios foi utilizada para melhor comparação dos resultados entre os diferentes cenários.

Tabela 8 - Parâmetros de configuração da camada MAC

\begin{tabular}{|l|l|}
\hline Parâmetro & Valor \\
\hline SlotTime_ & 0,000009 \\
\hline SIFS_ & 0,000010 \\
\hline DIFS_ & 0,000028 \\
\hline PIFS__ & 0,000019 \\
\hline RTSThreshold & 3000 \\
\hline ShortRetryLimit_ & 7 \\
\hline LongRetryLimit_ & 4 \\
\hline dataRate__ & $54 \mathrm{Mb}$ \\
\hline basicRate__ & $6 \mathrm{Mb}$ \\
\hline CWMin__ & 16 \\
\hline CWMax_ & 1024 \\
\hline
\end{tabular}

\subsection{Resultados das simulações}

Esta seção apresenta os resultados de valor gasto, bytes recebidos e número de handovers feitos 
pelo usuário móvel User1 nas simulações de acesso tradicional e sob demanda. Os resultados estão separados em cenário menos povoado e mais povoado.

O tempo decorrido para o usuário móvel foi de 760 segundos (12 minutos e 40 segundos) quando em movimento à $5 \mathrm{~km} / \mathrm{h}$, e 110 segundos (1 minuto e 50 segundos) quando em movimento à $36 \mathrm{~km} / \mathrm{h}$. Como tempo foi bem inferior a uma hora, os valores gastos pelo acesso estão em centavos $(\phi)$.

Todos os resultados estão reunidos em apêndices: Apêndice A (cenário menos povoado, $36 \mathrm{~km} / \mathrm{h}$ ), Apêndice B (cenário menos povoado, $5 \mathrm{~km} / \mathrm{h}$ ), Apêndice $\mathrm{C}$ (cenário mais povoado, 36 $\mathrm{km} / \mathrm{h}$ ) e Apêndice D (cenário mais povoado, $5 \mathrm{~km} / \mathrm{h}$ ).

\subsubsection{Resultados com o cenário menos povoado}

Os resultados desta seção estão divididos de acordo com a política de decisão de handover: acesso tradicional, acesso sob demanda priorizando preço, sob demanda priorizando força do sinal recebido (RSSI) e sob demanda priorizando carga no AP.

\subsubsection{Acesso tradicional}

Nas simulações de acesso tradicional, o usuário móvel conectou-se apenas às antenas pertencentes ao seu provedor home (P1), por isso o usuário gastou o mesmo valor em todas as simulações de mesma velocidade, mais precisamente $\not 15,29$ à $36 \mathrm{~km} / \mathrm{h}$ e $\not 105,64$ à $5 \mathrm{~km} / \mathrm{h}$.

Para ambas as velocidades do usuário móvel $(36 \mathrm{~km} / \mathrm{h}$ e $5 \mathrm{~km} / \mathrm{h})$ a quantidade de bytes recebidos diminuiu conforme o fluxo nos outros usuários aumentou, como mostrado na Tabela 9 colunas TRAD, devido ao maior tráfego competindo no mesmo meio sem fio. A Figura 17 apresenta a vazão nas simulações à $36 \mathrm{~km} / \mathrm{h}$ com tráfego VoIP, como um exemplo. Nesta figura,

é possível identificar os dois momentos que os handovers ocorreram (com 100kbps nos outros 
usuários), aos 36 e 79 segundos, momento em que a vazão diminuiu. Com 400kbps nos outros usuários, o tráfego VoIP é bastante prejudicado.

Tabela 9 - Bytes recebidos no cenário menos povoado (TRAD - acesso tradicional)

\begin{tabular}{|l|l|l|l|}
\hline Aplicação & $\begin{array}{l}\text { Tráfego nos outros } \\
\text { usuários (bps) }\end{array}$ & $\begin{array}{c}\mathbf{3 6} \mathbf{~ k m} / \mathbf{h} \\
\text { TRAD } \\
\text { (KBytes) }\end{array}$ & $\begin{array}{c}\text { 5 } \mathbf{~ k m} / \mathbf{h} \\
\text { TRAD } \\
\text { (KBytes) }\end{array}$ \\
\hline \multirow{5}{*}{ VoIP } & $100 \mathrm{k}$ & 847 & 5752 \\
\cline { 2 - 4 } & $200 \mathrm{k}$ & 786 & 5620 \\
\cline { 2 - 4 } & $400 \mathrm{k}$ & 605 & 3965 \\
\hline \multirow{2}{*}{$\begin{array}{l}\text { Vídeo } \\
\text { MPEG1 }\end{array}$} & $100 \mathrm{k}$ & 18601 & 129189 \\
\cline { 2 - 4 } & $200 \mathrm{k}$ & 14159 & 108724 \\
\cline { 2 - 4 } & $400 \mathrm{k}$ & 9110 & 62632 \\
\hline \multirow{3}{*}{ FTP } & $100 \mathrm{k}$ & 34725 & 234935 \\
\cline { 2 - 4 } & $200 \mathrm{k}$ & 21984 & 146301 \\
\cline { 2 - 4 } & $400 \mathrm{k}$ & 3612 & 48361 \\
\hline
\end{tabular}

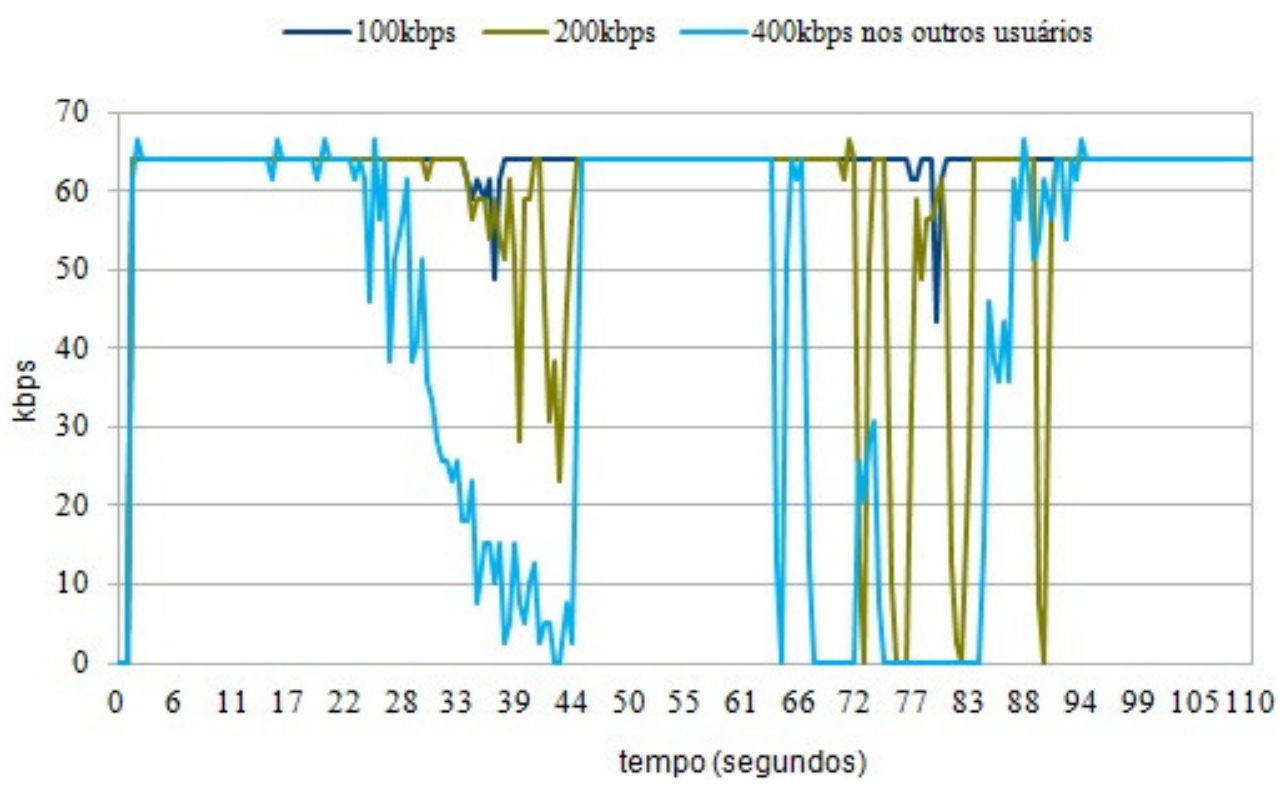

Figura 17 - Vazão à $36 \mathrm{~km} / \mathrm{h}$, tráfego VoIP, acesso tradicional, cenário menos povoado

A Tabela 10 (colunas TRAD) mostra o número de handovers feitos. Nas simulações à 36 $\mathrm{km} / \mathrm{h}$, o dispositivo móvel fez um ou dois handovers tipo ping-pong. Nas simulações à $5 \mathrm{~km} / \mathrm{h}$, o número de handovers aumentou significativamente comparado às simulações à $36 \mathrm{~km} / \mathrm{h}$. Isto 
aconteceu porque o usuário móvel, movendo-se mais devagar, permaneceu mais tempo no meio entre dois APs, causando mais handovers ping-pongs devido à variação da força do sinal recebido. Quando o tráfego aumentou (200kbps e 400kbps), o dispositivo perdeu mais ADVs, e os handovers passaram a ocorrer mais devido à expiração de ADV e menos devido à variação da força do sinal. Por exemplo, à $5 \mathrm{~km} / \mathrm{h}$ com tráfego VoIP e 100kbps nos outros usuários, 28 handovers ocorreram por variação da força do sinal (77\%) e 8 ocorreram por expiração de ADV, mas com 400kbps nos outros usuários, apenas 1 handover ocorreu por variação de RSSI (25\%) e 3 ocorreram por expiração de ADV. O mesmo ocorreu nas simulações com vídeo MPEG1 e FTP.

Tabela 10 - Número de handovers feitos no cenário menos povoado (TRAD - acesso tradicional)

\begin{tabular}{|c|c|c|c|}
\hline \multirow[b]{2}{*}{ Aplicação no móvel } & \multirow[b]{2}{*}{$\begin{array}{l}\text { Tráfego nos outros } \\
\text { usuários (bps) }\end{array}$} & $36 \mathrm{~km} / \mathrm{h}$ & $5 \mathrm{~km} / \mathrm{h}$ \\
\hline & & TRAD & TRAD \\
\hline \multirow{3}{*}{ VoIP } & $100 \mathrm{k}$ & 2 & 36 \\
\hline & $200 \mathrm{k}$ & 4 & 24 \\
\hline & $400 \mathrm{k}$ & 2 & 4 \\
\hline \multirow{3}{*}{ Vídeo MPEG1 } & $100 \mathrm{k}$ & 4 & 22 \\
\hline & $200 \mathrm{k}$ & 2 & 14 \\
\hline & $400 \mathrm{k}$ & 2 & 20 \\
\hline \multirow{3}{*}{ FTP } & $100 \mathrm{k}$ & 4 & 18 \\
\hline & $200 \mathrm{k}$ & 2 & 24 \\
\hline & $400 \mathrm{k}$ & 2 & 14 \\
\hline
\end{tabular}

\subsubsection{Acesso sob demanda priorizando preço}

Nas simulações priorizando preço, o usuário móvel User1 gastou menos que no acesso tradicional, uma vez que o dispositivo conectou-se com antenas do provedor P3 sempre que possível. Neste cenário menos povoado, as maiores economias foram de 27,07\% à velocidade de $36 \mathrm{~km} / \mathrm{h}$ (com tráfego FTP e 100kbps nos outros usuários) e de $25,53 \%$ à velocidade de $5 \mathrm{~km} / \mathrm{h}$ (com tráfego VoIP e 100kbps nos outros usuários). As Figuras 18 e 19 mostram o valor gasto priorizando preço comparado com o acesso tradicional, respectivamente, à $36 \mathrm{~km} / \mathrm{h}$ e à $5 \mathrm{~km} / \mathrm{h}$. 
Em todas as simulações, conforme o tráfego nos outros usuários tornava-se maior, o dispositivo móvel perdia o sinal da antena do provedor P3 com mais frequência (ADV expirava) e conectava-se a antenas mais caras, aumentando o valor gasto.

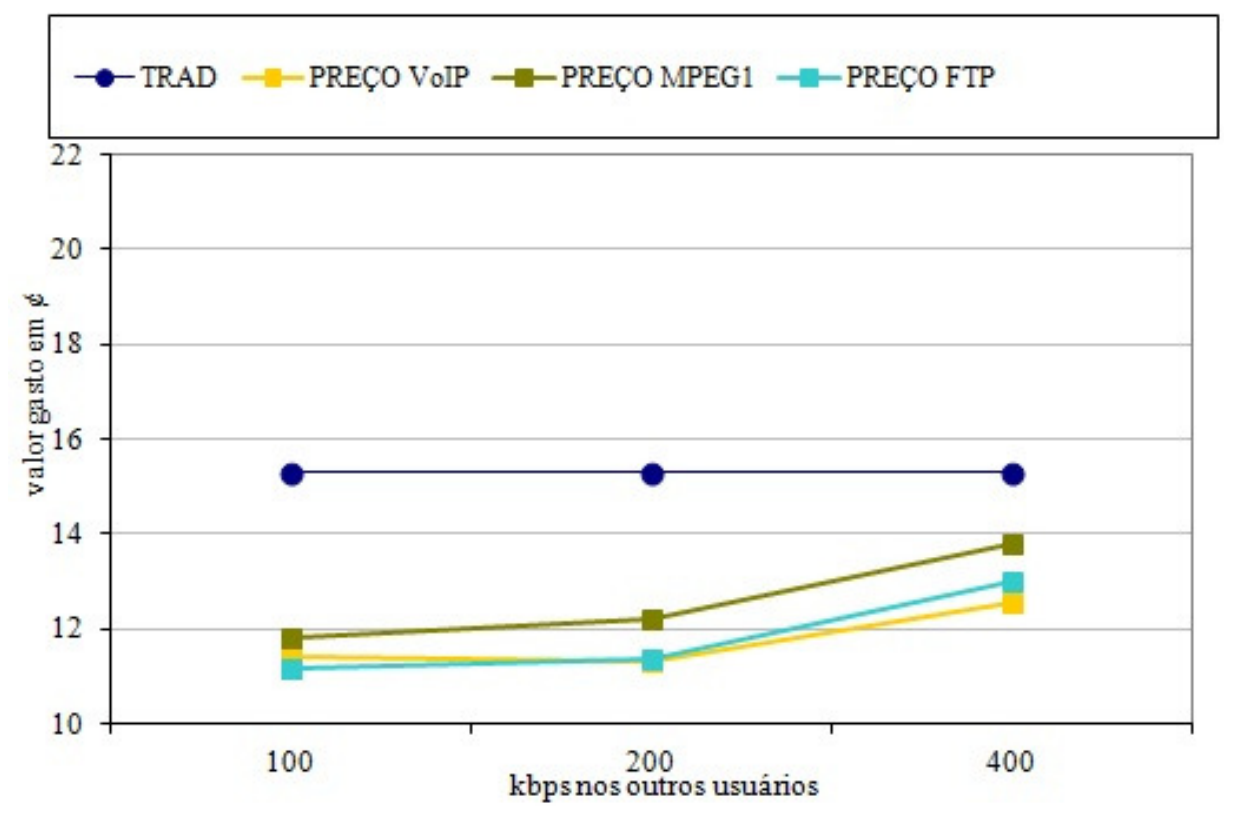

Figura 18 - Valor gasto, cenário menos povoado, à $36 \mathrm{~km} / \mathrm{h}$, priorizando preço

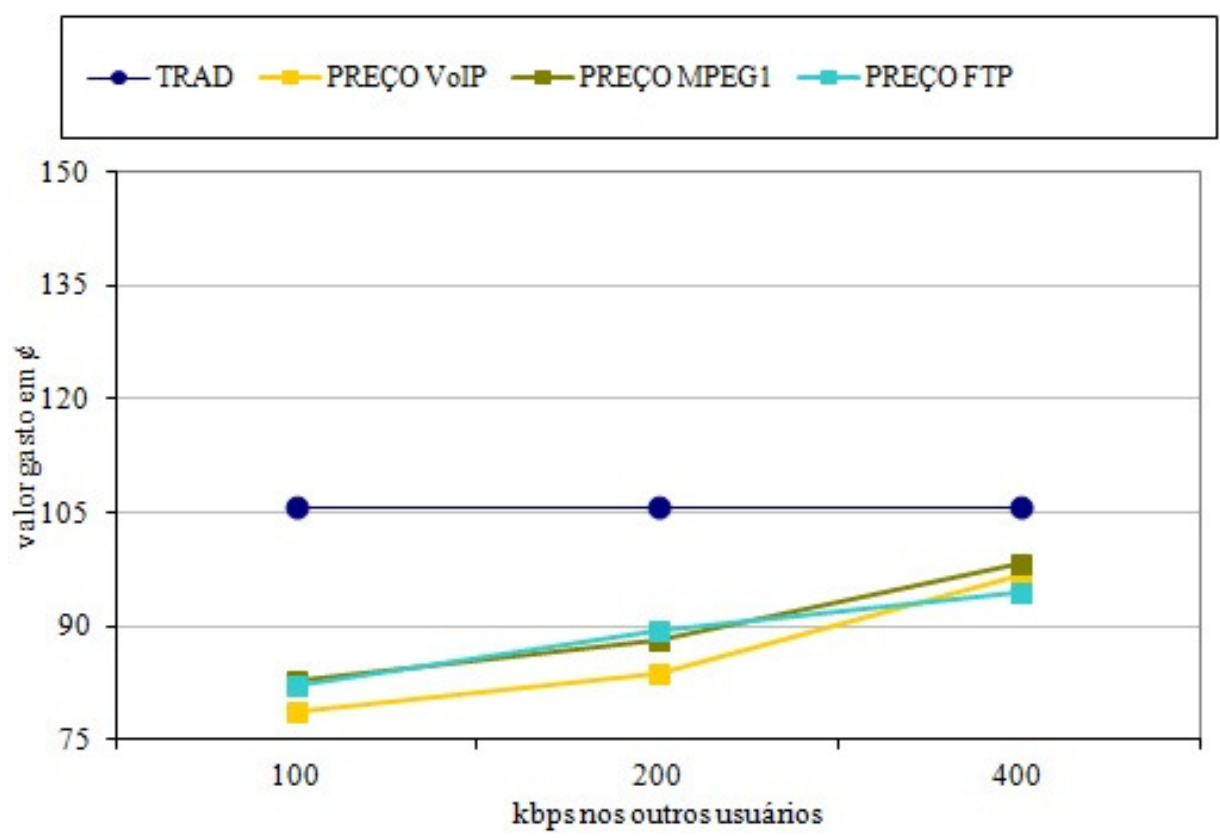

Figura 19 - Valor gasto, cenário menos povoado, à $5 \mathrm{~km} / \mathrm{h}$, priorizando preço 
Para ambas velocidades, a quantidade de bytes recebidos foi próxima ao acesso tradicional com pouco tráfego e também diminuiu com o aumento no tráfego dos outros usuários, como mostrado na Tabela 11 colunas PREÇO. Mas a queda foi menor comparado ao acesso tradicional, porque havia mais antenas disponíveis para conexão. Por esta razão, conforme o tráfego nos outros usuários se tornou maior, a quantidade de bytes recebidos, nas simulações priorizando preço, tornou-se maior que no acesso tradicional. A Figura 20 apresenta a vazão nas simulações à $36 \mathrm{~km} / \mathrm{h}$ com tráfego VoIP, como um exemplo. Nesta figura, com 100kbps nos outros usuários, por exemplo, quatro handovers ocorreram aos 11, 48, 71 e 103 segundos.

Tabela 11 - Bytes recebidos no cenário menos povoado (PREÇO - priorizando preço)

\begin{tabular}{|l|l|l|l|l|l|}
\hline \multirow{2}{*}{ Aplicação } & $\begin{array}{l}\text { Tráfego nos outros } \\
\text { usuários (bps) }\end{array}$ & \multicolumn{2}{|c|}{$\mathbf{3 6} \mathbf{~ k m} / \mathbf{h}$} & \multicolumn{2}{c|}{$\mathbf{5}$ km/h } \\
\cline { 3 - 6 } & $\begin{array}{c}\text { TRAD } \\
\text { (KBytes) }\end{array}$ & $\begin{array}{l}\text { PREÇO } \\
\text { (KBytes) }\end{array}$ & $\begin{array}{c}\text { TRAD } \\
\text { (KBytes) }\end{array}$ & $\begin{array}{l}\text { PREÇO } \\
\text { (KBytes) }\end{array}$ \\
\hline \multirow{4}{*}{ VoIP } & $100 \mathrm{k}$ & 847 & 821 & 5752 & 5872 \\
\cline { 2 - 6 } & $200 \mathrm{k}$ & 786 & 810 & 5620 & 5871 \\
\cline { 2 - 6 } & $400 \mathrm{k}$ & 605 & 772 & 3965 & 5663 \\
\hline \multirow{2}{*}{$\begin{array}{l}\text { Vídeo } \\
\text { MPEG1 }\end{array}$} & $100 \mathrm{k}$ & 18601 & 19077 & 129189 & 137706 \\
\cline { 2 - 6 } & $200 \mathrm{k}$ & 14159 & 18466 & 108724 & 131509 \\
\cline { 2 - 6 } & $400 \mathrm{k}$ & 9110 & 14814 & 62632 & 106629 \\
\hline \multirow{3}{*}{ FTP } & $100 \mathrm{k}$ & 34725 & 33493 & 234935 & 268815 \\
\cline { 2 - 6 } & $200 \mathrm{k}$ & 21984 & 22148 & 146301 & 204782 \\
\cline { 2 - 6 } & $400 \mathrm{k}$ & 3612 & 10002 & 48361 & 84349 \\
\hline
\end{tabular}

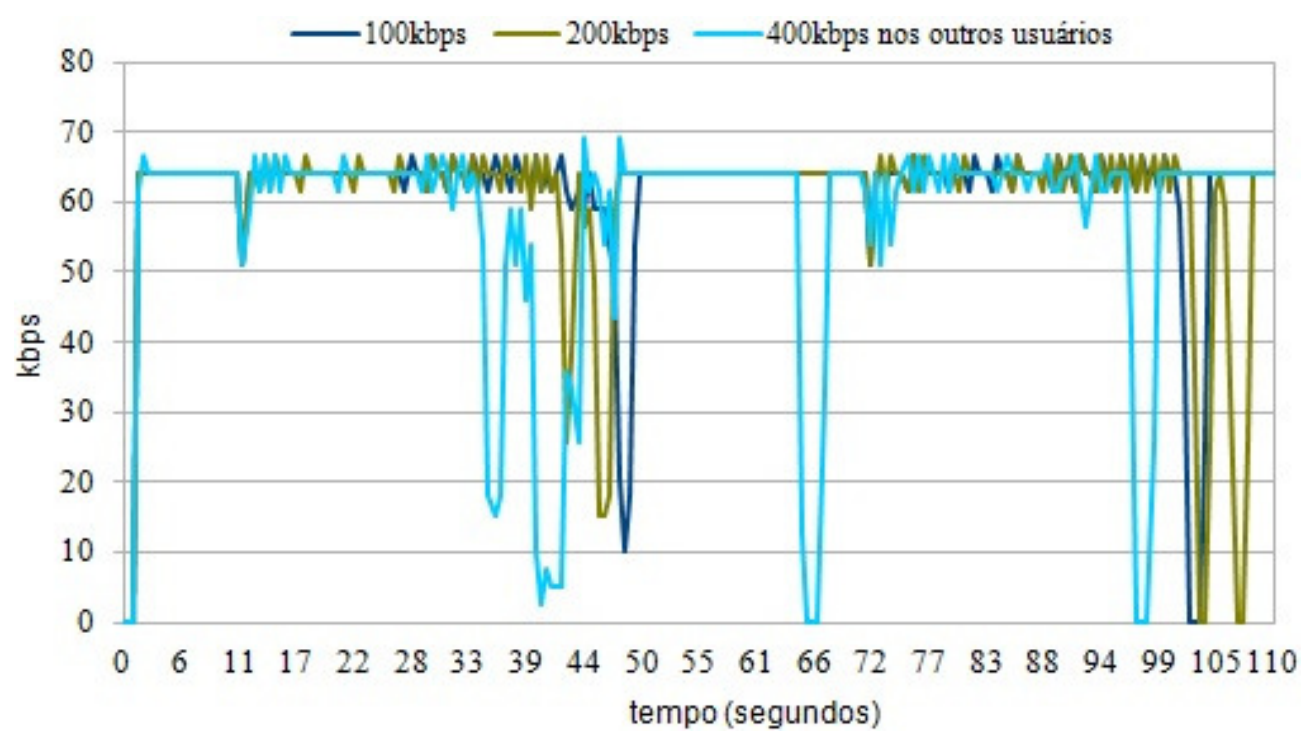

Figura 20 - Vazão à $36 \mathrm{~km} / \mathrm{h}$, tráfego VoIP, priorizando preço, cenário menos povoado 
As colunas PREÇO na Tabela 12 mostram o número de handovers realizados. Nas simulações à $36 \mathrm{~km} / \mathrm{h}$, o número de handovers aumentou comparado ao acesso tradicional porque havia mais antenas disponíveis. À $5 \mathrm{~km} / \mathrm{h}$, com 100kbps e 200kbps nos outros usuários, o número de handovers diminuiu, comparado ao acesso tradicional, devido ao algoritmo que, priorizando preço, tornou-se mais estável à variação da força do sinal, e alguns handovers ocorreram devido à expiração de ADV. Mas com 400kbps nos outros usuários, o número de handovers aumentou, comparado ao acesso tradicional, devido ao aumento no número de expirações de ADV e subsequente handovers ping-pong.

Tabela 12 - Número de handovers feitos no cenário menos povoado (PREÇO - priorizando preço)

\begin{tabular}{|c|c|c|c|c|c|}
\hline \multirow{2}{*}{$\begin{array}{c}\text { Aplicação } \\
\text { no móvel }\end{array}$} & \multirow{2}{*}{$\begin{array}{c}\text { Tráfego nos outros } \\
\text { usuários (bps) }\end{array}$} & \multicolumn{2}{|c|}{$\mathbf{3 6} \mathbf{~ k m} / \mathbf{h}$} & \multicolumn{2}{|c|}{$\mathbf{~ k m / h}$} \\
\cline { 3 - 6 } & $100 \mathrm{k}$ & 2 & 4 & 36 & 5 \\
\hline \multirow{4}{*}{ VoIP } & $200 \mathrm{k}$ & 4 & 4 & 24 & 5 \\
\cline { 2 - 6 } & $400 \mathrm{k}$ & 2 & 8 & 4 & 8 \\
\cline { 2 - 6 } & $100 \mathrm{k}$ & 4 & 5 & 22 & 5 \\
\hline \multirow{2}{*}{$\begin{array}{c}\text { Vídeo } \\
\text { MPEG1 }\end{array}$} & $200 \mathrm{k}$ & 2 & 5 & 14 & 6 \\
\cline { 2 - 6 } & $400 \mathrm{k}$ & 2 & 8 & 20 & 28 \\
\hline \multirow{2}{*}{ FTP } & $100 \mathrm{k}$ & 4 & 5 & 18 & 5 \\
\cline { 2 - 6 } & $200 \mathrm{k}$ & 2 & 7 & 24 & 10 \\
\cline { 2 - 6 } & $400 \mathrm{k}$ & 2 & 5 & 14 & 24 \\
\hline
\end{tabular}

\subsubsection{Acesso sob demanda priorizando força do sinal recebido}

Nas simulações priorizando força do sinal recebido (RSSI), o dispositivo móvel conectou-se a todas as antenas na sequência em que elas se encontravam ao longo da avenida, no momento em que o sinal da próxima antena tornava-se mais forte que o sinal do AP atual. Para ambas as velocidades, o total de bytes recebidos foi maior que no acesso tradicional, exceto nas simulações com tráfego VoIP, à $36 \mathrm{~km} / \mathrm{h}$, e 100kbps nos outros usuários. Esta exceção ocorreu devido ao 
baixo tráfego no dispositivo móvel e nos outros usuários, situação na qual o móvel, seguindo a política de acesso tradicional, pôde permanecer por mais tempo conectado à mesma antena sem haver queda na vazão, o que leva à conclusão de que nem sempre o acesso sob demanda é benéfico.

Para ambas as velocidades, a quantidade de bytes recebidos também diminuiu com o aumento no tráfego nos outros usuários, como mostrado nas Figuras 21 e 22, as quais mostram a quantidade de bytes recebidos pelo usuário móvel (em escala logarítmica), comparado ao acesso tradicional. Mas a queda foi menor comparado ao acesso tradicional, pois havia mais antenas disponíveis para conexão. Com tráfego FTP e 400kbps nos outros usuários, à $36 \mathrm{~km} / \mathrm{h}$ o dispositivo móvel baixou 4,46 vezes mais bytes que no acesso tradicional, e à $5 \mathrm{~km} / \mathrm{h}$ baixou 2,28 vezes mais.

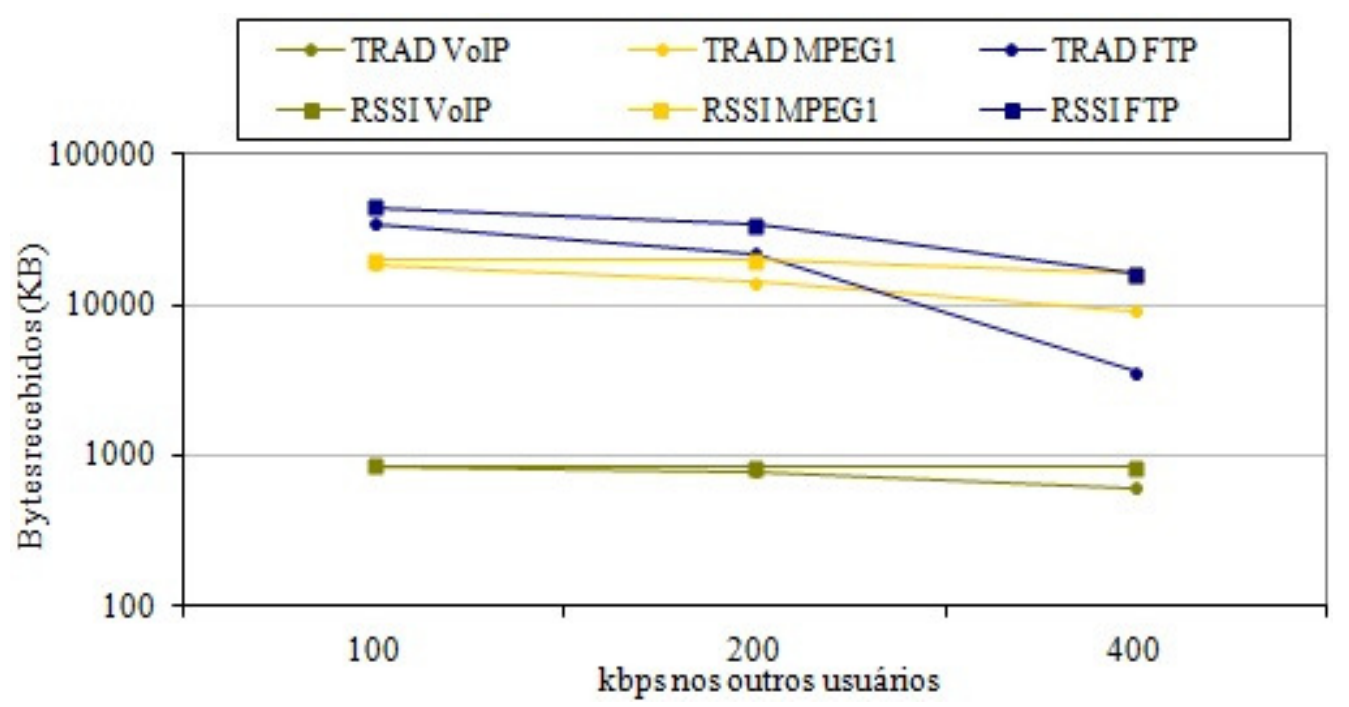

Figura 21 - Bytes recebidos, cenário menos povoado, à $36 \mathrm{~km} / \mathrm{h}$, priorizando força do sinal 


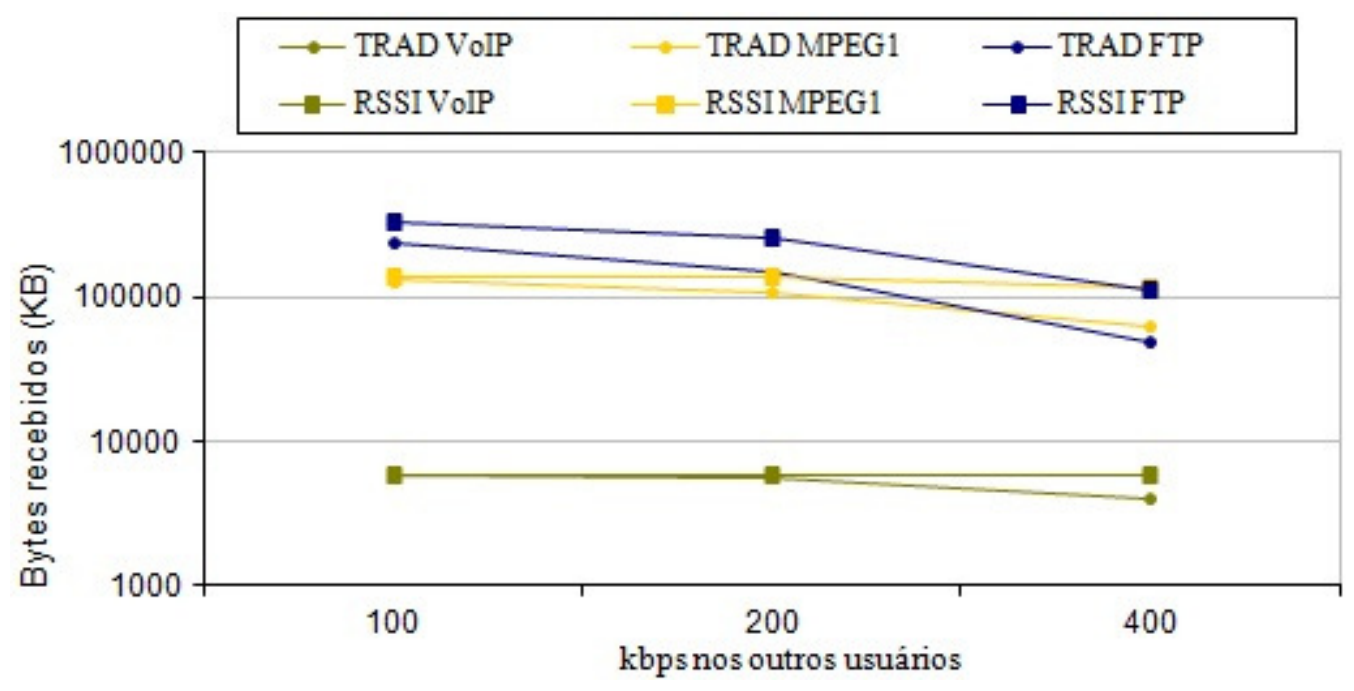

Figura 22 - Bytes recebidos, cenário menos povoado, à $5 \mathrm{~km} / \mathrm{h}$, priorizando força do sinal

A Figura 23 apresenta a vazão nas simulações à $36 \mathrm{~km} / \mathrm{h}$ com tráfego VoIP, como exemplo. É possível notar a melhor vazão comparada tanto ao acesso tradicional (Figura 17) quanto à priorização por preço (Figura 20).

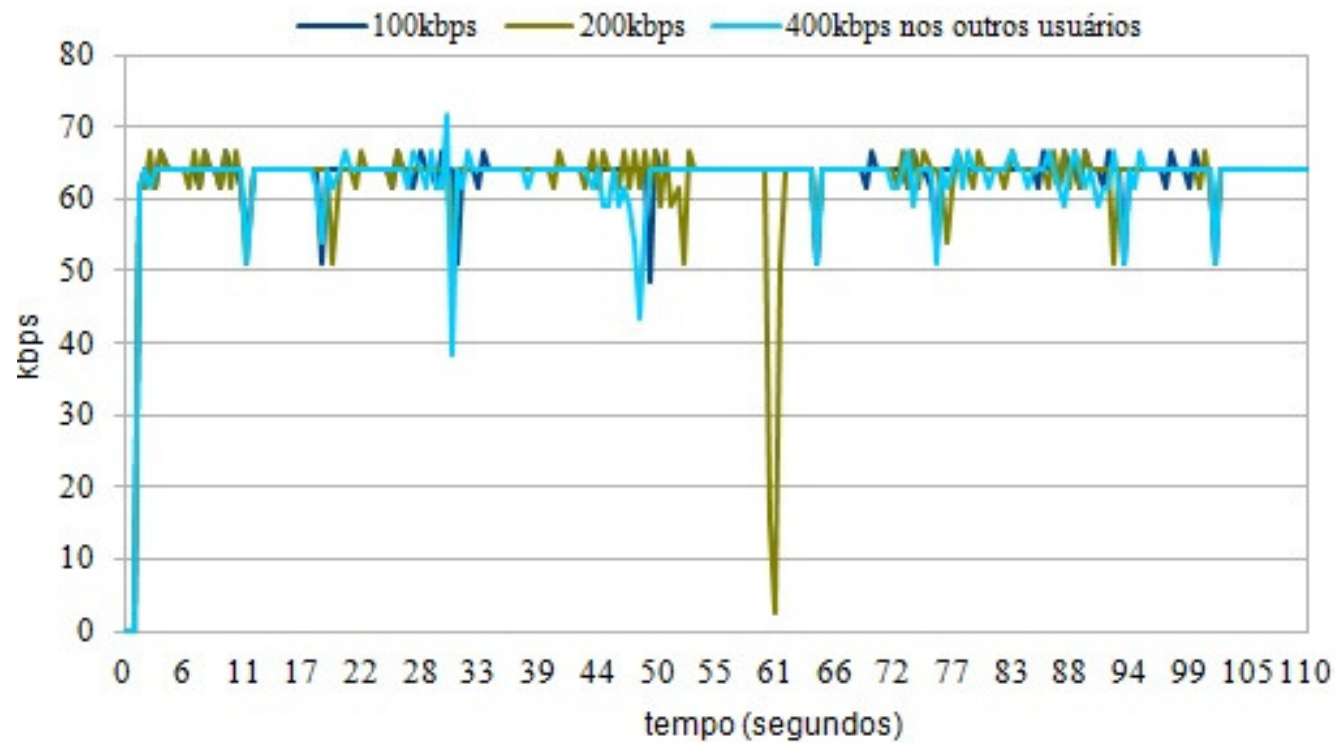

Figura 23 - Vazão à 36 km/h, tráfego VoIP, priorizando RSSI, cenário menos povoado 
Com velocidade de $36 \mathrm{~km} / \mathrm{h}$, o número de handovers foi maior que no acesso tradicional e ocorreu em função do número de antenas. Nenhum ou até poucos handovers ocorreram devido à expiração de ADV e/ou variação de RSSI. Na Figura 23, com 400kbps nos outros usuários, é possível identificar os momentos em que oito handovers ocorreram, momentos que apresentaram queda na vazão. A Tabela 13 (colunas RSSI) mostra o total de handovers realizados. Com velocidade de $5 \mathrm{~km} / \mathrm{h}$, mais handovers ocorreram devido à variação da força do sinal nas proximidades do meio entre dois APs mas a quantidade foi menor que no acesso tradicional com pouco tráfego e, com mais tráfego nos outros usuários, mais handovers ocorreram devido à expiração de ADV.

Tabela 13 - Número de handovers feitos no cenário menos povoado (RSSI - priorizando força do sinal)

\begin{tabular}{|c|c|c|c|c|c|}
\hline \multirow{2}{*}{$\begin{array}{c}\text { Aplicação } \\
\text { no móvel }\end{array}$} & \multirow{2}{*}{$\begin{array}{c}\text { Tráfego nos outros } \\
\text { usuários (bps) }\end{array}$} & \multicolumn{2}{|c|}{$\mathbf{3 6} \mathbf{~ k m} / \mathbf{h}$} & \multicolumn{2}{|c|}{$\mathbf{5} \mathbf{~ k m} / \mathbf{h}$} \\
\cline { 3 - 6 } & & TRAD & RSSI & TRAD & RSSI \\
\hline \multirow{3}{*}{ VoIP } & $100 \mathrm{k}$ & 2 & 8 & 36 & 18 \\
\cline { 2 - 6 } & $200 \mathrm{k}$ & 4 & 8 & 24 & 14 \\
\cline { 2 - 6 } & $400 \mathrm{k}$ & 2 & 8 & 4 & 18 \\
\hline \multirow{2}{*}{$\begin{array}{c}\text { Vídeo } \\
\text { MPEG1 }\end{array}$} & $100 \mathrm{k}$ & 4 & 8 & 22 & 20 \\
\cline { 2 - 6 } & $200 \mathrm{k}$ & 2 & 8 & 14 & 24 \\
\cline { 2 - 6 } & $400 \mathrm{k}$ & 2 & 10 & 20 & 43 \\
\hline \multirow{3}{*}{ FTP } & $100 \mathrm{k}$ & 4 & 8 & 18 & 25 \\
\cline { 2 - 6 } & $200 \mathrm{k}$ & 2 & 8 & 24 & 24 \\
\cline { 2 - 6 } & $400 \mathrm{k}$ & 2 & 8 & 14 & 30 \\
\hline
\end{tabular}

Para ambas as velocidades, o valor gasto aumentou comparado às simulações com acesso tradicional porque, embora o usuário tenha se conectado a antenas mais baratas (provedor P3), este também conectou a antenas mais caras que se encontravam em maior quantidade. Diferentemente do acesso sob demanda priorizando preço, o valor gasto manteve-se estável, independente dos outros tráfegos. As Figuras 24 e 25 mostram o valor gasto às velocidades de 36 $\mathrm{km} / \mathrm{h}$ e $5 \mathrm{~km} / \mathrm{h}$, o qual ficou em torno de 16 centavos e 113 centavos, respectivamente. 


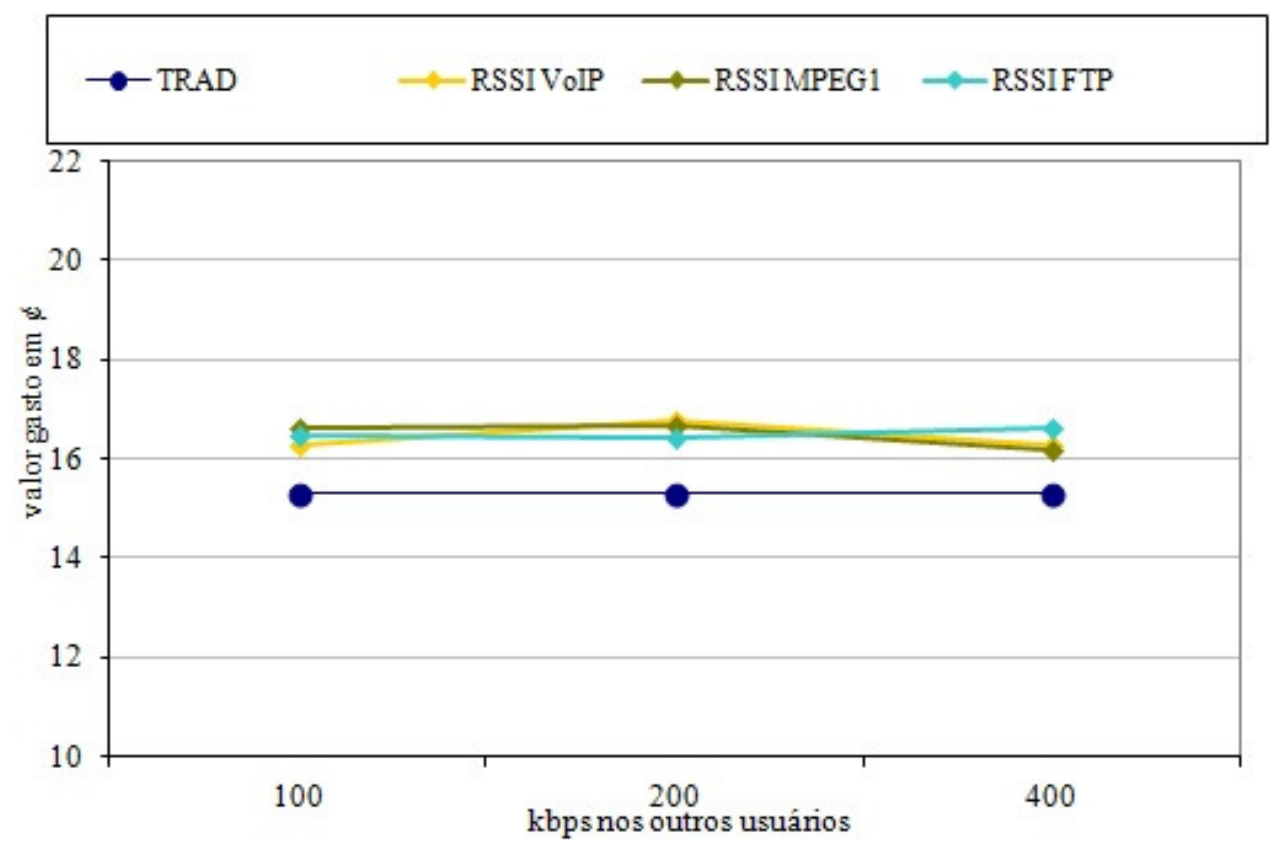

Figura 24 - Valor gasto, cenário menos povoado, à $36 \mathrm{~km} / \mathrm{h}$, priorizando força do sinal

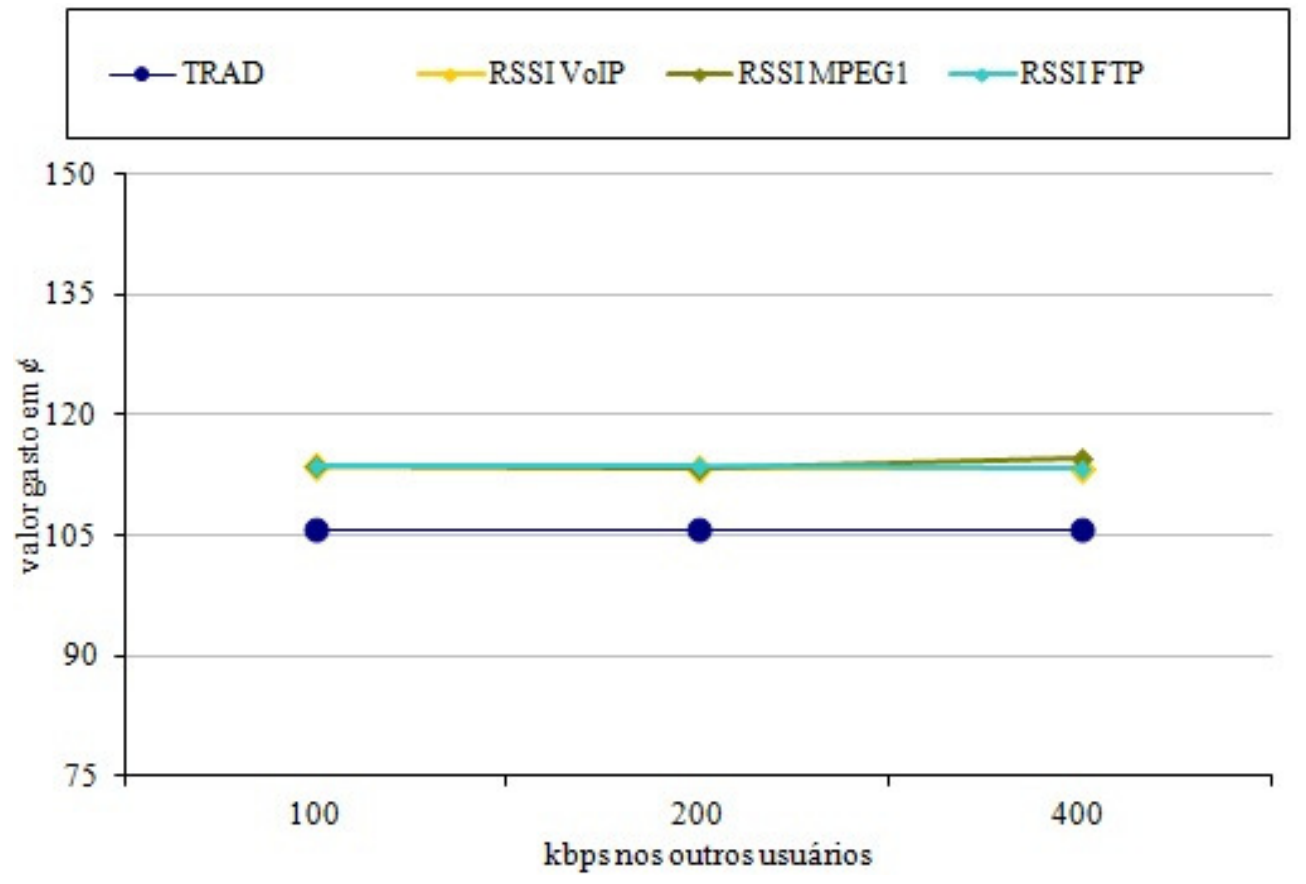

Figura 25 - Valor gasto, cenário menos povoado, à $5 \mathrm{~km} / \mathrm{h}$, priorizando força do sinal 


\subsubsection{Acesso sob demanda priorizando carga no AP}

Nas simulações priorizando carga no AP, o dispositivo móvel conectou-se, basicamente, aos pontos de acesso do provedor $\mathrm{P} 2$, os quais tinham menos usuários conectados $\mathrm{e}$, consequentemente, menor carga no AP. Para ambas velocidades, o total de bytes recebidos foi maior que nas simulações de acesso tradicional, exceto nas simulações com tráfego VoIP, à 36 $\mathrm{km} / \mathrm{h}$, e 100kbps nos outros usuários. Isto também aconteceu no acesso sob demanda priorizando RSSI e o motivo foi o mesmo. A quantidade de bytes recebidos também diminuiu com o aumento no tráfego nos outros usuários, como mostrado nas Figuras 26 e 27, mas a queda também foi menor que no acesso tradicional. Nas simulações com tráfego FTP e 400kbps nos outros usuários, o móvel baixou 3,18 vezes mais bytes do que no acesso tradicional à $36 \mathrm{~km} / \mathrm{h}$ e 2,15 vezes mais à $5 \mathrm{~km} / \mathrm{h}$.

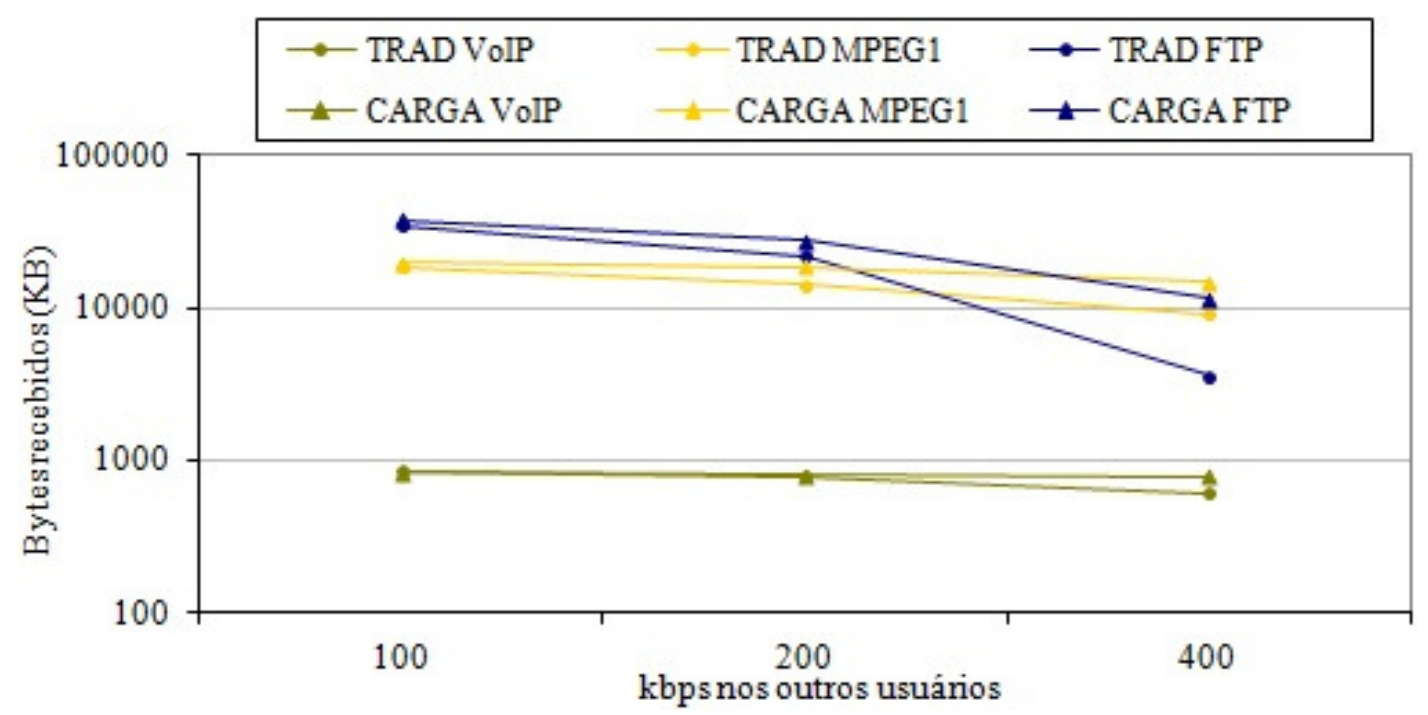

Figura 26 - Bytes recebidos, cenário menos povoado, à $36 \mathrm{~km} / \mathrm{h}$, priorizando carga no AP 


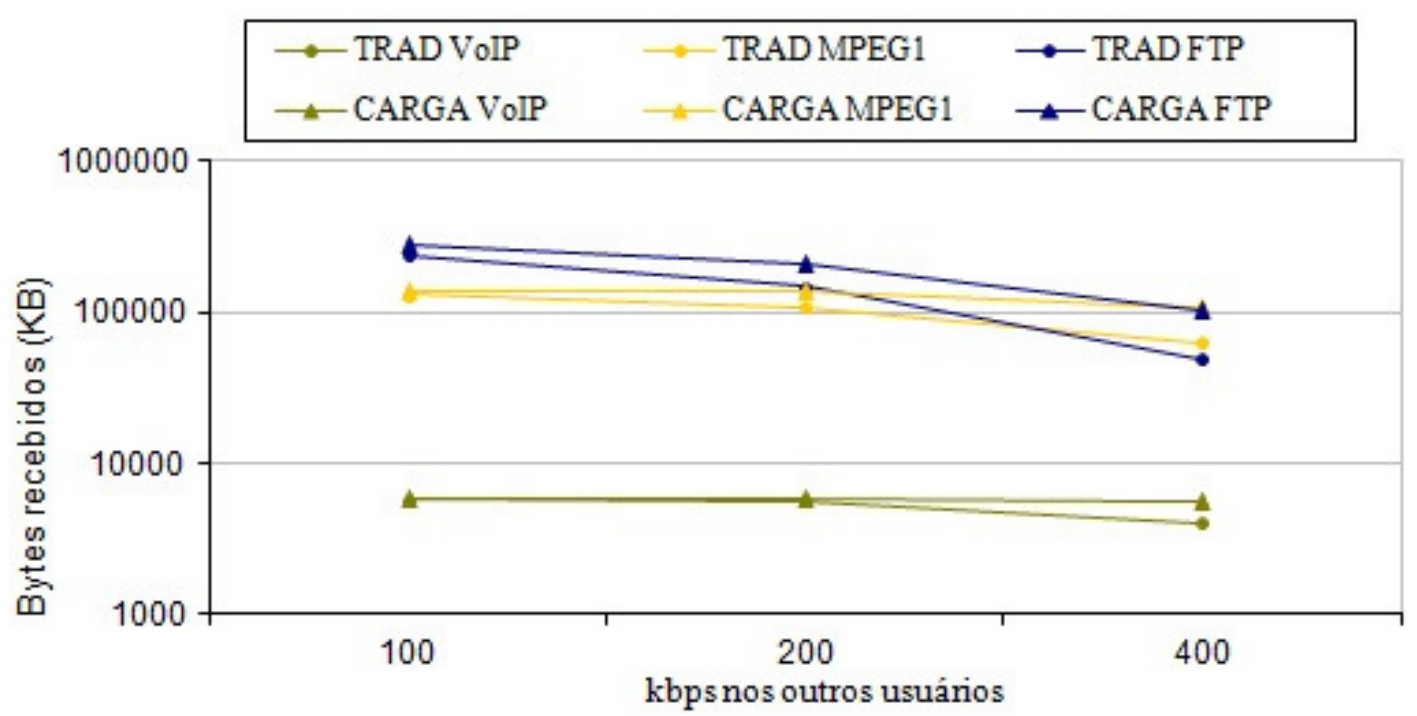

Figura 27 - Bytes recebidos, cenário menos povoado, à 5 km/h, priorizando carga no AP

O total de bytes recebidos foi menor do que no acesso sob demanda priorizando RSSI, levando à conclusão de que considerar apenas a carga no AP é menos eficiente que priorizar RSSI, com respeito à vazão. A Figura 28 apresenta a vazão nas simulações à $36 \mathrm{~km} / \mathrm{h}$ com tráfego VoIP, como um exemplo. Pode-se notar uma melhor vazão comparada ao acesso tradicional (Figura 17) mas, uma pior vazão comparada à priorização por RSSI (Figura 23).

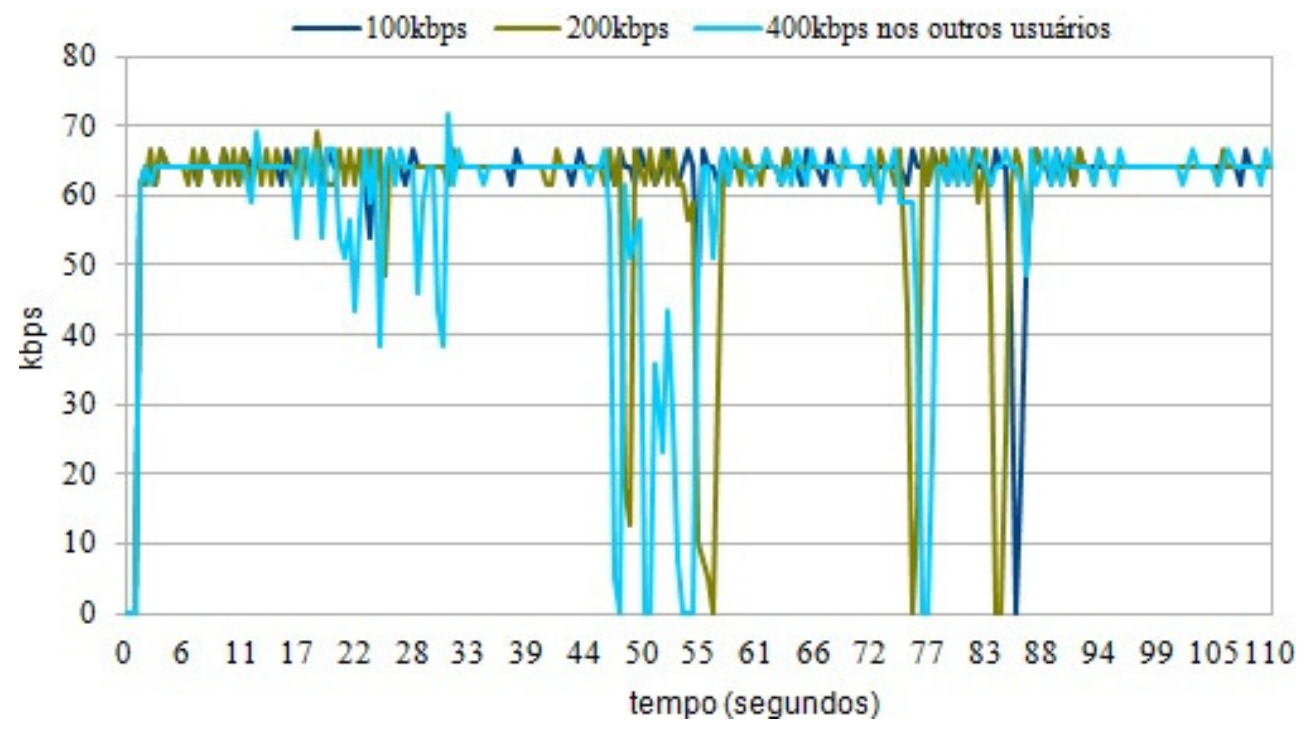

Figura 28 - Vazão à 36 km/h, tráfego VoIP, priorizando carga no AP, cenário menos povoado 
As colunas CARGA na Tabela 14 mostram o número de handovers realizados. A análise é similar ao acesso sob demanda priorizando preço, no qual, nas simulações à $36 \mathrm{~km} / \mathrm{h}$, o número de handovers aumentou comparado ao acesso tradicional e, à $5 \mathrm{~km} / \mathrm{h}$ com $100 \mathrm{kbps}$ e $200 \mathrm{kbps}$ nos outros usuários, o número de handovers diminuiu, comparado ao acesso tradicional, devido ao algoritmo que, priorizando carga no AP, tornou-se mais estável à variação da força do sinal, e com 400kbps nos outros usuários, o número de handovers aumentou devido ao aumento no número de expirações de ADV e subsequente handovers ping-pong.

Tabela 14 - Número de handovers feitos no cenário menos povoado (CARGA - priorizando carga no AP)

\begin{tabular}{|c|c|c|c|c|c|}
\hline \multirow{2}{*}{$\begin{array}{c}\text { Aplicação } \\
\text { no móvel }\end{array}$} & \multirow{2}{*}{$\begin{array}{c}\text { Tráfego nos outros } \\
\text { usuários (bps) }\end{array}$} & \multicolumn{2}{|c|}{$\mathbf{3 6} \mathbf{~ k m} / \mathbf{h}$} & \multicolumn{2}{|c|}{$\mathbf{5} \mathbf{~ k m} / \mathbf{h}$} \\
\cline { 3 - 6 } & & TRAD & CARGA & TRAD & CARGA \\
\hline \multirow{3}{*}{ VoIP } & $100 \mathrm{k}$ & 2 & 3 & 36 & 7 \\
\cline { 2 - 6 } & $200 \mathrm{k}$ & 4 & 4 & 24 & 14 \\
\cline { 2 - 6 } & $400 \mathrm{k}$ & 2 & 6 & 4 & 13 \\
\hline \multirow{2}{*}{$\begin{array}{c}\text { Vídeo } \\
\text { MPEG1 }\end{array}$} & $100 \mathrm{k}$ & 4 & 3 & 22 & 11 \\
\cline { 2 - 6 } & $200 \mathrm{k}$ & 2 & 7 & 14 & 12 \\
\cline { 2 - 6 } & $400 \mathrm{k}$ & 2 & 13 & 20 & 39 \\
\hline \multirow{2}{*}{ FTP } & $100 \mathrm{k}$ & 4 & 3 & 18 & 11 \\
\cline { 2 - 6 } & $200 \mathrm{k}$ & 2 & 7 & 24 & 11 \\
\cline { 2 - 6 } & $400 \mathrm{k}$ & 2 & 7 & 14 & 21 \\
\hline
\end{tabular}

Para ambas as velocidades, o valor gasto foi bem maior do que no acesso tradicional e também maior do que na priorização por RSSI, como mostrado nas Figuras 29 e 30, porque o móvel permaneceu mais tempo conectado a antenas pertencentes ao provedor $\mathrm{P} 2$. $\mathrm{O}$ valor gasto diminuiu com o aumento no tráfego devido à expiração de ADVs do provedor P2 e subsequente conexão com antenas mais baratas. 


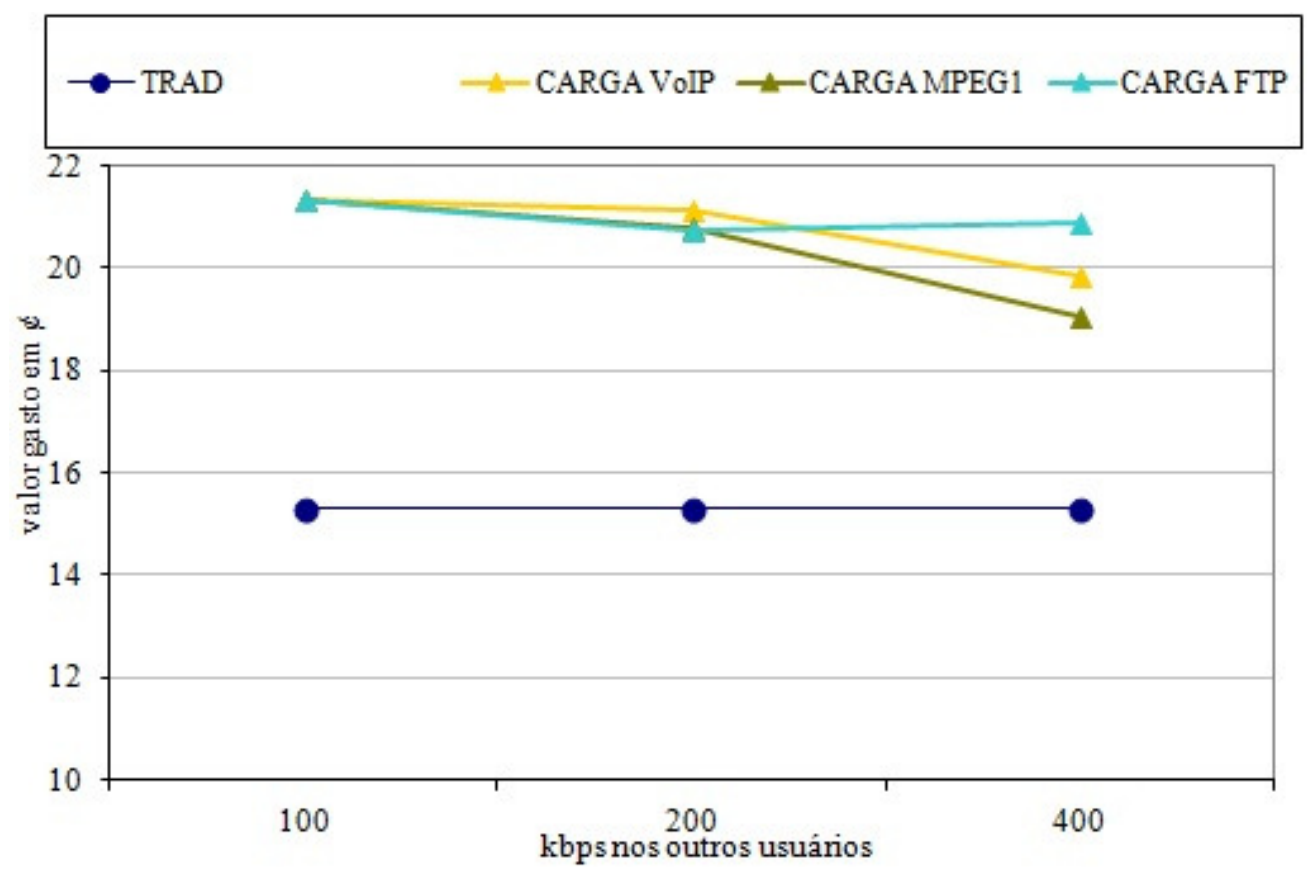

Figura 29 - Valor gasto, cenário menos povoado, à $36 \mathrm{~km} / \mathrm{h}$, priorizando carga no AP

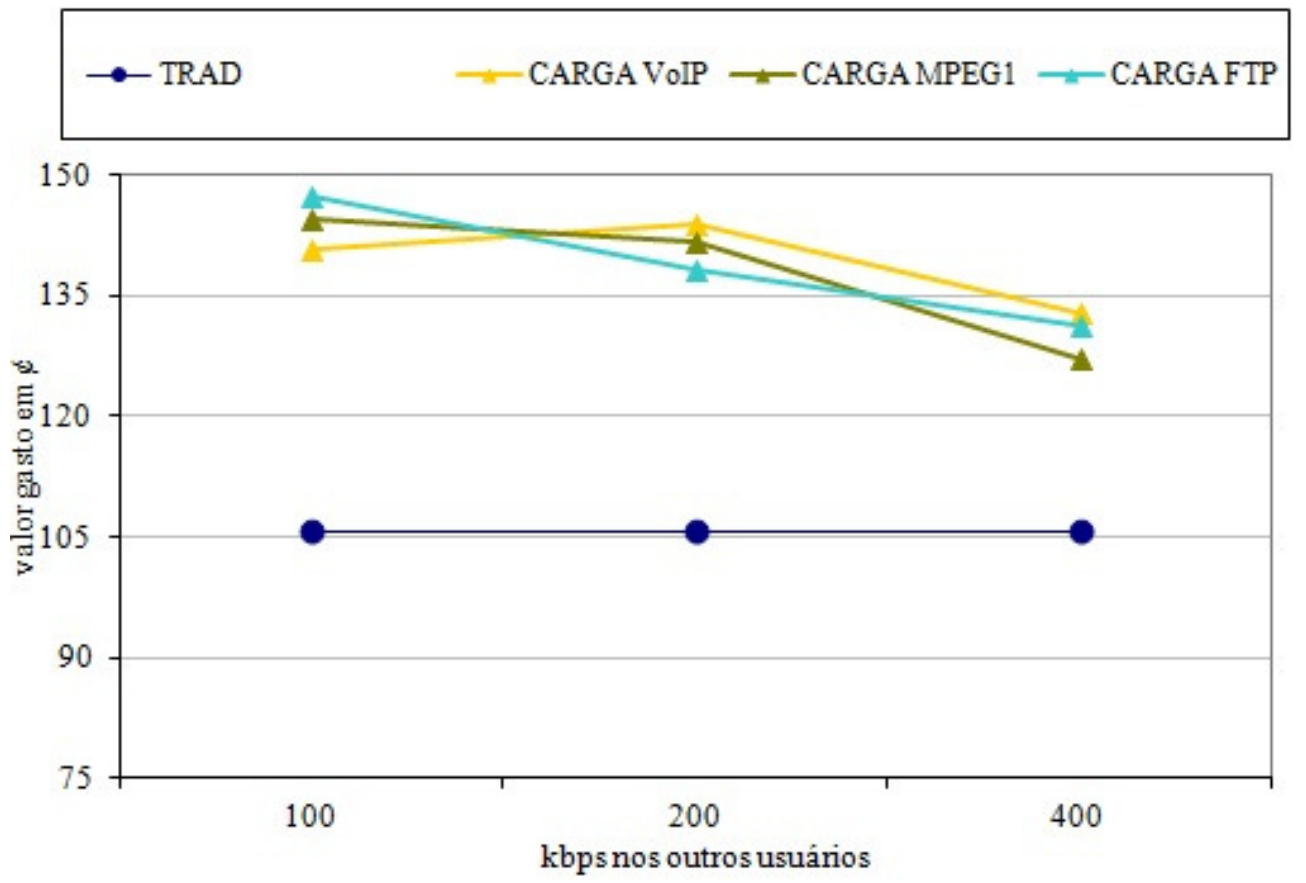

Figura 30 - Valor gasto, cenário menos povoado, à $5 \mathrm{~km} / \mathrm{h}$, priorizando carga no AP 


\subsubsection{Resumo dos resultados - cenário menos povoado}

Para facilitar a análise dos resultados de forma mais geral, a Tabela 15 mostra uma síntese dos resultados das simulações com o cenário menos povoado.

Tabela 15 - Resumo dos resultados - cenário menos povoado

\begin{tabular}{|c|l|l|l|}
\hline $\begin{array}{c}\text { Política de } \\
\text { decisão }\end{array}$ & \multicolumn{3}{|c|}{ Medição comparada com o acesso tradicional } \\
\cline { 2 - 5 } & Valor gasto & \multicolumn{1}{|c|}{ Bytes recebidos } & \multicolumn{1}{c|}{ Handovers feitos } \\
\hline PREÇO & Diminuiu & $\begin{array}{l}\text { Similar com pouco tráfego; } \\
\text { aumentou com maior tráfego }\end{array}$ & $\begin{array}{l}\text { Aumentou à } 36 \mathrm{~km} / \mathrm{h} ; \\
\text { diminuiu à } 5 \mathrm{~km} / \mathrm{h} \text { com } \\
\text { pouco tráfego; aumentou à } 5 \\
\mathrm{~km} / \mathrm{h} \text { com maior tráfego }\end{array}$ \\
\hline RSSI & Aumentou & $\begin{array}{l}\text { Aumentou, exceto com } \\
\text { tráfego VoIP, à 36 km/h e } \\
100 \text { Kbps nos outros usuários }\end{array}$ & $\begin{array}{l}\text { Aumentou à } 36 \mathrm{~km} / \mathrm{h} ; \\
\text { diminuiu à } 5 \mathrm{~km} / \mathrm{h} \text { com } \\
\text { pouco tráfego; aumentou à } 5 \\
\mathrm{~km} / \mathrm{h} \text { com maior tráfego }\end{array}$ \\
\hline CARGA & Aumentou & $\begin{array}{l}\text { Aumentou, exceto com } \\
\text { tráfego VoIP, à 36 } \mathrm{km} / \mathrm{h} \text { e } \\
100 \text { Kbps nos outros usuários }\end{array}$ & $\begin{array}{l}\text { Aumentou à 36 km/h; } \\
\text { diminuiu à } 5 \mathrm{~km} / \mathrm{h} \text { com } \\
\text { pouco tráfego; aumentou à } 5 \\
\mathrm{~km} / \mathrm{h} \text { com maior tráfego }\end{array}$ \\
\hline
\end{tabular}

\subsubsection{Resultados com o cenário mais povoado}

Os resultados desta seção também estão divididos de acordo com a política de decisão de handover, assim como nos resultados do cenário menos povoado: acesso tradicional, acesso sob demanda priorizando preço, sob demanda priorizando força do sinal recebido (RSSI) e sob demanda priorizando carga no AP. Os resultados são muito semelhantes aos resultados do cenário menos povoado. 


\subsubsection{Acesso tradicional}

Os valores gastos foram os mesmos que no cenário menos povoado, pois o usuário móvel conectou-se apenas com antenas pertencentes ao seu provedor home (P1): $₫ 15,29$ para $36 \mathrm{~km} / \mathrm{h} \mathrm{e}$ $ф 105,64$ para $5 \mathrm{~km} / \mathrm{h}$.

Para ambas as velocidades do usuário móvel (36 km/h e $5 \mathrm{~km} / \mathrm{h})$ a quantidade de bytes recebidos também diminuiu conforme o fluxo nos outros usuários aumentou, como mostrado na Tabela 16 colunas TRAD, devido ao maior tráfego competindo no mesmo meio sem fio.

Tabela 16 - Bytes recebidos no cenário mais povoado (TRAD - acesso tradicional)

\begin{tabular}{|l|l|l|l|}
\hline \multirow{2}{*}{$\begin{array}{c}\text { Aplicação no } \\
\text { móvel }\end{array}$} & $\begin{array}{c}\text { Tráfego nos outros } \\
\text { usuários (bps) }\end{array}$ & \multicolumn{1}{|c|}{$\begin{array}{c}\mathbf{3 6} \mathbf{~ k m} / \mathbf{h} \\
\text { TRAD } \\
\text { (KBytes) }\end{array}$} & \multicolumn{1}{|c|}{$\begin{array}{c}\mathbf{5} \mathbf{~ k m} / \mathbf{h} \\
\text { TRAD } \\
\text { (KBytes) }\end{array}$} \\
\hline \multirow{4}{*}{ VoIP } & $100 \mathrm{k}$ & 849 & 5893 \\
\cline { 2 - 4 } & $200 \mathrm{k}$ & 821 & 5686 \\
\cline { 2 - 4 } & $400 \mathrm{k}$ & 517 & 4094 \\
\hline \multirow{5}{*}{ Vídeo MPEG1 } & $100 \mathrm{k}$ & 19535 & 138284 \\
\cline { 2 - 4 } & $200 \mathrm{k}$ & 16376 & 116519 \\
\cline { 2 - 4 } & $400 \mathrm{k}$ & 8249 & 58030 \\
\hline \multirow{3}{*}{ FTP } & $100 \mathrm{k}$ & 35089 & 250332 \\
\cline { 2 - 4 } & $200 \mathrm{k}$ & 18525 & 136040 \\
\cline { 2 - 4 } & $400 \mathrm{k}$ & 3508 & 32434 \\
\hline
\end{tabular}

A Figura 31 apresenta a vazão nas simulações à $36 \mathrm{~km} / \mathrm{h}$ com tráfego VoIP, como um exemplo. Nesta figura, na simulação com 100kbps nos outros usuários, é possível identificar os três momentos em que os handovers ocorreram, aos 21,53 e 84 segundos, momento em que a vazão diminuiu. Com 400kbps nos outros usuários, o tráfego VoIP é bastante prejudicado. 


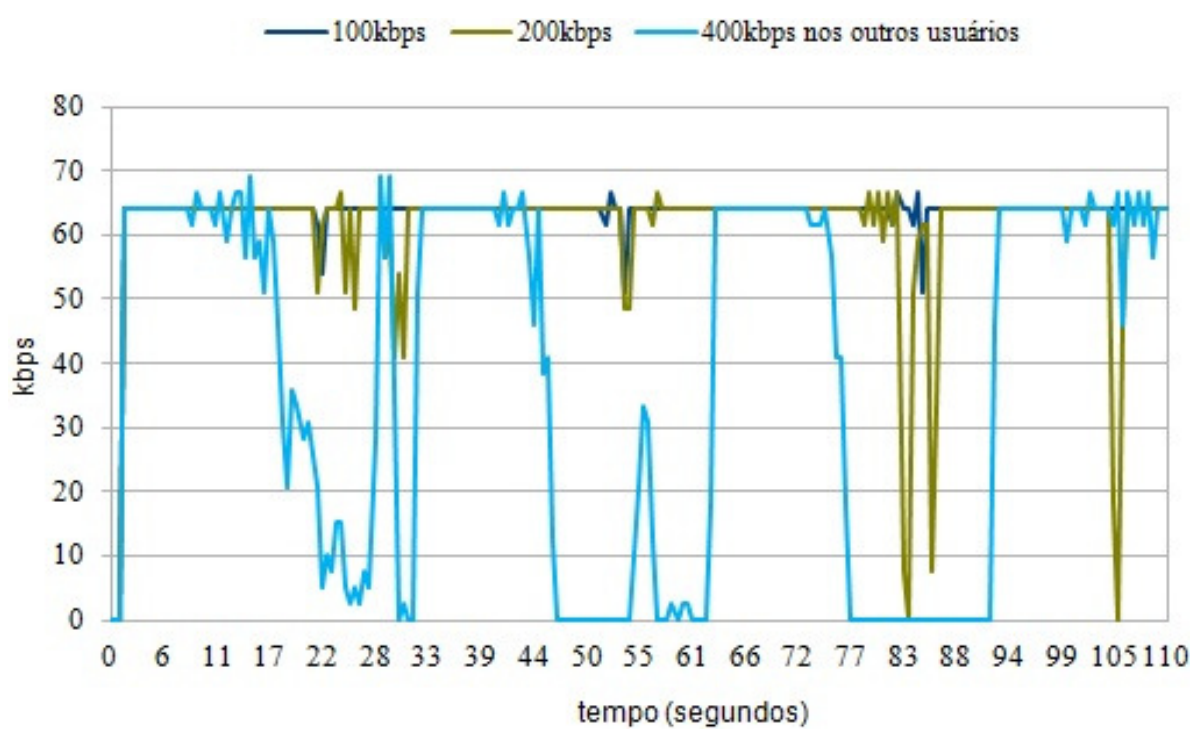

Figura 31 - Vazão à $36 \mathrm{~km} / \mathrm{h}$, tráfego VoIP, acesso tradicional, cenário mais povoado

A Tabela 17 (colunas TRAD) mostra o número de handovers feitos. Nas simulações à 36 km/h, o dispositivo móvel fez um ou dois handovers tipo ping-pong. Nas simulações à 5 km/h, o número de handovers também aumentou significativamente comparado às simulações à $36 \mathrm{~km} / \mathrm{h}$ devido ao efeito ping-pong observado no cenário menos povoado. Quando o tráfego nos outros usuários aumentou para 200kbps, o dispositivo começou a perder ADVs ocasionando aumento de handovers por expiração de ADV. Com 400kbps, diminuiu o número de handovers devido à variação do sinal, pois muitos ADVs eram perdidos e a causa dos handovers passou a ser, em maior parte, a expiração de ADVs. Como exemplo, à $5 \mathrm{~km} / \mathrm{h}$ com tráfego VoIP e 100kbps nos outros usuários, todos os 17 handovers ocorreram por variação da força do sinal (100\%); com 200kbps nos outros usuários, 20 ocorreram por variação do sinal $(86,95 \%)$ e 3 por expiração de ADV; e com 400kbps nos outros usuários, 3 handovers ocorreram por variação do sinal $(27,27 \%)$ e 8 por expiração de ADV. O mesmo ocorreu nas simulações com as aplicações de vídeo MPEG1 e FTP. 
Tabela 17 - Número de handovers feitos no cenário mais povoado (TRAD - acesso tradicional)

\begin{tabular}{|c|c|c|c|}
\hline \multirow[b]{2}{*}{$\begin{array}{l}\text { Aplicação } \\
\text { no móvel }\end{array}$} & \multirow[b]{2}{*}{$\begin{array}{r}\text { Tráfego nos outros } \\
\text { usuários (bps) }\end{array}$} & $36 \mathrm{~km} / \mathrm{h}$ & $5 \mathrm{~km} / \mathrm{h}$ \\
\hline & & TRAD & TRAD \\
\hline \multirow[t]{3}{*}{ VoIP } & $100 \mathrm{k}$ & 3 & 17 \\
\hline & $200 \mathrm{k}$ & 7 & 23 \\
\hline & $400 \mathrm{k}$ & 5 & 11 \\
\hline \multirow[t]{3}{*}{ MPEG1 } & $100 \mathrm{k}$ & 5 & 17 \\
\hline & $200 \mathrm{k}$ & 3 & 15 \\
\hline & $400 \mathrm{k}$ & 3 & 11 \\
\hline \multirow[t]{3}{*}{ FTP } & $100 \mathrm{k}$ & 3 & 21 \\
\hline & $200 \mathrm{k}$ & 3 & 33 \\
\hline & $400 \mathrm{k}$ & 5 & 15 \\
\hline
\end{tabular}

\subsubsection{Acesso sob demanda priorizando preço}

Nas simulações do cenário mais povoado priorizando preço, o usuário móvel User1 também gastou menos que no acesso tradicional, pois conectou-se com antenas do provedor P3 sempre que possível. Neste cenário, as maiores economias ocorreram nas simulações com tráfego VoIP e 100kbps nos outros usuários, nas quais o usuário economizou 37,67\% à velocidade de $36 \mathrm{~km} / \mathrm{h}$ e $35,16 \%$ à velocidade de $5 \mathrm{~km} / \mathrm{h}$. As Figuras 32 e 33 mostram o valor gasto priorizando preço comparado com o acesso tradicional, respectivamente, à $36 \mathrm{~km} / \mathrm{h}$ e $5 \mathrm{~km} / \mathrm{h}$. Em todas as simulações priorizando preço, conforme o tráfego nos outros usuários tornava-se maior, o dispositivo móvel perdia o sinal da antena do provedor P3 com mais frequência (ADV expirava) e conectava-se a antenas mais caras, aumentando o valor gasto. 


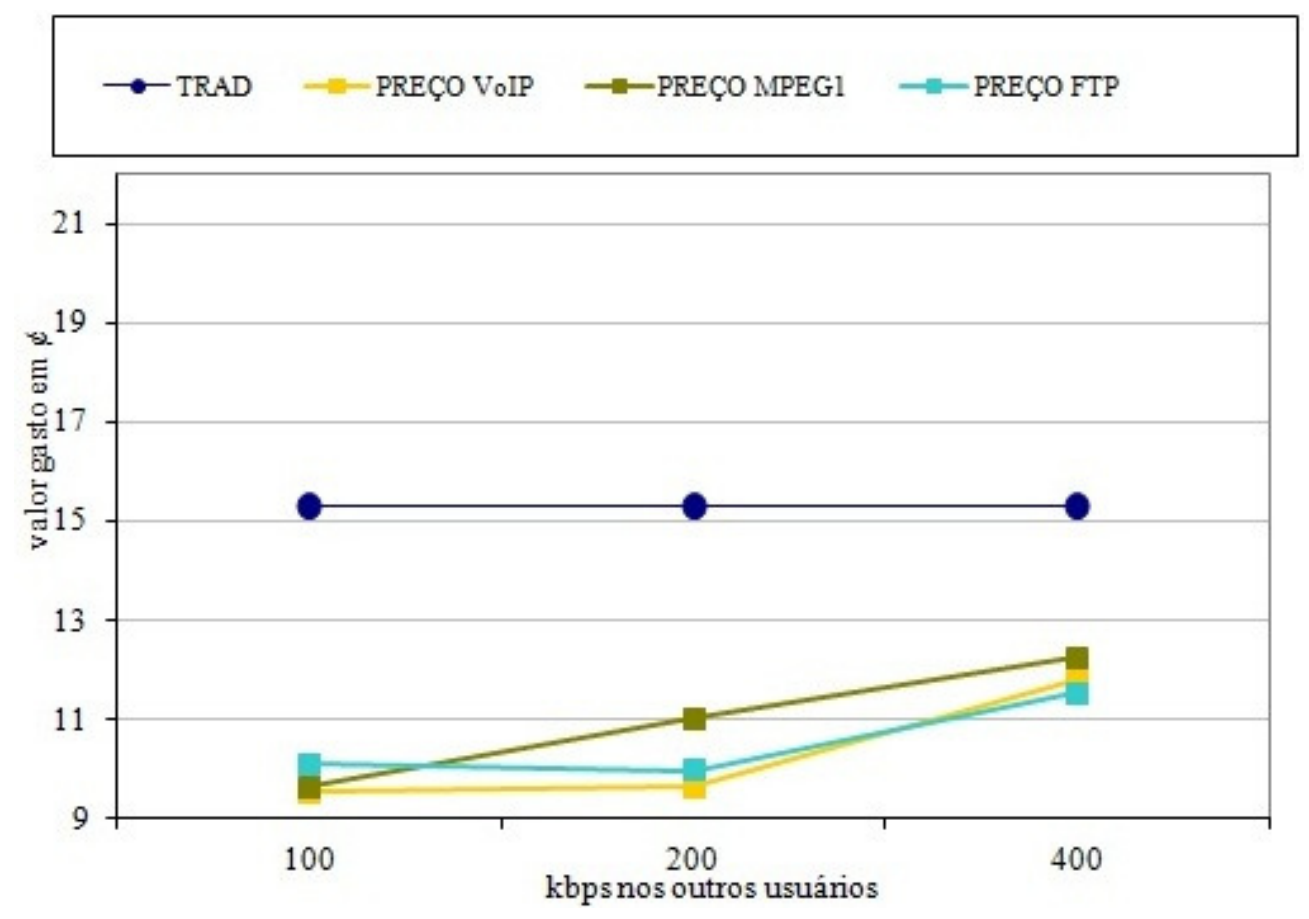

Figura 32 - Valor gasto, cenário mais povoado, à $36 \mathrm{~km} / \mathrm{h}$, priorizando preço

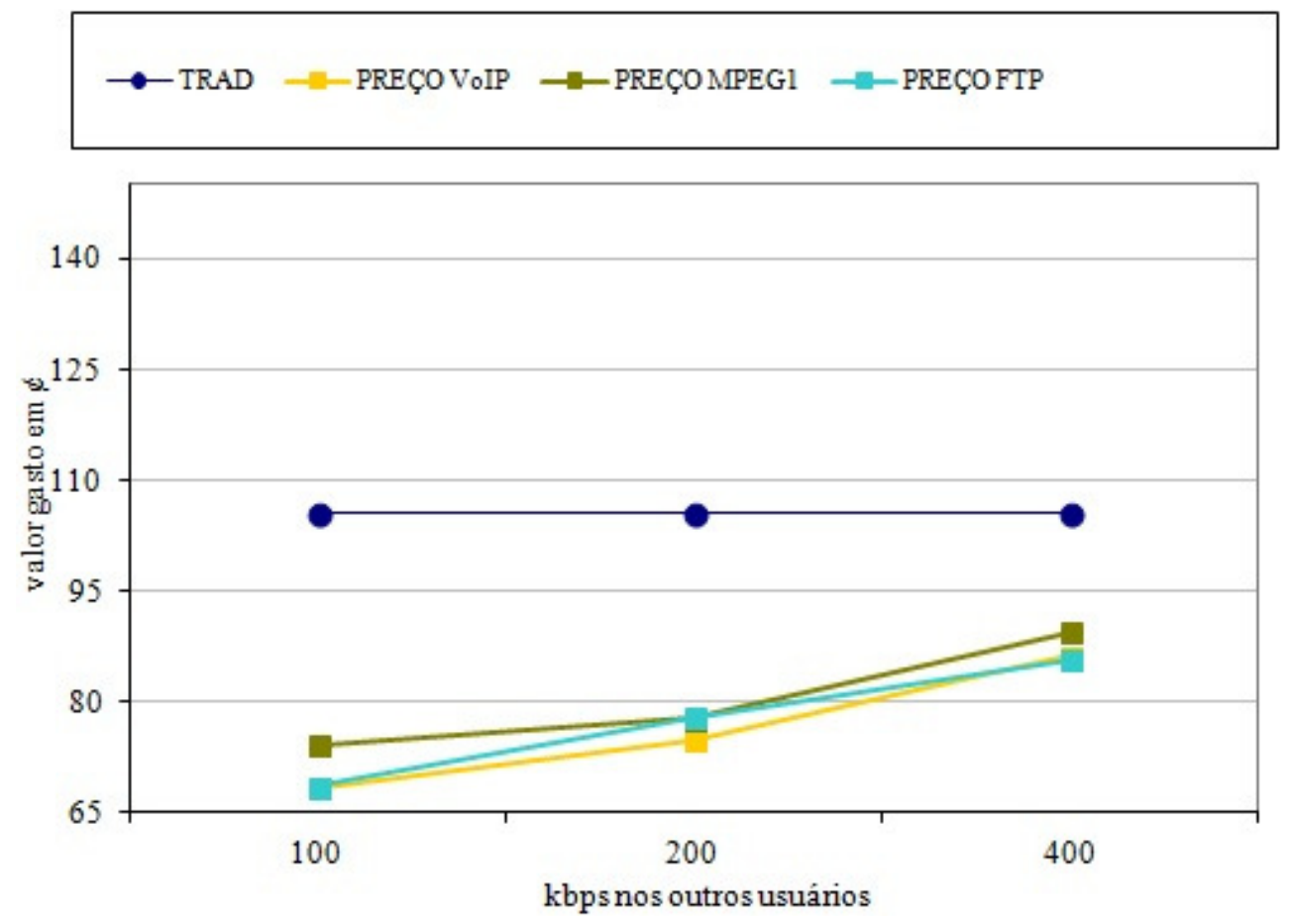

Figura 33 - Valor gasto, cenário mais povoado, à $5 \mathrm{~km} / \mathrm{h}$, priorizando preço 
Para ambas as velocidades, a quantidade de bytes recebidos foi próxima ao acesso tradicional com pouco tráfego (tráfego da aplicação do móvel e dos outros usuários) e também diminuiu com o aumento no tráfego dos outros usuários, como mostrado na

Tabela 18, colunas PREÇO. Mas a queda também foi menor comparado ao acesso tradicional, porque havia mais antenas disponíveis para conexão, por isso a quantidade de bytes recebidos tornou-se maior que no acesso tradicional.

Tabela 18 - Bytes recebidos no cenário mais povoado (PREÇO - priorizando preço)

\begin{tabular}{|l|l|l|l|l|l|}
\hline \multirow{3}{*}{$\begin{array}{c}\text { Aplicação } \\
\text { no móvel }\end{array}$} & \multirow{2}{*}{$\begin{array}{c}\text { Tráfego nos outros } \\
\text { usuários (bps) }\end{array}$} & $\begin{array}{c}\text { 36 } \\
\text { (KBAD }\end{array}$ & $\begin{array}{l}\text { PREÇO } \\
\text { (KBytes) }\end{array}$ & $\begin{array}{l}\text { TRAD } \\
\text { (KBytes) }\end{array}$ & $\begin{array}{l}\text { PREÇO } \\
\text { (KBytes) }\end{array}$ \\
\hline \multirow{4}{*}{ VoIP } & $100 \mathrm{k}$ & 849 & 830 & 5893 & 5878 \\
\cline { 2 - 6 } & $200 \mathrm{k}$ & 821 & 805 & 5686 & 5855 \\
\cline { 2 - 6 } & $400 \mathrm{k}$ & 517 & 694 & 4094 & 5435 \\
\hline \multirow{2}{*}{$\begin{array}{l}\text { Vídeo } \\
\text { MPEG1 }\end{array}$} & $100 \mathrm{k}$ & 19535 & 18809 & 138284 & 138145 \\
\cline { 2 - 6 } & $200 \mathrm{k}$ & 16376 & 18404 & 116519 & 132635 \\
\cline { 2 - 6 } & $400 \mathrm{k}$ & 8249 & 10290 & 58030 & 83159 \\
\hline \multirow{3}{*}{ FTP } & $100 \mathrm{k}$ & 35089 & 31141 & 250332 & 234098 \\
\cline { 2 - 6 } & $200 \mathrm{k}$ & 18525 & 15715 & 136040 & 156100 \\
\cline { 2 - 6 } & $400 \mathrm{k}$ & 3508 & 3401 & 32434 & 38003 \\
\hline
\end{tabular}

A Figura 34 apresenta a vazão nas simulações à $36 \mathrm{~km} / \mathrm{h}$ com tráfego VoIP, como um exemplo. Nesta figura, com 100kbps nos outros usuários, por exemplo, três handovers ocorreram aos 36 (handover para P3A2), 75 (handover para P1A3) e 81 segundos (handover para P3A3), após conectar-se inicialmente ao ponto de acesso P1A1. 


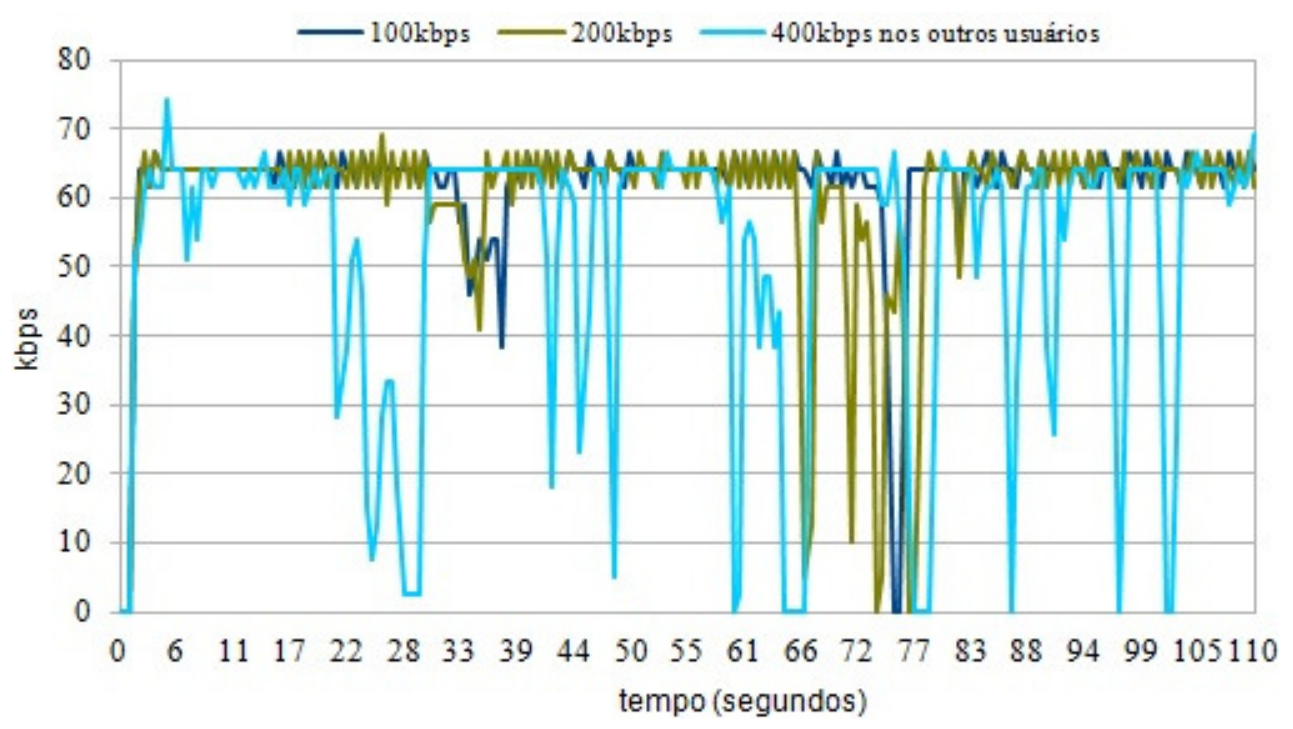

Figura 34 - Vazão à $36 \mathrm{~km} / \mathrm{h}$, tráfego VoIP, priorizando preço, cenário mais povoado

As colunas PREÇO na Tabela 19 mostram o número de handovers realizados. Nas simulações à $36 \mathrm{~km} / \mathrm{h}$, o número de handovers aumentou comparado ao acesso tradicional porque havia mais antenas disponíveis. À $5 \mathrm{~km} / \mathrm{h}$, com 100kbps e 200kbps nos outros usuários, o número de handovers diminuiu, comparado ao acesso tradicional, pois a política de decisão de handover tornou-se mais estável à variação da força do sinal. Mas com 400kbps nos outros usuários, o número de handovers aumentou devido ao aumento no número de expirações de ADV e subsequente handover ping-pong.

Tabela 19 - Número de handovers feitos no cenário mais povoado (PREÇO - priorizando preço)

\begin{tabular}{|c|c|c|c|c|c|}
\hline \multirow{2}{*}{$\begin{array}{c}\text { Aplicação } \\
\text { no móvel }\end{array}$} & \multirow{2}{*}{$\begin{array}{c}\text { Tráfego nos outros } \\
\text { usuários (bps) }\end{array}$} & \multicolumn{2}{|c|}{$\mathbf{3 6} \mathbf{~ k m} / \mathbf{h}$} & \multicolumn{2}{|c|}{$\mathbf{5} \mathbf{~ k m} / \mathbf{h}$} \\
\hline \multirow{3}{*}{ VoIP } & $100 \mathrm{k}$ & 3 & 3 & 17 & 12 \\
\cline { 2 - 6 } & $200 \mathrm{k}$ & 7 & 3 & 23 & 5 \\
\cline { 2 - 6 } & $400 \mathrm{k}$ & 5 & 14 & 11 & 39 \\
\hline \multirow{4}{*}{ MPEG1 } & $100 \mathrm{k}$ & 5 & 3 & 17 & 6 \\
\cline { 2 - 6 } & $200 \mathrm{k}$ & 3 & 4 & 15 & 9 \\
\cline { 2 - 6 } & $400 \mathrm{k}$ & 3 & 11 & 11 & 65 \\
\hline \multirow{3}{*}{ FTP } & $100 \mathrm{k}$ & 3 & 4 & 21 & 9 \\
\cline { 2 - 6 } & $200 \mathrm{k}$ & 3 & 4 & 33 & 10 \\
\cline { 2 - 6 } & $400 \mathrm{k}$ & 5 & 8 & 15 & 24 \\
\hline
\end{tabular}




\subsubsection{Acesso sob demanda priorizando força do sinal recebido}

Nestas simulações, assim como no cenário menos povoado, o dispositivo móvel conectou-se a todas as antenas na sequência em que elas se encontravam ao longo da avenida, no momento em que o sinal da próxima antena tornava-se mais forte que o sinal da antena atual. Para ambas as velocidades, o total de bytes recebidos foi maior que no acesso tradicional, exceto nas simulações com tráfego VoIP, à 36 km/h, e 100kbps nos outros usuários, devido ao baixo tráfego, da mesma forma que no cenário menos povoado, reforçando a conclusão de que nem sempre o acesso sob demanda é benéfico.

Para ambas as velocidades, a quantidade de bytes recebidos também diminuiu com o aumento no tráfego nos outros usuários, como mostrado nas Figuras 35 e 36, as quais mostram a quantidade de bytes recebidos pelo usuário móvel (em escala logarítmica), comparado ao acesso tradicional. Mas a queda foi menor comparado ao acesso tradicional, pois havia mais antenas disponíveis para conexão. Os melhores resultados, comparados com o acesso tradicional, foram com tráfego FTP e 400kbps nos outros usuários, à 36 km/h no qual o dispositivo móvel baixou 3,11 vezes mais bytes que no acesso tradicional, e à $5 \mathrm{~km} / \mathrm{h}$ no qual baixou 2,79 vezes mais.

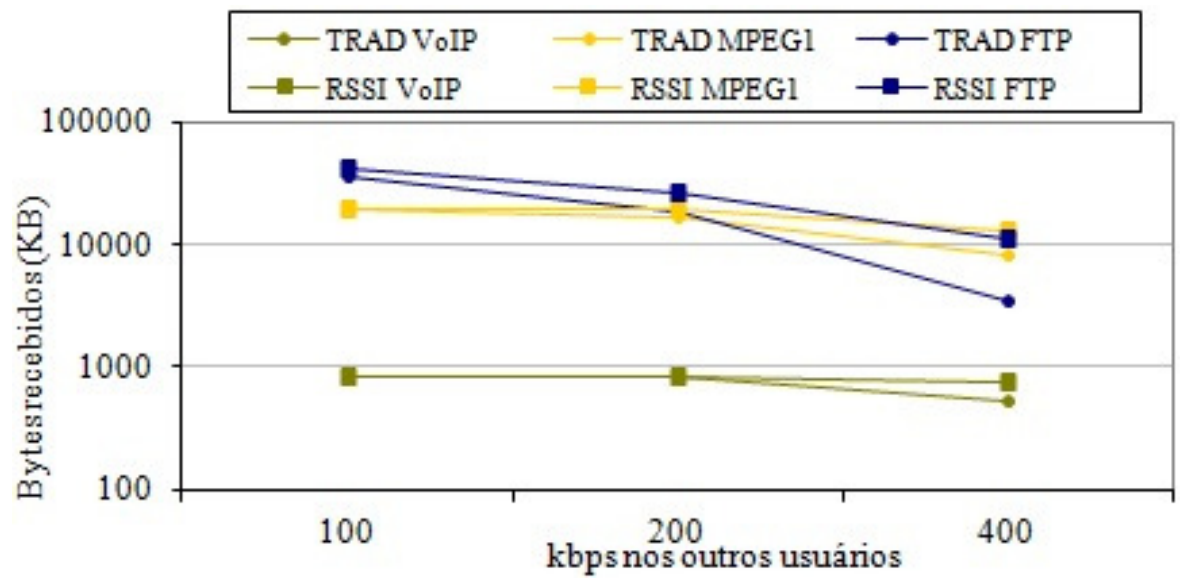

Figura 35 - Bytes recebidos, cenário mais povoado, à $36 \mathrm{~km} / \mathrm{h}$, priorizando força do sinal 


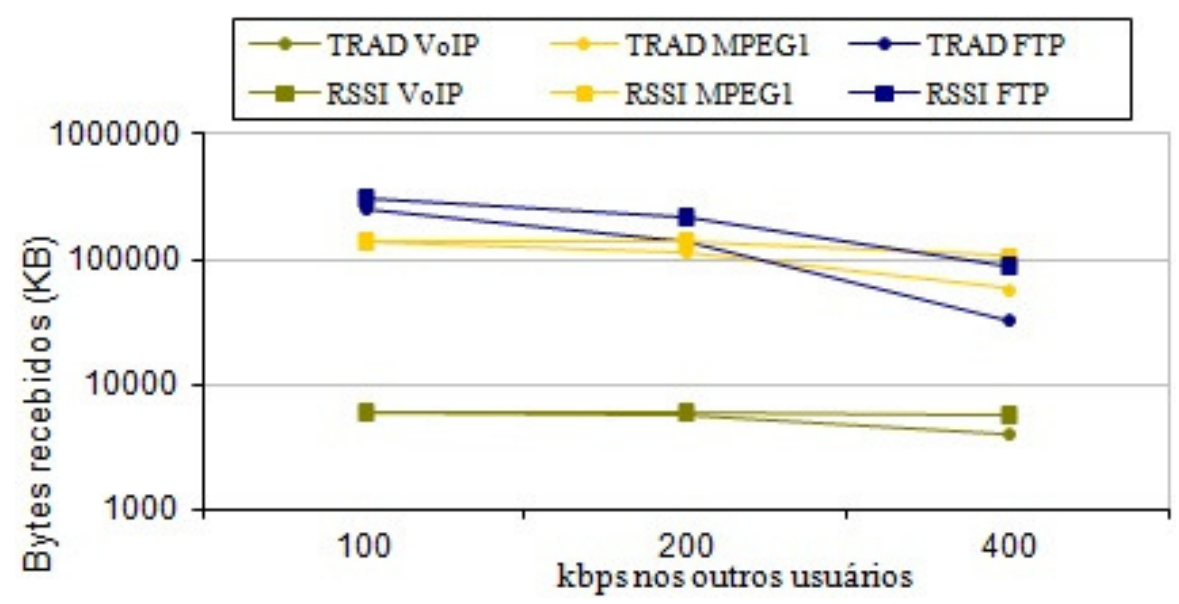

Figura 36 - Bytes recebidos, cenário mais povoado, à $5 \mathrm{~km} / \mathrm{h}$, priorizando força do sinal

A Figura 37 apresenta a vazão nas simulações à $36 \mathrm{~km} / \mathrm{h}$ com tráfego VoIP, como exemplo. É possível notar a melhor vazão comparada tanto ao acesso tradicional (Figura 31) quanto à priorização por preço (Figura 34).

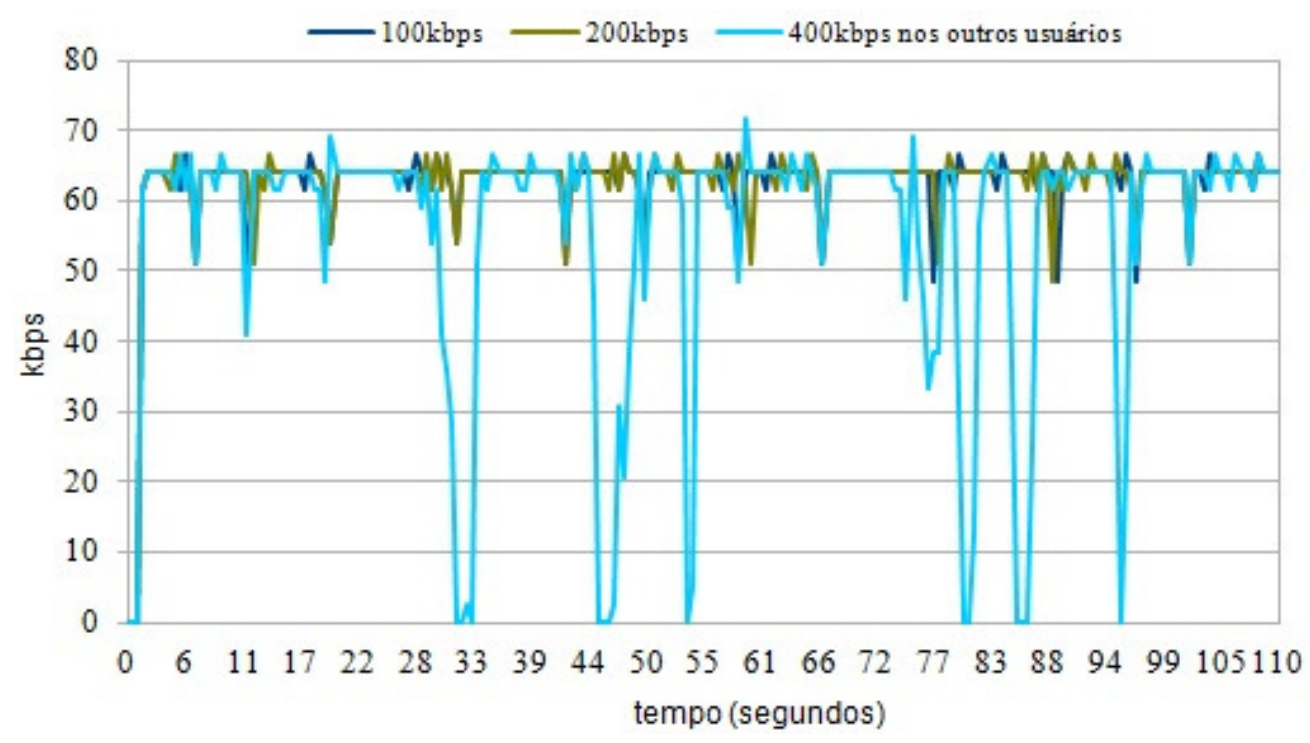

Figura 37 - Vazão à $36 \mathrm{~km} / \mathrm{h}$, tráfego VoIP, priorizando RSS, cenário mais povoado

O número de handovers, com velocidade de $36 \mathrm{~km} / \mathrm{h}$, foi maior que no acesso tradicional e ocorreu em função do número de antenas. Nenhum ou até poucos handovers ocorreram devido à expiração de ADV e/ou variação de RSSI. A Tabela 20 (colunas RSSI) mostra o total de handovers realizados comparado com o acesso tradicional. Com velocidade de $5 \mathrm{~km} / \mathrm{h}$, mais 
handovers ocorreram devido à variação da força do sinal nas proximidades do meio entre dois APs e aumentou bastante com 400kbps nos outros usuários devido à expiração de ADV.

Tabela 20 - Número de handovers feitos no cenário mais povoado (RSSI - priorizando força do sinal)

\begin{tabular}{|c|c|c|c|c|c|}
\hline \multirow{2}{*}{ Aplicação no móvel } & Tráfego nos outros & \multicolumn{2}{|c|}{$\mathbf{3 6} \mathbf{~ k m} / \mathbf{h}$} & \multicolumn{2}{|c|}{$\mathbf{~ k m / h}$} \\
\cline { 2 - 6 } & usuários (bps) & TRAD & RSSI & TRAD & RSSI \\
\hline \multirow{3}{*}{ VoIP } & $100 \mathrm{k}$ & 3 & 12 & 17 & 24 \\
\cline { 2 - 6 } & $200 \mathrm{k}$ & 7 & 12 & 23 & 20 \\
\cline { 2 - 6 } & $400 \mathrm{k}$ & 5 & 17 & 11 & 38 \\
\hline \multirow{2}{*}{ MPEG1 } & $100 \mathrm{k}$ & 5 & 12 & 17 & 32 \\
\cline { 2 - 6 } & $200 \mathrm{k}$ & 3 & 12 & 15 & 26 \\
\cline { 2 - 6 } & $400 \mathrm{k}$ & 3 & 14 & 11 & 50 \\
\cline { 2 - 6 } & $100 \mathrm{k}$ & 3 & 14 & 21 & 27 \\
\cline { 2 - 6 } & $200 \mathrm{k}$ & 3 & 12 & 33 & 16 \\
\cline { 2 - 6 } & $400 \mathrm{k}$ & 5 & 13 & 15 & 40 \\
\hline
\end{tabular}

Para ambas as velocidades, o valor gasto aumentou comparado às simulações com acesso tradicional porque, embora o usuário tenha se conectado a antenas mais baratas (provedor P3), este também conectou a antenas mais caras que se encontravam em maior quantidade. Diferentemente do acesso sob demanda priorizando preço, o valor gasto manteve-se estável, independente dos outros tráfegos. As Figuras 38 e 39 mostram o valor gasto a velocidades de 36 $\mathrm{km} / \mathrm{h}$ e $5 \mathrm{~km} / \mathrm{h}$, o qual ficou em torno de 17 centavos e 116 centavos, respectivamente.

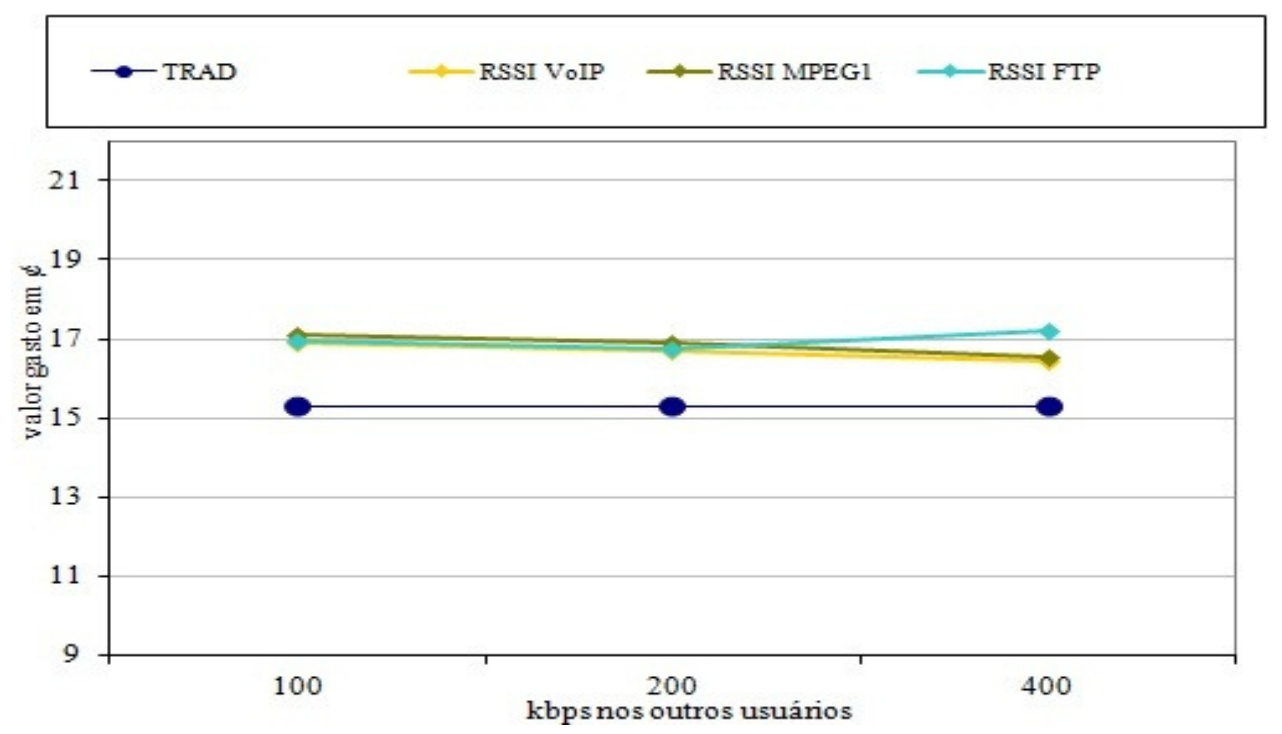

Figura 38 - Valor gasto, cenário mais povoado, à $36 \mathrm{~km} / \mathrm{h}$, priorizando força do sinal 


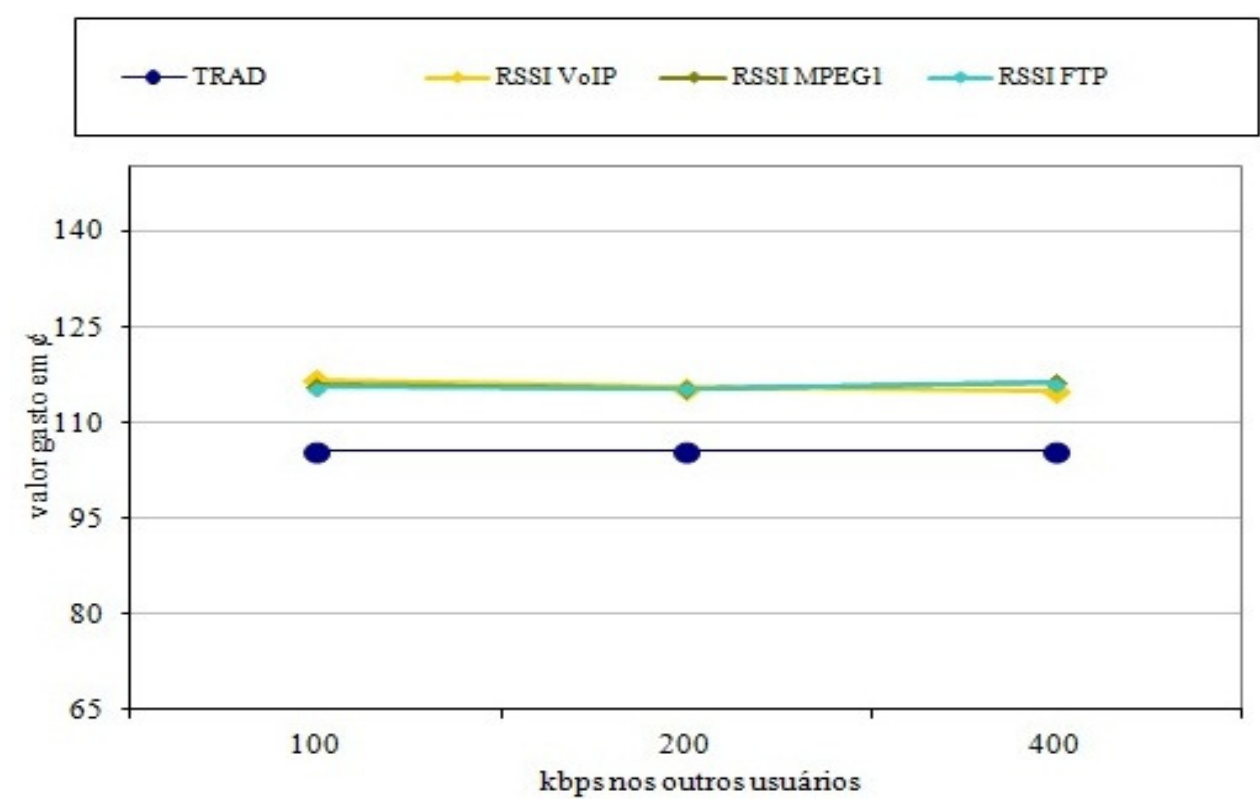

Figura 39 - Valor gasto, cenário mais povoado, à $5 \mathrm{~km} / \mathrm{h}$, priorizando força do sinal

\subsubsection{Acesso sob demanda priorizando carga no AP}

Nas simulações priorizando carga no ponto de acesso, o dispositivo móvel conectou-se, basicamente, aos pontos de acesso do provedor $\mathrm{P} 2$ pois estes tinham menos usuários conectados. Para ambas as velocidades, o total de bytes recebidos foi maior que nas simulações de acesso tradicional, como pode ser observado nas Figuras 40 e 41, com a mesma exceção do cenário menos povoado nas simulações com tráfego VoIP, à 36 km/h, e 100kbps. Esta exceção também ocorreu devido ao baixo tráfego, situação na qual o móvel pôde permanecer por mais tempo conectado à mesma antena (no caso do acesso tradicional) sem haver queda na vazão. A quantidade de bytes recebidos também diminuiu com o aumento no tráfego nos outros usuários, mas a queda também foi menor que no acesso tradicional. Nas simulações com tráfego FTP e 400kbps nos outros usuários, o móvel baixou 2,59 vezes mais bytes do que no acesso tradicional à $36 \mathrm{~km} / \mathrm{h}$ e 2,32 vezes mais à $5 \mathrm{~km} / \mathrm{h}$. 


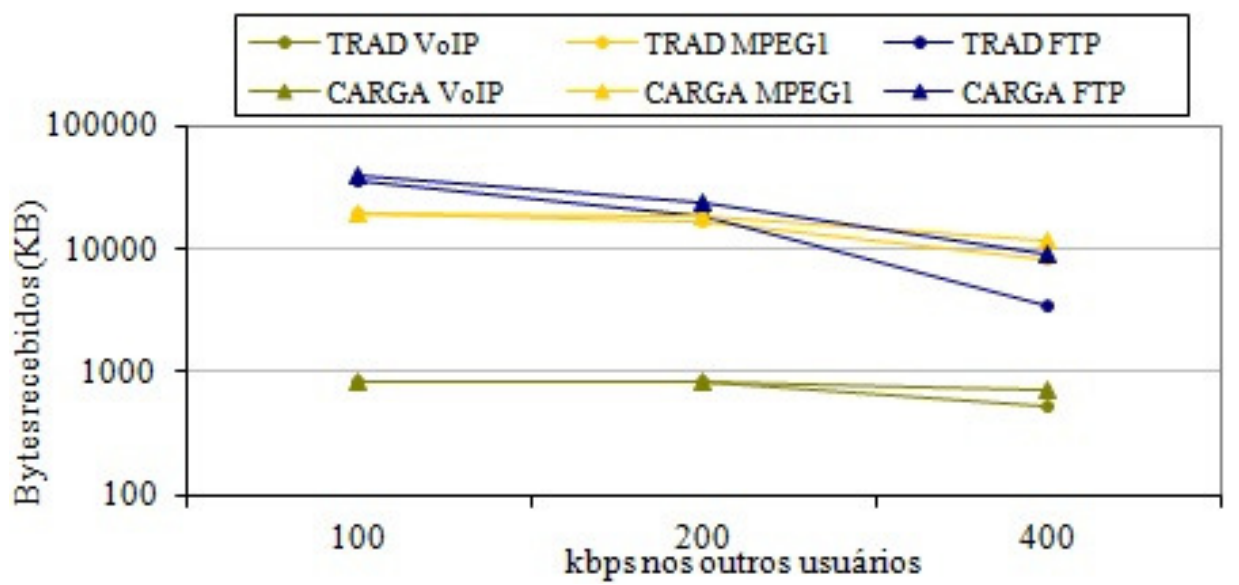

Figura 40 - Bytes recebidos, cenário mais povoado, à $36 \mathrm{~km} / \mathrm{h}$, priorizando carga no $\mathrm{AP}$

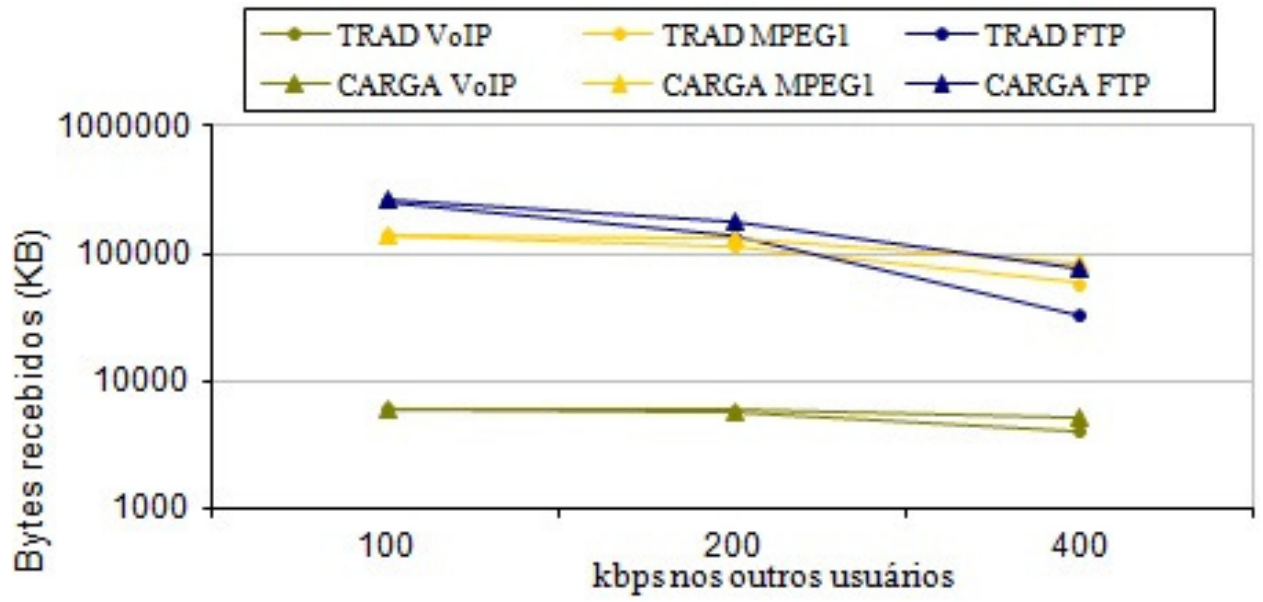

Figura 41 - Bytes recebidos, cenário mais povoado, à 5 km/h, priorizando carga no AP

Na maioria destas simulações, o total de bytes recebidos também foi menor do que no acesso sob demanda priorizando RSSI, reforçando a conclusão de que considerar apenas a carga no AP é menos eficiente que priorizar RSSI, com respeito à vazão. As exceções ocorreram com velocidade de $36 \mathrm{~km} / \mathrm{h}$ e tráfego VoIP, velocidade de $36 \mathrm{~km} / \mathrm{h}$ e tráfego de vídeo MPEG1, e velocidade de $5 \mathrm{~km} / \mathrm{h}$ e tráfego MPEG, as três com 100kbps nos outros usuários. A Figura 42 apresenta a vazão nas simulações à 36 km/h com tráfego VoIP, como um exemplo. 


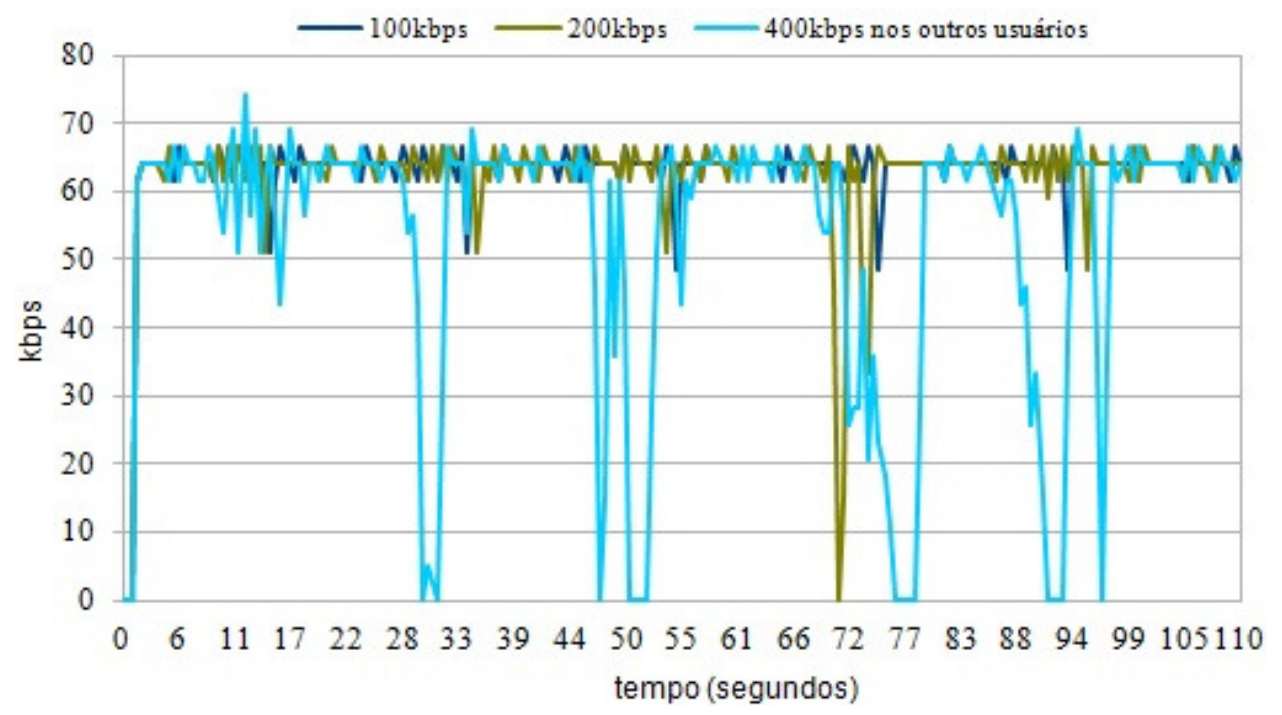

Figura 42 - Vazão à $36 \mathrm{~km} / \mathrm{h}$, tráfego VoIP, priorizando carga no AP, cenário mais povoado

As colunas CARGA na Tabela 21 mostram o número de handovers realizados. A análise é similar ao acesso sob demanda priorizando preço. Nas simulações à $36 \mathrm{~km} / \mathrm{h}$ o número de handovers também aumentou comparado ao acesso tradicional, com uma única exceção (tráfego VoIP e 200kbps nos outros usuários). Nas simulações à $5 \mathrm{~km} / \mathrm{h}$ com 100kbps e 200kbps nos outros usuários, o número de handovers permaneceu praticamente o mesmo, comparado ao acesso tradicional, mas com 400kbps nos outros usuários, o número de handovers aumentou bastante, devido ao aumento no número de expirações de ADV e subsequente handover pingpong.

Tabela 21 - Número de handovers feitos no cenário mais povoado (CARGA - priorizando carga no AP)

\begin{tabular}{|c|c|c|c|c|c|}
\hline \multirow[b]{2}{*}{$\begin{array}{l}\text { Aplicação } \\
\text { no móvel }\end{array}$} & \multirow[b]{2}{*}{$\begin{array}{l}\text { Tráfego nos outros } \\
\text { usuários (bps) }\end{array}$} & \multicolumn{2}{|c|}{$36 \mathrm{~km} / \mathrm{h}$} & \multicolumn{2}{|c|}{$5 \mathrm{~km} / \mathrm{h}$} \\
\hline & & TRAD & CARGA & TRAD & CARGA \\
\hline \multirow[t]{3}{*}{ VoIP } & $100 \mathrm{k}$ & 3 & 5 & 17 & 17 \\
\hline & $200 \mathrm{k}$ & 7 & 5 & 23 & 23 \\
\hline & $400 \mathrm{k}$ & 5 & 8 & 11 & 59 \\
\hline \multirow[t]{3}{*}{ MPEG1 } & $100 \mathrm{k}$ & 5 & 5 & 17 & 19 \\
\hline & $200 \mathrm{k}$ & 3 & 5 & 15 & 27 \\
\hline & $400 \mathrm{k}$ & 3 & 11 & 11 & 99 \\
\hline \multirow[t]{3}{*}{ FTP } & $100 \mathrm{k}$ & 3 & 5 & 21 & 21 \\
\hline & $200 k$ & 3 & 7 & 33 & 35 \\
\hline & $400 \mathrm{k}$ & 5 & 7 & 15 & 68 \\
\hline
\end{tabular}


Para ambas as velocidades, o valor gasto foi bem maior do que no acesso tradicional e também maior do que na priorização por RSSI, como mostrado nas Figuras 43 e 44, porque o usuário móvel permaneceu mais tempo conectado às antenas pertencentes ao provedor $\mathrm{P} 2$. O valor gasto diminuiu com o aumento no tráfego devido à expiração de ADVs do provedor P2 e subsequente conexão com antenas mais baratas.

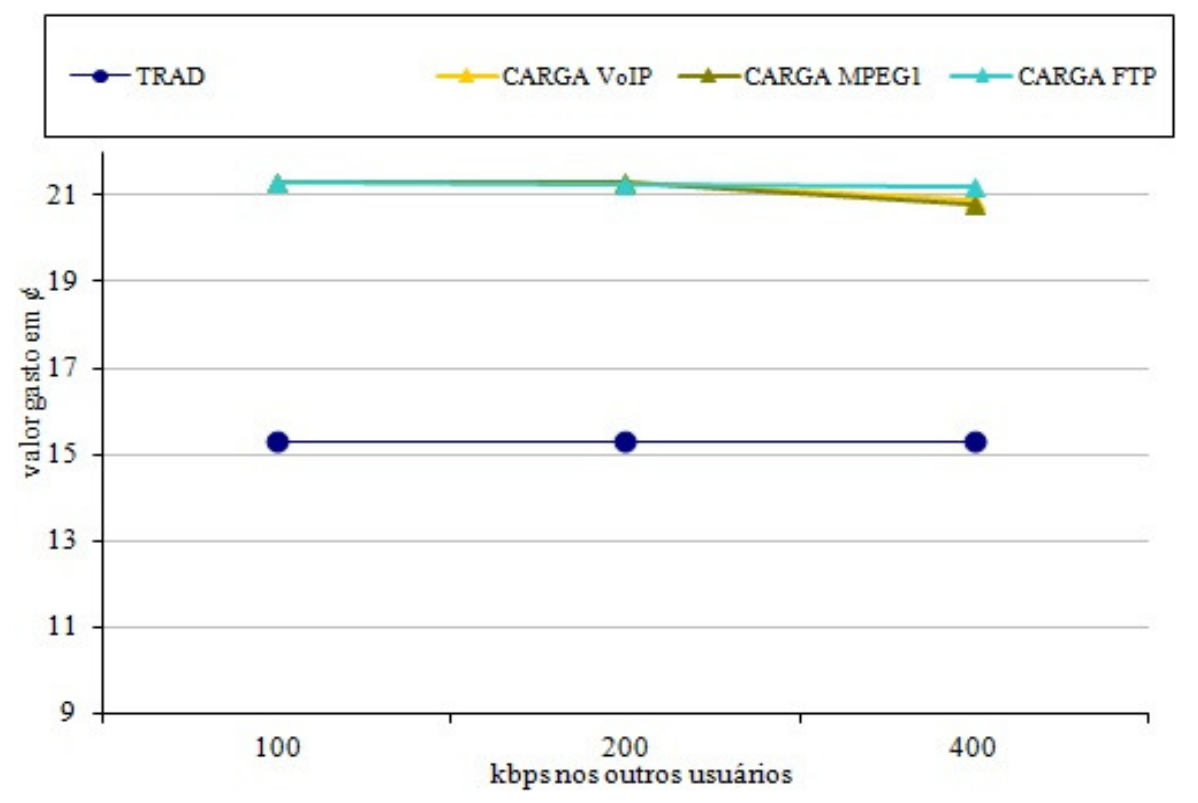

Figura 43 - Valor gasto, cenário mais povoado, à $36 \mathrm{~km} / \mathrm{h}$, priorizando carga no AP

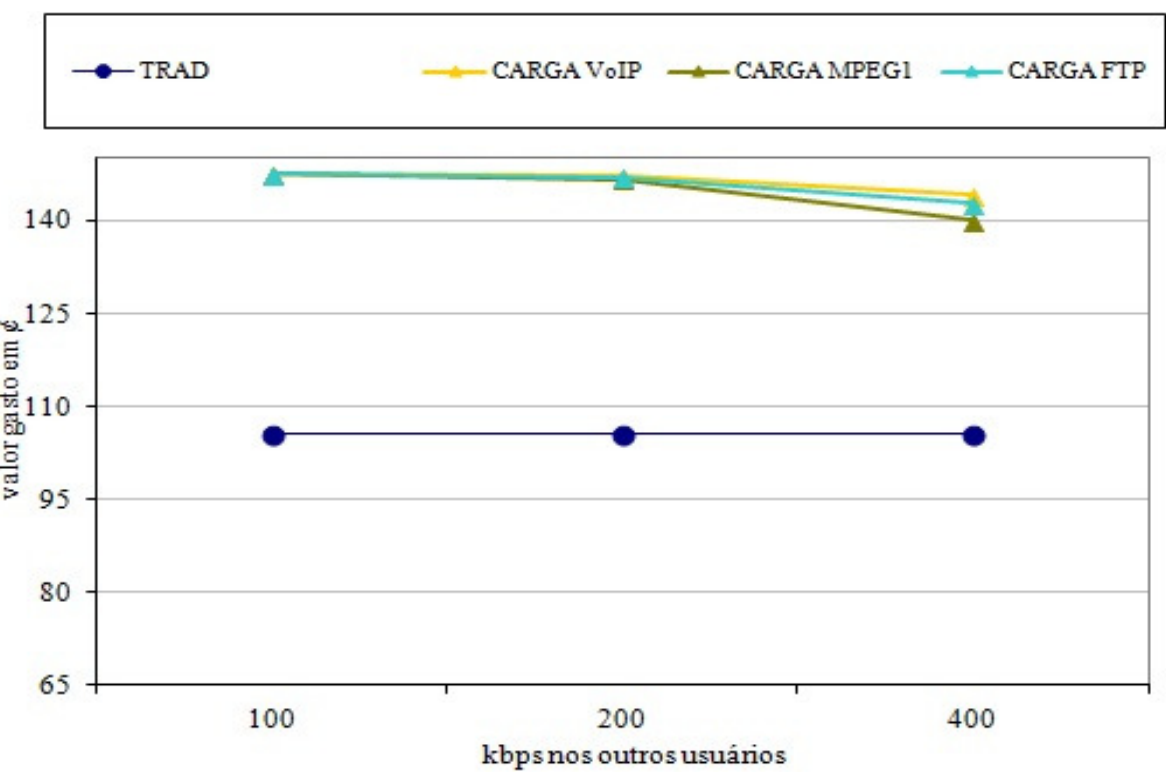

Figura 44 - Valor gasto, cenário mais povoado, à 5 km/h, priorizando carga no AP 


\subsubsection{Resumo dos resultados - cenário mais povoado}

A Tabela 22 mostra uma síntese dos resultados das simulações com o cenário mais povoado.

Tabela 22 - Resumo dos resultados - cenário mais povoado

\begin{tabular}{|c|l|l|l|}
\hline $\begin{array}{c}\text { Política de } \\
\text { decisão }\end{array}$ & \multicolumn{3}{|c|}{ Medição comparada com o acesso tradicional } \\
\cline { 2 - 4 } & Valor gasto & \multicolumn{1}{c|}{ Bytes recebidos } & \multicolumn{1}{|c|}{ Handovers feitos } \\
\hline PREÇO & Diminuiu & $\begin{array}{l}\text { Similar com pouco tráfego; } \\
\text { aumentou com maior tráfego }\end{array}$ & $\begin{array}{l}\text { Aumentou à } 36 \mathrm{~km} / \mathrm{h} ; \\
\text { diminuiu à } 5 \mathrm{~km} / \mathrm{h} \text { com } \\
\text { pouco tráfego; aumentou à } 5 \\
\mathrm{~km} / \mathrm{h} \text { com maior tráfego }\end{array}$ \\
\hline RSSI & Aumentou & $\begin{array}{l}\text { Aumentou, exceto com } \\
\text { tráfego VoIP, à 36 km/h e } \\
100 \text { Kbps nos outros usuários }\end{array}$ & Aumentou \\
\hline CARGA & Aumentou & $\begin{array}{l}\text { Aumentou, exceto com } \\
\text { tráfego VoIP, à 36 km/h e } \\
\text { 100 Kbps nos outros usuários }\end{array}$ & Aumentou \\
\hline
\end{tabular}




\section{Capítulo 5 Arquitetura MYHand para provimento de informações}

De acordo com os resultados apresentados no capítulo anterior, obtidos das simulações de acesso sob demanda, o usuário móvel pode economizar com o acesso sabendo o preço cobrado por cada rede e decidindo o handover, sem prejuízos na quantidade de bytes recebidos pela rede. Também foi observado que em algumas simulações priorizando carga no AP, o usuário móvel baixou mais bytes do que nas simulações priorizando força do sinal recebido, contrariando a maioria dos outros resultados. Nas simulações priorizando força do sinal, o usuário baixou mais bytes que no acesso tradicional e na priorização por preço, mas conhecer apenas a força do sinal recebido pode ser insuficiente se o dispositivo não tiver garantia de que a rede tem banda disponível para a aplicação em uso pelo usuário.

Para ser possível oferecer acesso sob demanda com gerenciamento de handover centrado no usuário, é necessário que o dispositivo móvel obtenha informações das várias redes disponíveis como, por exemplo, preços, parâmetros de QoS, frequência do canal, entre outras, para melhor decidir uma troca. Além de obter estas informações, é importante obtê-las de forma antecipada a fim de preparar a troca de rede antes de haver perda de QoS. O ambiente heterogêneo da NGN, com várias tecnologias de acesso e provedores diferentes, resulta em uma implicação a mais, que é o uso de termos diferentes para a mesma informação, por exemplo, a variação do atraso é chamada de “jitter" em redes 802.11, “tolerated jitter" em redes 802.16 e “delay variation” em redes 3GPP [Wu, 2009].

Este capítulo apresenta a arquitetura MYHand que visa melhorar o gerenciamento das trocas de rede em ambiente NGN, através do fornecimento de informação adicional ao dispositivo móvel e baseando-se no gerenciamento de handover centrado no usuário. MYHand 
utiliza a arquitetura Y-Comm juntamente com os serviços de informação (MIIS), de evento (MIES) e de comandos (MICS) do protocolo 802.21 e uma extensão ao esquema básico deste protocolo (Extended Schema). Além das informações fornecidas pela arquitetura MYHand, o usuário móvel pode fazer uma avaliação da vizinhança em paralelo.

\subsection{Esquema estendido proposto}

Tendo em vista os resultados das simulações e a necessidade do usuário obter informações adicionais como preço e carga no AP, foi proposta uma extensão ao Esquema Básico do IEEE 802.21 .

Como visto na seção 3.3.3, a estrutura de cada Elemento de Informação e seus relacionamentos do Serviço de Informações (MIIS) do protocolo IEEE 802.21 podem ser representados por um esquema RDF/OWL, o qual consiste de um Esquema Básico que pode ser expandido de acordo com a necessidade de cada fabricante ou provedor de acesso.

O esquema estendido proposto na arquitetura MYHand estende a seleção de novas redes, embutindo informações relacionadas a incentivos, enriquecendo o processo de handover alternativo, no qual o dispositivo pode realizar a escolha da rede com base em incentivos oferecidos pela rede de acesso. Este esquema com informações de incentivos através de pontuação apenas exemplifica uma ampla gama de informações adicionais que podem ser disponibilizadas pelos provedores através da arquitetura MYHand.

A Figura 45 mostra o elemento Incentive proposto, relacionado com os elementos Thing e NETWORK (ver Figura 14). Thing é um elemento genérico da linguagem RDF/OWL da qual todos os outros elementos herdam suas propriedades. O elemento NETWORK agrega informações dos outros elementos como, por exemplo, tipo da rede (network type), lista de PoA 
(Point of Access), identificador do operador (Operator ID), entre outros, e o elemento Incentive passa a ser um outro atributo de NETWORK.

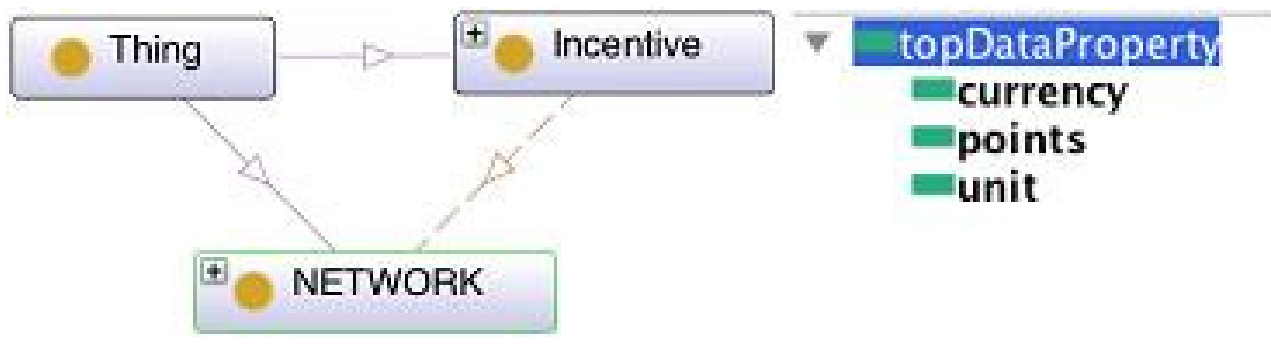

Figura 45 - Esquema estendido proposto

O elemento Incentive fornecerá a informação de pontuação a ser creditada ao usuário da rede. Essa pontuação poderá ser utilizada em futuras conexões para, por exemplo, trocar por desconto, e assim ser um atrativo à fidelidade do usuário à rede. Este elemento possui três campos:

- Currency: código de três letras representando a moeda corrente (p. ex., "USD") como especificado em [ISO4217, 2012];

- $\quad$ Points: pontos a serem adquiridos pelo usuário durante o uso da rede, associado a uma unidade;

- Unit: unidade refere-se à quantidade de valor gasto para se obter determinada pontuação. Por exemplo, o usuário ganhará 20 pontos a cada 1 dólar gasto com acesso. A unidade também poderia ser uma unidade de tempo, por exemplo, o usuário ganhará 20 pontos a cada 30 minutos conectado ao provedor.

A definição do esquema estendido proposto é mostrada na Tabela 23 como um documento XML. Este esquema estendido pode ser obtido pelo dispositivo móvel por meio do serviço DHCP, da mesma forma que se obtém o Esquema Básico [IEEE, 2009a]. 
Tabela 23 - Definição do esquema estendido proposto

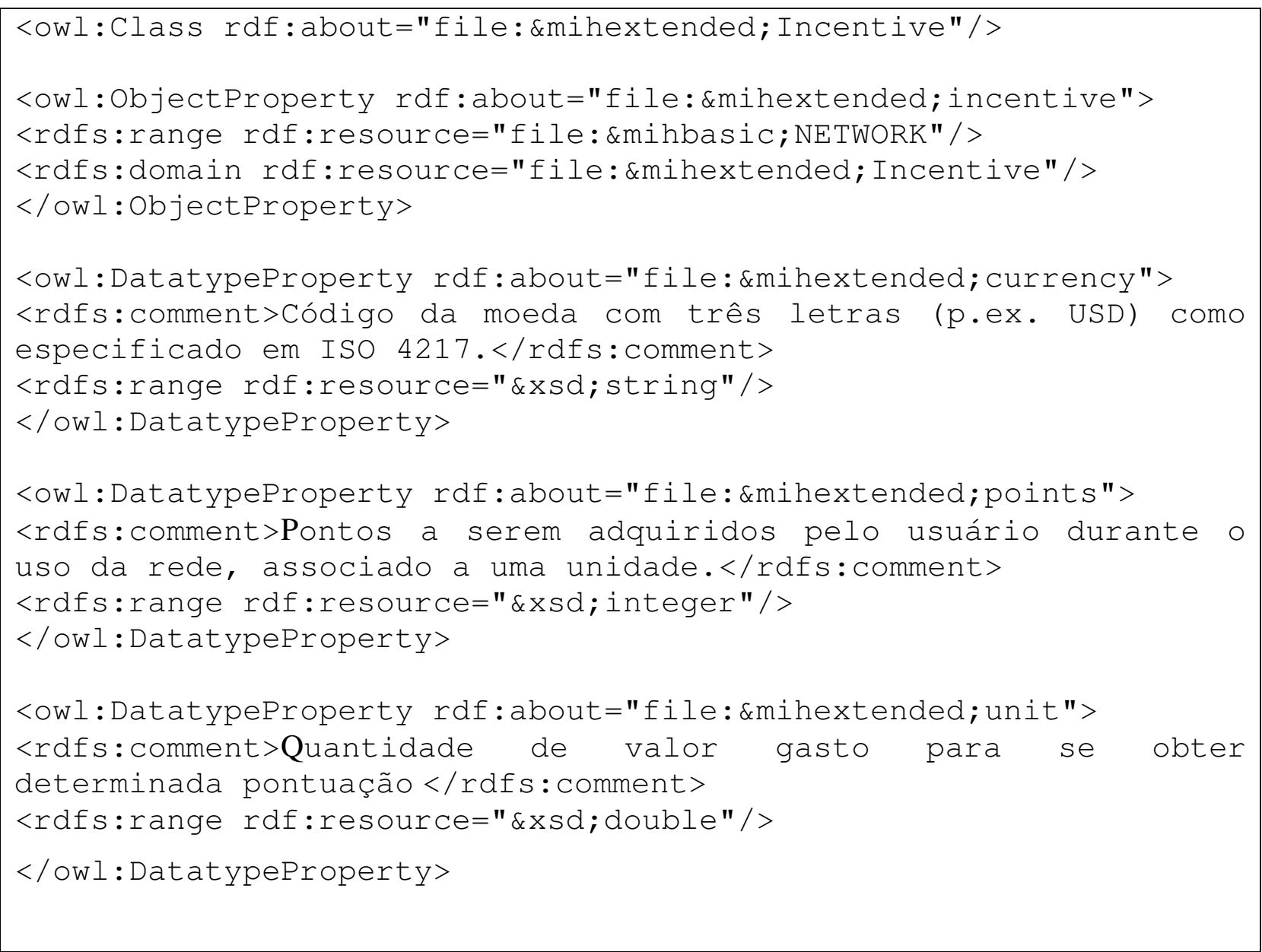

\subsection{Arquitetura MYHand}

A Figura 46 apresenta a arquitetura MYHand de fornecimento de informações adicionais com quatro entidades envolvidas: o nó móvel, denominado de MN (Mobile Node), o ponto de acesso atual, denominado de PoS-S (Serving Point of Service), uma rede canditada/alvo (Candidate/Target Network) e um Servidor MIIS (MIIS Server), cada uma com módulos 802.21 devidamente inseridos nas camadas Y-Comm. Os comandos iniciados por "MIH_" são comandos do protocolo 802.21. 


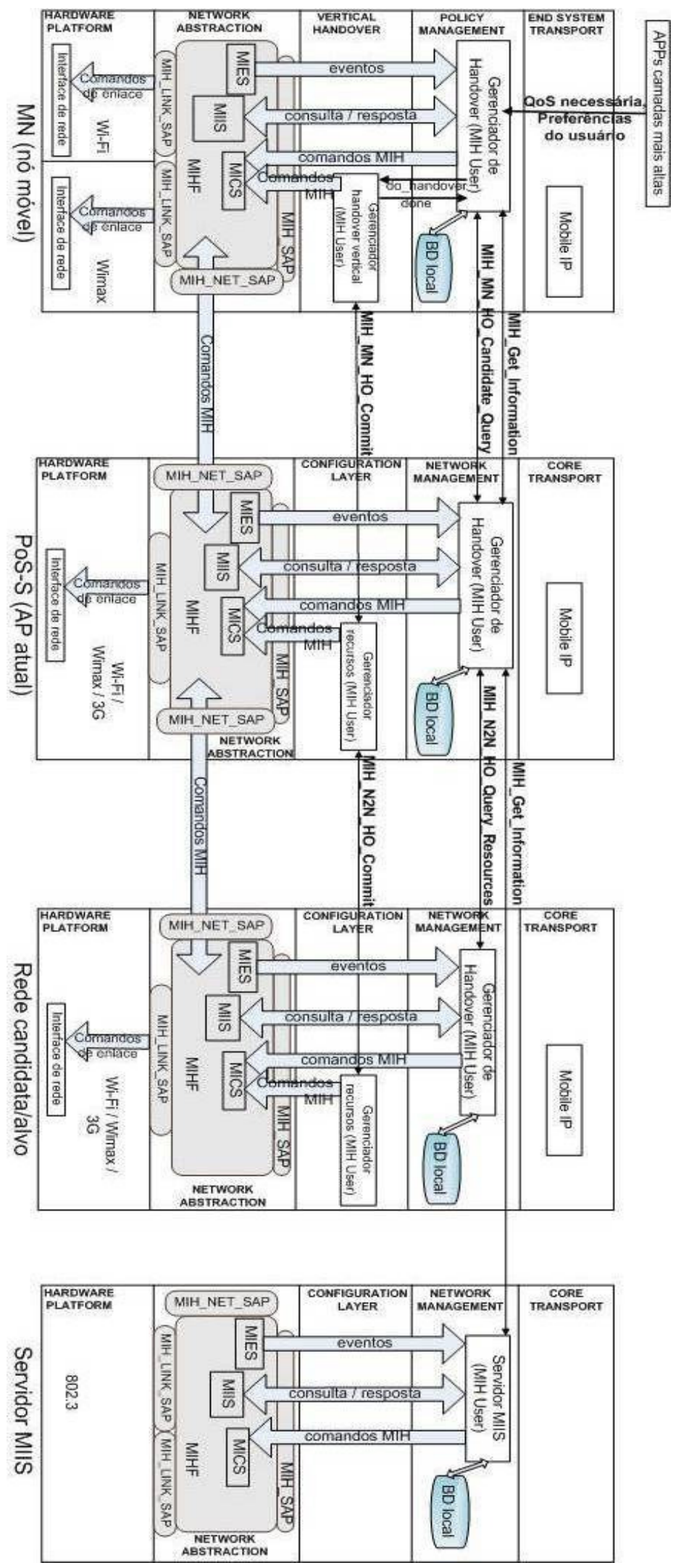

Figura 46 - Arquitetura MYHand 
O nó móvel (MN) pode possuir mais de uma interface de rede. O módulo MIHF situa-se na camada de Abstração de Rede (Network Abstraction) e é responsável pela abstração das interfaces de rede para as camadas superiores. Este módulo recebe comandos e envia eventos e informações para o módulo Gerenciador de Handover, recebe comandos do Gerenciador de Handover Vertical e envia os comandos provenientes dos módulos superiores para MIHF remotos. Os Pontos de Acesso de Serviço (Service Access Points) MIH_SAP, MIH_LINK_SAP e MIH_NET_SAP fazem a interface entre o MIHF e os outros módulos. O módulo Gerenciador de Handover adquire informações do dispositivo, do usuário e das redes através dos comandos MIH_Get_Information e MIH_MN_HO_Candidate_Query, e decide quando e para qual antena um handover deve ser feito. O módulo Gerenciador de Handover Vertical recebe comandos do módulo Gerenciador de Handover solicitando a realização de um handover (do_handover), adquire recursos da rede alvo e realiza, de fato, o handover(MIH_MN_HO_Commit).

Ainda na Figura 46, o PoS-S é o ponto de rede ao qual o MN está diretamente conectado e possui apenas uma interface de rede para conexão pelos usuários móveis. O módulo MIHF abstrai a interface de rede para as camadas superiores e repassa comandos MIH remotos para os respectivos módulos. O módulo Handover Manager funciona como um Servidor MIIS proxy e é responsável por fornecer informações ao MN. Estas informações são provenientes de uma base de dados local (BD local), do servidor de informações MIIS (através do comando MIH_Get_Information) e de outras possíveis fontes. Este módulo também verifica a disponibilidade de recursos em redes candidatas através do comando MIH_N2N_HO_Query_Resources. O módulo Gerenciador de Recursos é responsável por solicitar alocação de recursos para o MN na rede alvo.

Na Rede Candidata/Alvo, o módulo MIHF tem a mesma função que no PoS-S. O módulo Gerenciador de Handover verifica e informa sobre a disponibilidade de recursos para novos 
usuários ao módulo Gerenciador de Handover do PoS-S. O módulo Gerenciador de Handover aloca recursos de rede para um usuário que irá se conectar neste ponto de acesso, quando este for solicitado pelo Gerenciador de Handover do PoS-S.

No Servidor MIIS, o módulo que implementa o servidor de informações recebe e responde às requisições de informações sobre redes disponíveis em determinada área. O protocolo Mobile IP [Johnson, 2011], presente nas três primeiras entidades, possibilita a mobilidade do usuário no nível de rede.

Para detalhar mais o funcionamento desta arquitetura, a Figura 47 apresenta um fluxograma com o procedimento de um handover alternativo com requisito mínimo de vazão, e que tem como política de decisão de handover priorizar a pontuação pelo acesso conforme explicado na seção anterior (seção 5.1).

Seguindo o procedimento apresentado na Figura 47, antes de iniciar o handover, o MN encontra-se conectado à rede $\mathrm{A}$ pela sua interface Wi-Fi e encontra-se executando uma determinada aplicação com exigência de vazão mínima de 500Kbps. Aplicações de camadas mais altas no MN informam ao módulo Gerenciador de Handover (com a frequência adequada) sobre informações de QoS mínima, preferências do usuário (provedor, tecnologia de acesso, preço de acesso ou pontuação mínima, por exemplo). No caso do MN ainda não estar conectado a alguma rede, é necessário fazer uma busca por pontos de acesso disponíveis (scanning), através do comando MIH_Link_Actions.request, para procurar uma rede disponível. Este comando retorna informações de endereço do ponto de acesso, identificador de rede, força do sinal da antena, entre outras. 


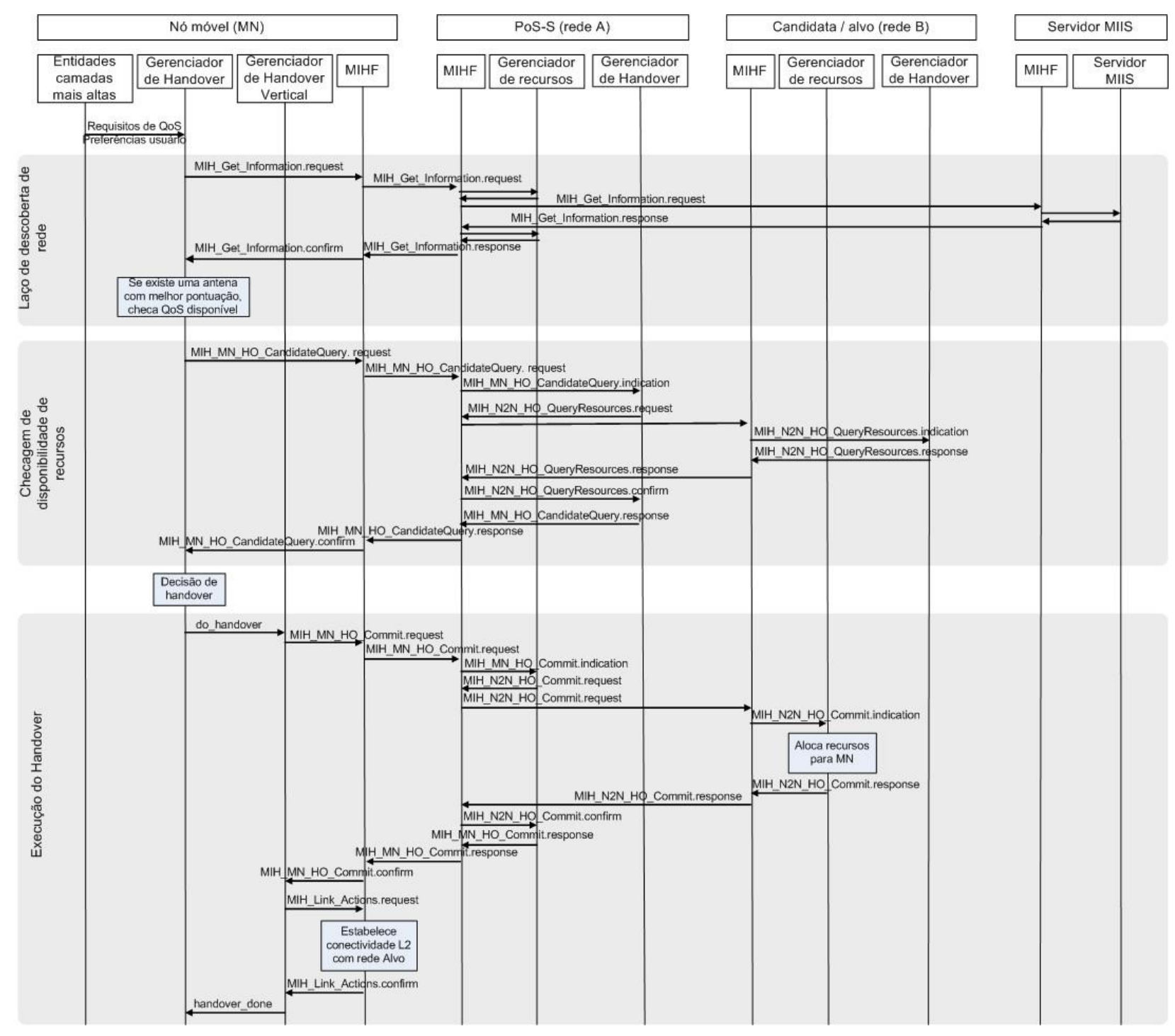

Figura 47 - Procedimento de handover alternativo

Para possibilitar um handover alternativo, o módulo Gerenciador de Handover (HM) do nó móvel periodicamente solicita informações ao HM do PoS-S sobre as redes disponíveis naquela região através da mensagem MIH_Get_Information.request. Nesta mensagem, o MN envia sua localização e tecnologia de acesso desejável (de acordo com suas interfaces de rede disponíveis e preferências do usuário) e recebe informações (MIH_Get_Information.response) sobre cada rede candidata como, por exemplo, SSID do provedor de acesso, parceiros com acordo de roaming (roaming partners), custo do acesso, taxa máxima de transferência de dados, e 
pontuação (no caso do esquema estendido proposto), e informações de cada antena disponível como, por exemplo, endereço MAC, tecnologia, posição geográfica, canal utilizado e endereço IP. Eventualmente o HM do PoS-S pode consultar o Servidor MIIS para atualizar informações. As redes candidatas escolhidas pelo PoS-S para serem informadas ao MN podem ser todas as redes disponíveis em determinada localidade, ou apenas aquelas que oferecem a tecnologia especificada pelo $\mathrm{MN}$, ou a rede especificada pelo MN. Todas as mensagens $\mathrm{MIH}$ remotas passam pelo MIHF das respectivas entidades.

O MN pode identificar cada rede como pertencente a um provedor ao qual ele tenha contrato de conexão, ou pertencente a um provedor parceiro de seu provedor home (através do campo roaming partners do protocolo 802.21).

Se, após uma consulta por redes disponíveis, o MN identificar uma rede com melhor pontuação que a rede atualmente sendo utilizada, o módulo Gerenciador de Handover (HM) pode decidir fazer um handover para esta rede. Como a aplicação exige um mínimo de vazão, o módulo HM envia o comando MIH_MN_HO_CandidateQuery.request para o módulo HM do PoS-S solicitando a verificação de recursos, informando qual(is) rede(s) deve(m) ser verificada(s) (redes candidatas) e os recursos mínimos exigidos. Este por sua vez, consulta a disponibilidade de recursos em cada rede candidata enviando o comando MIH_N2N_HO_QueryResources.request para o módulo HM de cada rede candidata, informando quais os recursos exigidos. As redes candidatas respondem com uma mensagem MIH_N2N_HO_QueryResources.response informando sobre a disponibilidade ou não dos recursos. Então, o HM do PoS-S junta as informações de disponibilidade das redes candidatas e responde ao MN com a mensagem MIH_MN_HO_CandidateQuery.response.

Com todas as informações necessárias, o módulo HM do MN decide se deve ou não fazer um handover. Em caso afirmativo, este envia um comando do_handover ao módulo Gerenciador 
de Handover Vertical (VHM) para proceder com o handover, informando o tipo do enlace (GSM, IEEE802.11, UMTS, IEEE802.16, etc) e para qual rede o handover deve ser feito. O módulo VHM, por sua vez, notifica o módulo Gerenciador de Recursos (RM) do PoS-S através do comando MIH_MN_HO_Commit.request sobre a rede alvo escolhida. O módulo RM do PoS-S envia um comando MIH_N2N_HO_Commit.request ao módulo RM da rede alvo para avisar que o MN irá se conectar naquela rede. Então o RM da rede alvo aloca os recursos necessários para o MN e responde à requisição com uma mensagem MIH_N2N_HO_Commit.response avisando se a alocação foi realizada com sucesso ou não. Em caso positivo, o módulo RM do PoS-S avisa ao VHM do MN sobre o sucesso na operação através do comando MIH_MN_HO_Commit.response.

Com os recursos já alocados na rede alvo, o módulo VHM envia o comando MIH_Link_Actions.request para o MIHF solicitando que a interface seja ligada para o estabelecimento da conexão no nível de enlace com a antena alvo em determinado canal ou solicitando que a interface atual se desconecte da antena atual e se conecte com a antena alvo. Por fim, a conexão com a rede alvo é estabelecida e o VHM avisa ao HM que o handover foi realizado (mensagem handover_done).

Após isso, o protocolo de mobilidade Mobile IP é executado em conjunto com o MN e o Home Agent para a continuidade da conexão para a camada de transporte.

Opcionalmente, o módulo HM do MN envia um comando MIH_MN_HO_Complete.request ao PoS da rede alvo, solicitando que este avise o antigo PoS que ele já pode liberar os recursos que estavam alocados ao MN naquela rede.

Diferentemente do handover alternativo, o handover imperativo reativo ocorre por razões técnicas como, por exemplo, queda na vazão ou perda do sinal da antena, obrigando o dispositivo 
móvel a realizar a troca de rede. O fluxograma da Figura 48 apresenta um exemplo de procedimento de handover deste tipo.

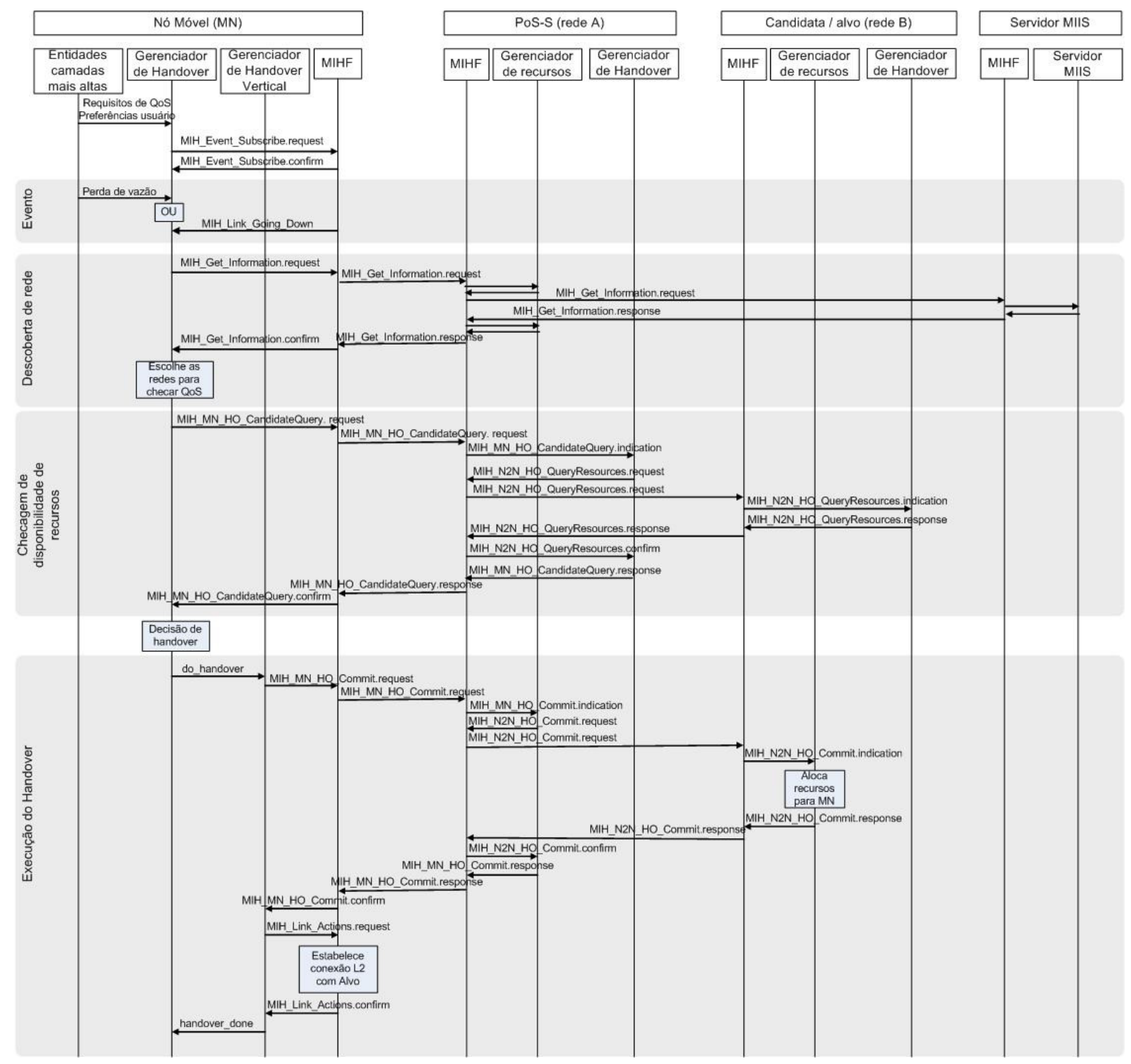

Figura 48 - Procedimento de handover imperativo reativo

No exemplo da Figura 48, para monitorar a situação da conexão atual, o Gerenciador de Handover (HM) do MN inscreve-se no evento Link_Going_Down através do comando MIH_Event_Subscribe.request, enviado ao MIHF local. Este evento avisa às camadas superiores quando o enlace está para se perder. O MIHF responde ao HM com um 
MIH_Event_Subscribe.confirm. Opcionalmente, se o HM desejar monitorar a queda do sinal ou aumento de taxa de erro de pacotes, por exemplo, este inscreve-se no evento MIH_Link_Parameters_Report e configura limites (thresholds) utilizando o comando MIH_Link_Configure_Threshold.

Dois eventos podem desencadear um handover neste exemplo. Primeiro, se a aplicação ou um monitor de QoS da camada superior detectar queda de vazão, o módulo HM é notificado do fato (mensagem perda de vazão). Segundo, se o módulo HM receber um aviso do MIHF de que o enlace irá se perder (MIH_Link_Going_Down). Independente do evento que ocorra, o módulo HM solicita informações sobre as redes disponíveis através do comando MIH_Get_Information. Request, como descrito no caso do handover alternativo. Os passos seguintes são os mesmos que no exemplo anterior: o módulo HM escolhe as redes candidatas, verifica a disponibilidade de recursos, decide se faz o handover e para qual rede, e o módulo VHM (Gerenciador de Handover Vertical) executa a troca de rede.

\subsection{Validação da modelagem da arquitetura}

Para validar a modelagem da arquitetura MYHand, um cenário com três provedores de acesso foi simulado. Cada provedor possui quatro antenas Wi-Fi posicionadas ao longo de uma avenida de 1000 metros de extensão, como pode ser observado na Figura 49. Um usuário móvel, denominado User1, caminha pela avenida à uma velocidade de $4 \mathrm{~km} / \mathrm{h}$ e realiza trocas de rede de acordo com duas políticas de decisão diferentes, totalizando 15 minutos de caminhada. 


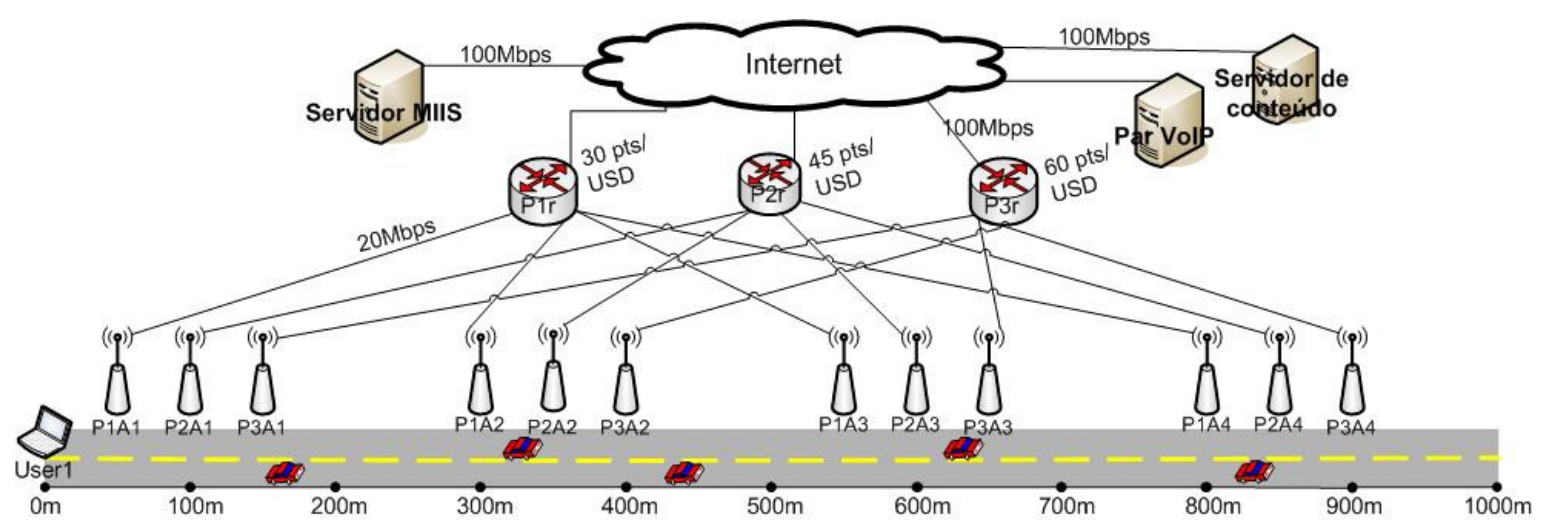

Figura 49 - Cenário para validação da modelagem da arquitetura

A primeira política de decisão, bastante comum, prioriza a força do sinal recebido (RSSI). Desta forma, o dispositivo realizou handover quando a força do sinal da próxima antena tornavase maior que o sinal da antena atual. Para evitar o efeito ping-pong, discutido no capítulo 4, foi utilizada a média das últimas cinco medidas de RSSI e uma diferença mínima de 0,1*10E-10 na RSSI de uma antena para outra, ou seja, o dispositivo faz handover se a força do sinal do novo AP é maior que a força do sinal do AP atual mais esta diferença. A segunda política prioriza a pontuação oferecida pelo provedor, simulando a arquitetura MYHand com o esquema estendido proposto. Assim, se o usuário móvel encontrar uma antena que ofereça maior pontuação, desde que a força do sinal recebido esteja acima de um limite (threshold) mínimo $(0,2 * 10 \mathrm{E}-10)$, um handover é feito para esta antena.

Ainda na Figura 49, P1r, P2r e P3r são os roteadores de borda dos provedores P1, P2 e P3, respectivamente. $\mathrm{O}$ provedor $\mathrm{P} 1$ oferece 30 pontos para cada dólar gasto conectado ao provedor P1, o provedor P2 oferece 45 pontos e o provedor P3 oferece 60 pontos por dólar gasto. Para facilitar a compreensão dos resultados, o valor cobrado pelos provedores é o mesmo, 1 dólar a cada minuto conectado ao provedor. As configurações de modelo de propagação e camada MAC foram as mesmas das simulações apresentadas no Capítulo 4. 
Em cada uma das 12 antenas, outros três usuários estacionados estão conectados para gerar tráfego na rede. Variou-se o tráfego nestes usuários em cada simulação: uma bateria de simulações com fluxos UDP de taxa constante de bit (CBR) de $100 \mathrm{Kbps}$ em cada usuário e outra bateria com fluxo de $200 \mathrm{Kbps}$ em cada um, cuja origem dos dados foi o nó Servidor de Conteúdo. No usuário móvel User1, uma conexão VoIP (64Kbps) com o host denominado Par VoIP foi executada durante sua caminhada. O total de bytes recebidos pelo usuário móvel e a pontuação obtida foi medida.

A Tabela 24 mostra os resultados de bytes recebidos e pontuação obtida com tráfego de $100 \mathrm{Kbps}$ e $200 \mathrm{Kbps}$ nos outros usuários. É possível observar na priorização por pontuação, o quanto o usuário móvel conseguiu ganhar a mais de pontuação, comparado com a priorização por força do sinal em ambos os tráfegos nos outros usuários. A vazão diminuiu pouco, em média 2bps (com $100 \mathrm{Kbps}$ de tráfego) e 45bps (com 200 Kbps de tráfego), como pode ser observado pela quantidade de bytes recebidos.

Tabela 24 - Validação da modelagem da arquitetura - parte 1

\begin{tabular}{|c|l|c|c|}
\hline Tráfego nos outros usuários & \multicolumn{1}{|c|}{ Medida } & $\begin{array}{c}\text { Priorizando } \\
\text { RSSI }\end{array}$ & $\begin{array}{c}\text { Priorizando } \\
\text { PONTUAÇÃO }\end{array}$ \\
\hline \multirow{2}{*}{$100 \mathrm{Kbps}$} & bytes recebidos & $7013 \mathrm{~KB}$ & $7011 \mathrm{~KB}$ \\
\cline { 2 - 4 } & Pontos ganhos & 689 & 873 \\
\hline \multirow{2}{*}{$200 \mathrm{Kbps}$} & bytes recebidos & $6996 \mathrm{~KB}$ & $6955 \mathrm{~KB}$ \\
\cline { 2 - 4 } & Pontos ganhos & 693 & 844 \\
\hline
\end{tabular}

Para variar mais o cenário, foram feitas as mesmas simulações com as pontuações invertidas, ou seja, provedor P1 oferecendo 60 pontos, P2 oferecendo 45 pontos e P3 oferecendo 30 pontos por dólar gasto. Os resultados destas simulações, mostrados na Tabela 25, também demonstram o aumento na pontuação obtida e leve queda na vazão. 
Tabela 25 - Validação da modelagem da arquitetura - parte 2

\begin{tabular}{|c|l|c|c|}
\hline Tráfego nos outros usuários & \multicolumn{1}{|c|}{ Medida } & $\begin{array}{c}\text { Priorizando } \\
\text { RSSI }\end{array}$ & $\begin{array}{c}\text { Priorizando } \\
\text { PONTUAÇÃO }\end{array}$ \\
\hline \multirow{2}{*}{$100 \mathrm{Kbps}$} & bytes recebidos & $7013 \mathrm{~KB}$ & $7005 \mathrm{~KB}$ \\
\cline { 2 - 4 } & Pontos ganhos & 660 & 900 \\
\hline \multirow{2}{*}{$200 \mathrm{Kbps}$} & bytes recebidos & $6996 \mathrm{~KB}$ & $6922 \mathrm{~KB}$ \\
\cline { 2 - 4 } & Pontos ganhos & 656 & 879 \\
\hline
\end{tabular}

O custo do lado cliente para a obtenção das informações de incentivo não foi calculado, mas seria da ordem de algumas dezenas de bytes. Estas informações serão recebidas juntamente com as outras informações do esquema básico, não havendo necessidade de realização de scanning. 


\section{Capítulo 6 Conclusões e trabalhos futuros}

Conforme previsto nas Redes de Próxima Geração (NGN), um usuário móvel poderá acessar sob demanda várias redes de tecnologias diferentes, mesmo sem ter contrato com a rede à qual irá se conectar, e será o responsável pelo gerenciamento de handover. Estas características podem melhorar ou piorar a experiência de acesso do usuário e causar alguns impactos na vazão recebida, no valor gasto pelo acesso e no número de handovers feitos. Ainda, para o usuário poder decidir uma troca, ele precisará obter parâmetros de acesso das várias redes disponíveis, preferencialmente, antes de alcançar a área de cobertura daquela rede para poder antecipar a troca.

Esta tese apresentou, por meio de simulações, uma avaliação dos resultados de valor gasto com o acesso, quantidade de bytes recebidos e número de handovers feitos em um cenário com redes Wi-Fi e acesso sob demanda, comparado com o acesso tradicional (como é feito atualmente), no qual o usuário móvel pôde decidir o handover priorizando preço, força do sinal recebido ou carga de trabalho no ponto de acesso. Foram criados dois cenários, um menos povoado e outro mais povoado em termos de antenas e usuários, e para cada um variou-se a velocidade do usuário móvel ( $5 \mathrm{~km} / \mathrm{h}$ e $36 \mathrm{~km} / \mathrm{h}$ ), a aplicação (VoIP, vídeo MPEG1 e FTP), e o tráfego nos outros usuários (100 kbps, 200 kbps e 400 kbps), totalizando 144 configurações diferentes de simulações diferentes. Esta tese apresentou também uma arquitetura de provimento de informações adicionais, denominada MYHand, que pode ser utilizada por um usuário móvel em um ambiente com acesso sob demanda em NGN para melhor decidir quando e para qual antena um handover deve ser feito. Para a montagem desta arquitetura, utilizou-se o protocolo 802.21, juntamente com um novo esquema estendido, e a arquitetura Y-Comm. 
Nas simulações nas quais o preço de acesso foi priorizado, o valor gasto diminuiu comparado ao acesso tradicional. Este valor aumentou com o aumento de tráfego nos outros usuários, pois com a perda de advertisements (pacotes de aviso de presença), o dispositivo móvel era obrigado a conectar-se a antenas mais caras. Com o usuário em movimento à $5 \mathrm{~km} / \mathrm{h}$, no qual o número de handovers pode aumentar devido ao efeito ping-pong, com pouco tráfego, menos handovers foram feitos, comparado ao acesso tradicional, pois a política de decisão tornou-se mais estável à variação da força do sinal. Porém, com mais tráfego, o número de handovers aumentou. A quantidade de bytes recebidos foi próxima ao acesso tradicional com pouco tráfego nos outros usuários e tornou-se maior que no acesso tradicional com o aumento de tráfego nos outros usuários.

Nas simulações nas quais a força do sinal recebido foi priorizada, o número total de bytes recebidos aumentou comparado ao acesso tradicional, exceto nas simulações com tráfego VoIP, à 36 km/h e 100kbps nos outros usuários, nas quais o usuário móvel, seguindo a política de acesso tradicional, pôde permanecer por mais tempo conectado à mesma antena sem queda na vazão, podendo-se concluir que nem sempre o acesso sob demanda é benéfico. Movimentando-se à 36 $\mathrm{km} / \mathrm{h}$, o número de handovers foi maior que no acesso tradicional; à $5 \mathrm{~km} / \mathrm{h}$ com mais tráfego, o número de handovers foi maior, e com pouco tráfego variou, ou seja, em algumas simulações foi maior e em outras foi menor. Em todas as simulações, o usuário móvel gastou mais que no acesso tradicional e este valor permaneceu estável independente do aumento de tráfego na rede (diferentemente da priorização por preço).

Nas simulações nas quais a carga de trabalho no ponto de acesso foi priorizada, o número total de bytes recebidos também aumentou comparado ao acesso tradicional, exceto nas simulações com tráfego VoIP à 36 km/h e 100 kbps nos outros usuários, reforçando a conclusão de que nem sempre o acesso sob demanda é benéfico. Porém o desempenho foi inferior à 
priorização por força do sinal, obtendo uma vazão menor. De forma geral, comparado ao acesso tradicional, o número de handovers foi pareceido ou até menor quando em movimento à $5 \mathrm{~km} / \mathrm{h}$ com baixo tráfego, e mais handovers foram feitos quando em movimento à $5 \mathrm{~km} / \mathrm{h}$ com mais tráfego ou à 36 km/h (com baixo e alto tráfego). Considerando o valor gasto, esta abordagem teve o pior desempenho.

As simulações realizadas envolveram apenas redes Wi-Fi para melhor comparar o acesso sob demanda e o acesso tradicional. Em um contexto multitecnologia, ou seja, em redes heterogêneas, os resultados poderiam ser diferentes devido às diferentes características de cobertura, capacidade de vazão, e preço, por exemplo. Tendo disponível uma tecnologia com maior cobertura (LTE, por exemplo) o usuário móvel poderia permanecer mais tempo conectado à mesma antena e diminuir a quantidade de trocas de rede, podendo mudar assim sua decisão de handover.

O estudo envolvendo as simulações proporcionou um aprendizado bastante rico, aumentando o conhecimento e a prática relacionados principalmente ao Mobile IP, ao comportamento da força do sinal recebido em função da distância, à programação C++ e OTcl, à análise do efeito ping-pong em função da distância entre antenas e tráfego no meio sem fio, e ao próprio ambiente de simulação.

Com relação à arquitetura MYHand, esta não especifica um algoritmo de decisão, mas pode ser utilizada em conjunto com um algoritmo para auxiliar no processo de tomada de decisão através do fornecimento de informações adicionais. Não há exigência de mudança nos equipamentos de rede e protocolos além das mudanças já planejadas pelo 802.21 e Y-Comm, apenas será necessária a disponibilidade do esquema estendido juntamente com o Esquema Básico do padrão IEEE 802.21. O modelo de incentivo via pontuação apresentado com a 
arquitetura MYHand é apenas um exemplo entre uma gama grande de informações adicionais que podem ser disponibilizadas pelos provedores de acesso através desta arquitetura.

\subsection{Contribuições}

Os resultados desta tese, tanto das simulações quanto da arquitetura proposta, contribuem no gerenciamento de handovers em redes com acesso sob demanda. Os resultados das simulações podem auxiliar usuários móveis a escolherem melhor uma política de decisão em função do contexto atual, mais precisamente quando tiverem disponíveis informações de número de antenas ao redor, preço do acesso, carga de trabalho nos pontos de acesso, velocidade, e ainda levando em consideração a aplicação que está sendo executada no dispositivo móvel. Além disso, a arquitetura MYHand permitirá aos provedores de acesso oferecerem informações adicionais para que clientes em potencial possam decidir melhor uma troca de rede. Da mesma forma que pode ocasionar maior concorrência entre provedores.

Os resultados desta tese também tiveram contribuições para a literatura, conforme a lista de artigos abaixo:

- $\quad$ Access on demand in NGN: a methodology for assessing the impacts of dynamic changes of wireless providers [Augusto, 2009]. Este artigo apresenta uma metodologia para avaliação dos impactos do acesso sob demanda em redes sem fio. Esta metodologia foi utilizada, em parte, para a montagem dos cenários e simulações desta tese. Este artigo foi aceito para publicação no 8th International Information and Telecommunication Technologies Symposium (I2TS'2009);

- $\quad$ Exploring Efficient Imperative Handover Mechanisms for Heterogeneous Wireless Networks [Mapp, 2009]. Este artigo apresenta de forma mais detalhada algumas partes da arquitetura Y-Comm e uma classificação dos tipos de handover. Estas duas partes do artigo 
foram debatidas em reuniões com o primeiro autor do artigo em sua visita ao ICMC em 2008 e estão apresentadas nesta tese. Este artigo foi aceito para publicação no $12^{\text {th }}$ International Conference on Network-Based Information Systems (NBIS'2009);

- Exploiting Location and Contextual Information to Develop a Comprehensive Framework for Proactive Handover in Heterogeneous Environments [Mapp, 2012]. Este artigo explora o desenvolvimento de um arcabouço que pode otimizar a comunicação em redes heterogêneas usando informação de localização e contexto. Inclui a classificação dos tipos de handover. Este artigo foi aceito para publicação no Journal of Computer Networks and Communications (JCNC), edição especial "Context-Enriched and Location-Aware Services";

- Access on Demand on Wi-Fi Networks: the Impact of Dynamic Switching of Providers for the Mobile User [Augusto, 2012a]. Este artigo apresenta os resultados das simulações de um ambiente com acesso sob demanda apresentados no Capítulo 4 desta tese. Este artigo foi aceito para publicação no XI Workshop em Desempenho de Sistemas Computacionais e de Comunicação (Wperformance 2012);

- A Novel Architecture for Improving Alternative Handovers in NGNs [Augusto, 2012b]. Este artigo apresenta a arquitetura para provimento de informações adicionais para acesso sob demanda em ambiente NGN, apresentada no Capítulo 5 desta tese. Este artigo foi submetido ao 7th Latin America Networking Conference (LANC'2012) e aguarda resultado de aceitação.

\subsection{Trabalhos Futuros}

Como sugestões para trabalhos futuros, com relação às simulações, poderia ser trabalhado o estresse de carga na rede para procurar limites. Por exemplo, nos gráficos de valor gasto em função do tráfego nos outros usuários, o valor gasto é menor quando o usuário prioriza preço, 
porém, quanto maior o tráfego, maior o gasto. Até que ponto compensa priorizar preço, considerando o tráfego nos outros usuários? Também poderia ser feito um estudo mais detalhado investigando as perdas associadas ao tempo de handover (100ms), principalmente com fluxo TCP devido à necessidade de recebimento de ACKs (acknowledgement) no transmissor dos pacotes. Outra sugestão é simular políticas de decisão de handover mais complexas ou até mesmo baseadas em teoria dos jogos, que considerem outras métricas além das trabalhadas nesta tese.

Com relação à arquitetura MYHand, poderia ser implementada uma negociação de parâmetros de acesso entre o dispositivo móvel e as redes de acesso tais como privacidade, segurança e incentivos utilizando-se o protocolo 802.21. 


\section{Referências Bibliográficas}

[3GPP 22.934] Third Generation Partnership Projetct - 3GPP, "Feasibility study on 3GPP system to Wireless Local Area Network (WLAN) interworking”, Release 7, Junho, 2007.

[3GPP 23.101] Third Generation Partnership Projetct - 3GPP, "General UMTS Architecture", Release 7, Junho, 2007.

[Araujo, 2003] Araújo, R. B., “Computação Ubíqua: Princípios, Tecnologias e Desafios”, XXI Simpósio Brasileiro de Redes de Computadores, p. 45-115, Maio, 2003.

[Augusto, 2009] Augusto, M., Moreira, E. S., “Access on demand in ngn: a methodology for assessing the impacts of dynamic changes of wireless providers", In: Proceedings of the $8^{\text {th }}$ International Information and Telecommunication Technologies Symposium - I2TS'09, p. 254257, Dezembro, 2009.

[Augusto, 2012a] Augusto, M., Moreira, E. S., "Access on Demand on Wi-Fi Networks: the Impact of Dynamic Switching of Providers for the Mobile User", In: XI Workshop em Desempenho de Sistemas Computacionais e de Comunicação (Wperformance 2012), Anais do XXXII Congresso da Sociedade Brasileira de Computação, Julho, 2012.

[Augusto, 2012b] Augusto, M., Vanni, R. P., Guardia, H. C., Aiash, M., Mapp, G., Moreira, E. S., "A Novel Architecture for Improving Alternative Handovers in NGNs", submetido ao 7th Latin America Networking Conference (LANC'2012), Outubro, 2012.

[Aust, 2003] Aust, S., Proetel, D., Fikouras, N. A., Paupu, C., Gorg, D., "Policy based mobile IP handoff decision (POLIMAND) using generic link layer information", In: Proceedings of the $5^{\text {th }}$ IEEE International Conference on Mobile and Wireless Communication Networks, 2003, Outubro, 2003.

[Bluetooth, 2009] The Official Bluetooth Technology Info Site. Disponível em: http://www.bluetooth.com. Acessado em junho/2012.

[Blunk, 1998] Blunk, L., Vollbreach, J., "PPP Extensible Authentication Protocol (EAP)" RFC2284, Março, 1998.

[Bresil, 2004] Bresil, R., "Integração Entre Redes Locais sem Fio (WLANs) e Redes de Sistemas Celulares", dissertação de mestrado, Instituto de Computação - Unicamp, Agosto, 2004.

[Cicconetti, 2011] Cicconetti, C., Galeassi, F., Mambrini, R., "A software architecture for network-assisted handover in IEEE 802.21", Journal of Communications, vol. 6, $\mathrm{n}^{\mathrm{o}}$ 1, p. 44-55, 2011.

[Cisco, 2008] Cisco Network Security Fundamentals: Wireless Security. Disponível em: http://www.ciscopress.com/articles/article.asp?p=360065\&seqNum=3. Acessado em junho/2012.

[DeVriendt, 2002] De Vriendt, J., Laine, P., Lerouge, C., Xiaofeng, X., "Mobile Network Evolution: A Revolution on the Move", IEEE Communications Magazine, vol. 40, n 4, p. $104-$ 111, Abril, 2002. 
[Dutta, 2006] Dutta, A., Madhani, S., Zhang, T., "Network Discovery Mechanisms for Fasthandoff", In: Proceedings of the $3^{\text {rd }}$ International Conference on Broadband Communications, Networks and Systems, p. 1-11, Outubro, 2006.

[Gast, 2002] Gast, M., 802.11 Wireless Networks: The Definitive Guide, Editora O'Reilly, 2002.

[Harte, 2002] Harte, L., Levine, R. e Kikta, R., 3G Wireless Demystified, McGraw-Hill, 2002.

[Hecker, 2005] Hecker, A., Pujolle, G., Afifi, H., Serhrouchini, A., "A New Access Control Solution for a Multi-Provider Wireless Environment", Telecommunication Systems, vol. 29, nº 2, p. 131-152, 2005.

[IEEE, 2007] Institute of Electrical and Electronics Engineers, "IEEE Standard for Information Technology - Telecommunications and Information Exchange Between Systems - Local and Metropolitan Area Networks - Specific Requirements - Part 11: Wireless LAN Medium Access Control (MAC) and Physical Layer (PHY) Specifications", IEEE Std 802.11-2007, DOI: 10.1109/IEEESTD.2007.373646, Junho, 2007.

[IEEE, 2009a] Institute of Electrical and Electronics Engineers, "IEEE Standard for Local and Metropolitan Area Networks - Part 21: Media Independent Handover Services", IEEE Std 802.21-2008, DOI: 10.1109/IEEESTD.2009.4769367, Janeiro, 2009

[IEEE, 2009b] Institute of Electrical and Electronics Engineers, "IEEE Standard for Information Technology - Telecommunications and Information Exchange Between Systems - Local and Metropolitan Area Networks - Specific Requirements - Part 11: Wireless LAN Medium Access Control (MAC) and Physical Layer (PHY) Specifications - Amendment 5: Enhancements for Higher Throughput”, IEEE Std 802.11n-2009, Outubro, 2009.

[ISO4217, 2012] International Organization for Standardization - ISO, "Current currencies \& funds". Disponível em: http://www.iso.org/iso/currency_codes_list-1. Acessado em junho/2012.

[ITU, 2004] International Telecommunication Union - ITU-T Recommendation Y.2001, "General overview of NGN", Disponível em: http://www.itu.int/rec/T-REC-Y.2001-200412-I/e. Acessado em junho/2012.

[ITU, 2009] International Telecommunication Union. Disponível em: http://www.itu.int/home/imt.html. Acessado em julho/2012.

[Johnson , 2004] Johnson, D., Perkins, C., Arkko, J., "Mobility Support in Ipv6" - RFC 3775, Junho, 2004.

[Johnson, 2011] Johnson, D., Perkins, C., Arkko, J., "Mobility Support in Ipv6" - RFC 6275, Julho, 2011.

[Kappler, 2004] Kappler, C., Mendes, P., Prehofer, C., Poyhonen, P., Zhou, D., "A framework for self-organized network composition", In: Proceedings of the First international IFIP Conference on Autonomic Communication WAC'04, p. 139-151, 2004, ISBN:3-540-27417-0 978-3-540-27417-9, DOI 10.1007/11520184 11. 
[Kassar, 2008] Kassar, M., Kervella, B., and Pujolle, G.. "An overview of vertical handover decision strategies in heterogeneous wireless networks". Computer Communications, vol. 31, $\mathrm{n}^{\mathrm{o}}$ 10, p. 2607-2620, Junho, 2008.

[Korhonen, 2008] Korhonen, J., Aboba, B., Bari, F., Arkko, J., "Network Discovery and Selection Problem" - RFC 5113, 2008.

[Li, 2007] Li, B., Qin, Y., Low, C. P., Gwee, C. L., "A Survey on Mobile WiMAX”, IEEE Communications Magazine, vol. 5, nº 12, p. 70-75, Dezembro, 2007.

[Loa, 2010] Loa, K., Wu, C., Sheu, S., Yuan, Y., Chion, M., Huo, D., Xu, L., "IMT-Advanced Relay Standards - WiMax/LTE Update", IEEE Communications Magazine, vol. 48, nº 8, p. 4048, DOI 10.1109/MCOM.2010.5534586, Agosto, 2010.

[Lopes, 2007] Lopes, R. R. F., Yokoyama, R. S., Santos, D. P., Moreira, E. S., Guardia, H. C., "Wireless Footprinting: Um mecanismo ciente de contexto para gerenciar handovers entre redes de acesso sem fio", In: I Workshop on Pervasive and Ubiquitous Computing - WPUC 2007, 2007.

[Lyytinen, 2002] Lyytinen, K., Yoo, Y., "Issues and Challenges in Ubiquitous Computing", Communications of the ACM, vol. 45, $\mathrm{n}^{\circ}$ 12, p. 62-65, Dezembro, 2002.

[Mapp, 2007] Mapp, G., Shaikh, F., Cottingham, D., Crowcroft, J., Baliosian, J., "Y-Comm: a global architecture for heterogeneous networking", In: Proceeding of the $3^{\text {rd }}$ International Conference on Wireless Internet (WICON 2007), 2007, ISBN: 978-963-9799-12-7.

[Mapp, 2009] Mapp, G., Shaikh, F., Aiash, M., Vanni, R.M. P., Augusto, M., Moreira, E. S., "Exploring efficient imperative handover mechanisms for heterogenous wireless", In: Proceedings of the 12th International Conference on Network-Based Information Systems NBiS, p. 286-291, Agosto, 2009.

[Mapp, 2012] Mapp, G., Katsriku, F., Aiash, M., Chinnam, N., Lopes, R., Moreira, E. S., Vanni, R. M. P., Augusto, M., "Exploiting Location and Contextual Information to Develop a Comprehensive Framework for Proactive Handover in Heterogeneous Environments", Journal of Computer Networks and Communications (JCNC), 2012.

[Martins, 2003] Martins, L., Barbosa, A., Lima, M. B., "Redes móveis baseadas nos protocolos IPv4 e IPv6 - uma visão geral do MIP e MIPv6", Boletim bimestral sobre tecnologia de redes RNP Rede Nacional de Ensino e Pesquisa, ISSN 1518-5974, vol. 7, nº 1, Abril, 2003.

[Mateus, 2010] Mateus, A., Marinheiro, R. N., "A Media Independent Information Service Integration Architecture for Media Independent Handover", In: Proceedings of $9^{\text {th }}$ International Conference on Networks (ICN 2010), p. 173-178, French Alps, France, Abril, 2010.

[Medepalli, 2004] Medepalli, K., Gopalakrishnan, P., Famolari, D., Kodama, T., "Voice capacity of IEEE 802.11b, 802.11a and 802.11g wireless LANs", In: Proceedings of IEEE Global Telecommunications Conference - Globecom 2004, vol. 3, p. 1549-1553, 2004. 
[Moreira, 2007] Moreira, E. S., Cottingham, D., Crowcroft, J., Hui, P., Mapp, G., Vanni, R. M. P., "Exploiting Handovers to Improve Business in $4^{\text {th }}$ Generation Environments", In: Proceedings of the $2^{\text {nd }}$ IEEE International Conference on Digital Information Management (ICDIM'07), 2007.

[Niebert, 2004] Niebert, N., Schieder, A., Abramowicz, H., Prehofer, C., Karl, H., "Ambient Networks: An Architecture for Communication Networks Beyond 3G", IEEE Wireless Communication, vol. 11, no 2, p. 14-22, Abril, 2004.

[NOAH, 2012] The NO Ad-Hoc Routing Agent (NOAH) website. Disponível em: http://icapeople.epfl.ch/widmer/uwb/ns-2/noah/. Acessado em junho/2012.

[NS2, 2012] The Network Simulator - NS2. Disponível em: http://nsnam.isi.edu/nsnam. Acessado em junho/2012.

[OWL2, 2012] OWL2. Web Ontology Language (OWL2). Disponível em: http://www.w3.org/TR/owl2-overview. Acessado em junho/2012.

[Palazzi, 2007] Palazzi, C. E., Chin, B., Ray, P., Pau, G., Gerla, M., Roccetti, M.,’High Mobility in a Realistic Wireless Environment: a Mobile IP Handoff Model for NS-2", In: Proceedings of the $3^{\text {rd }}$ International Conference on Testbeds and Research Infrastructures for the Development of Networks and Communities - TridentCom 2007, p. 1-7, Maio, 2007.

[Perkins, 2002] Perkins, C., "IP Mobility Support for Ipv4” - RFC 3344, Agosto, 2002.

[Perkins, 2010] Perkins, C., "IP Mobility Support for Ipv4, Revised" - RFC 5944, Novembro, 2010.

[Peterson, 2005] Peterson, J., “A Presence-based GEOPRIV Location Object Format" - RFC 4119, Dezembro, 2005.

[Polk, 2004] Polk, J., Schnizlein, J., Linsner, M., "Dynamic Host Configuration Protocol Option for Coordinate-based Location Configuration Information” - RFC 3825, Julho, 2004.

[Pollini, 1996] Pollini, G. P., "Trends in handover design”, IEEE Communications Magazine, vol. 34, n 3, p. 82-90, Março, 1996.

[Rigney, 2000] Rigney, C., Willats, W., Calhoun, P., "RADIUS Extensions" - RFC 2869, Junho, 2000.

[Rizvi, 2010] Rizvi, S., Aziz, A., and Saad, N.. "An overview of vertical handoff decision policies for next generation wireless networks". IEEE Asia Pacific Conference on Circuits and Systems (APCCAS), p. 88-91, Dezembro, 2010.

[Samjani, 2002] Samjani, A., "General Packet Radio Service (GPRS)”, IEEE Potentials, vol. 21, no 2, p. 12-15, Abril-Maio, 2002.

[Sharma, 2004] Sharma, S., Zhu, N., Chieueh, T., "Low-latency mobile IP handoff for infrastructure-mode wireless LANs", IEEE Journal on Selected Areas in Communications, vol. 22, no 4, p. 643-652, Maio, 2004. 
[Srivastava, 2005] Srivastava, V., Motani, M., "Cross-layer design: A survey and the road ahead”, IEEE Communications Magazine, vol. 43, nº 12, p. 112-119, Dezembro, 2005.

[Su, 2007] Su, J., Scott, J., Hui, P., Upton, E., Lim, M. H., Diot, C., Crowcroft, J., Goel, A., Lara, E., "Haggle: Clean-Slate Networking for Mobile Devices", Technical report UCAM-CL-TR-680, University of Cambridge, Janeiro, 2007.

[Symington, 2009] Symington, A., Kritzinger, P., "A Hardware Test Bed for Measuring IEEE 802.11g Distribution Coordination Function Performance", In: Proceedings of the $17^{\text {th }}$ IEEE/ACM International Sysmposium on Modelling, Analysis and Simulation of Computer and Telecommunication Systems - MASCOTS 2009, p. 1-7, Setembro, 2009.

[Tanembaum, 2003] Tanembaum, A. S., Redes de Computadores, Editora Campus, 4a edição, 2003.

[Urien, 2002] Urien, P., Tizraoui, A., Loutrel, M., Lu, K., "Integration EAP in SIM-IP smartcards", Workshop ASWN, 2002.

[Vanni, 2006] Vanni, R. M. P., Moreira, E. S., Goularte, R., "DOHand: An ontology to support building services to exploit handover information in mobile heterogeneous networks", In: Proceedings of the $5^{\text {th }}$ International Information and Telecommunication Technologies Symposium - I2TS'06, vol. 1, p. 105-112, Dezembro, 2006.

[Wang, 1999] Wang, H. J., Katz, R. H., Giese, J., "Policy-enabled handoffs across heterogeneous wireless networks", In: Proceedings of the $2^{\text {nd }}$ IEEE Workshop on Mobile Computing Systems and Applications - WMCSA'99, p. 51-60, Fevereiro, 1999.

[Weiser, 1991] Weiser, M., "The Computer for the $21^{\text {st }}$ Century", Scientific American, vol. 265, no 3, p. 94-104, Setembro, 1991.

[WiFi, 2009] Wireless Ethernet Compatibility Alliance. Disponível em: http://www.wi-fi.org. Acessado em junho/2012.

[Wiki, 2012] Wikipedia - The Free Encyclopedia, "IEEE 802.11ac". Disponível em: http://en.wikipedia.org/wiki/IEEE_802.11ac. Acessado em julho/2012.

[WiMAX, 2009] WiMAX Forum, "Mobile WiMAX - Part I: A Technical Overview and Performance Evaluation". Disponível em: http://www.wimaxforum.org. Acessado em junho/2012.

[Wu, 2009] Wu, J., Yang, S., Hwang, B., "A terminal-controlled vertical handover decision scheme in IEEE 802.21-enabled heterogeneous wireless networks", International Journal of Communication Systems, vol. 22, no 7, p. 819-834, Julho, 2009.

[Yokoyama, 2008] Yokoyama, R. S., Kimura, B. Y., Lopes, R. R. F., Moreira, E. S., "Uma abordagem ciente de contexto para handovers orientados a serviços em ambientes NGN", In: Proceedings of the $7^{\text {th }}$ International Information and Telecommunication Technologies Sysmposium - I2TS'08, Dezembro, 2008. 
[Zhu, 2006] Zhu, F., Mcnair, J., "Multiservice vertical handoff decision algorithm", EURASIP Journal on Wireless Communications and Networking, vol. 6, n 2, p. 1-13, Abril, 2006. 


\section{Apêndice A - Resultados do cenário menos povoado à 36 $\mathrm{km} / \mathrm{h}$}

\begin{tabular}{|c|c|c|c|c|c|c|}
\hline \multirow{2}{*}{$\begin{array}{l}\text { Aplicação } \\
\text { no móvel }\end{array}$} & \multirow{2}{*}{$\begin{array}{l}\text { Tráfego outros } \\
\text { usuários (bps) }\end{array}$} & \multirow[t]{2}{*}{ Medida } & \multirow{2}{*}{$\begin{array}{c}\text { Acesso } \\
\text { tradicional }\end{array}$} & \multicolumn{3}{|c|}{ Acesso sob demanda } \\
\hline & & & & PREÇO & RSSI & CARGA \\
\hline \multirow{9}{*}{ VoIP } & \multirow[t]{3}{*}{$100 \mathrm{k}$} & Valor pago & 15.29 & 11.42 & 16.28 & 21.33 \\
\hline & & Bytes recebidos & 868000 & 840800 & 865440 & 861280 \\
\hline & & Nro handovers & 2 & 4 & 8 & 3 \\
\hline & \multirow[t]{3}{*}{$200 \mathrm{k}$} & Valor pago & 15.29 & 11.31 & 16.77 & 21.11 \\
\hline & & Bytes recebidos & 805120 & 829440 & 857120 & 826560 \\
\hline & & Nro handovers & 4 & 4 & 8 & 4 \\
\hline & \multirow[t]{3}{*}{$400 \mathrm{k}$} & Valor pago & 15.29 & 12.56 & 16.28 & 19.83 \\
\hline & & Bytes recebidos & 620320 & 791200 & 859680 & 804640 \\
\hline & & Nro handovers & 2 & 8 & 8 & 6 \\
\hline \multirow{9}{*}{ MPEG1 } & \multirow[t]{3}{*}{$100 \mathrm{k}$} & Valor pago & 15.29 & 11.81 & 16.64 & 21.33 \\
\hline & & Bytes recebidos & 19047800 & 19535800 & 20279400 & 20276200 \\
\hline & & Nro handovers & 4 & 5 & 8 & 3 \\
\hline & \multirow[t]{3}{*}{$200 \mathrm{k}$} & Valor pago & 15.29 & 12.20 & 16.69 & 20.77 \\
\hline & & Bytes recebidos & 14499800 & 18910000 & 20278400 & 19149800 \\
\hline & & Nro handovers & 2 & 5 & 8 & 7 \\
\hline & \multirow[t]{3}{*}{$400 \mathrm{k}$} & Valor pago & 15.29 & 13.82 & 16.19 & 19.06 \\
\hline & & Bytes recebidos & 9329400 & 15170000 & 16392600 & 15141200 \\
\hline & & Nro handovers & 2 & 8 & 10 & 13 \\
\hline \multirow{9}{*}{ FTP } & \multirow[t]{3}{*}{$100 \mathrm{k}$} & Valor pago & 15.29 & 11.15 & 16.50 & 21.33 \\
\hline & & Bytes recebidos & 35558640 & 34297380 & 45876640 & 38256720 \\
\hline & & Nro handovers & 4 & 5 & 8 & 3 \\
\hline & \multirow[t]{3}{*}{$200 \mathrm{k}$} & Valor pago & 15.29 & 11.36 & 16.44 & 20.72 \\
\hline & & Bytes recebidos & 22511760 & 22679620 & 35065840 & 27969520 \\
\hline & & Nro handovers & 2 & 7 & 8 & 7 \\
\hline & \multirow[t]{3}{*}{$400 \mathrm{k}$} & Valor pago & 15.29 & 13.01 & 16.64 & 20.88 \\
\hline & & Bytes recebidos & 3699120 & 10242580 & 16525780 & 11779500 \\
\hline & & Nro handovers & 2 & 5 & 8 & 7 \\
\hline
\end{tabular}




\section{Apêndice B - Resultados do cenário menos povoado à 5 $\mathrm{km} / \mathrm{h}$}

\begin{tabular}{|c|c|c|c|c|c|c|}
\hline \multirow{2}{*}{$\begin{array}{l}\text { Aplicação } \\
\text { no móvel }\end{array}$} & \multirow{2}{*}{$\begin{array}{l}\text { Tráfego outros } \\
\text { usuários (bps) }\end{array}$} & \multirow[t]{2}{*}{ Medida } & \multirow{2}{*}{$\begin{array}{c}\text { Acesso } \\
\text { tradicional }\end{array}$} & \multicolumn{3}{|c|}{ Acesso sob demanda } \\
\hline & & & & PREÇO & RSSI & CARGA \\
\hline \multirow{9}{*}{ VoIP } & \multirow[t]{3}{*}{$100 \mathrm{k}$} & Valor pago & 105.64 & 78.67 & 113.50 & 140.71 \\
\hline & & Bytes recebidos & 5890080 & 6013760 & 6057920 & 6041120 \\
\hline & & Nro handovers & 36 & 5 & 18 & 7 \\
\hline & \multirow[t]{3}{*}{$200 \mathrm{k}$} & Valor pago & 105.64 & 83.62 & 113.30 & 143.72 \\
\hline & & Bytes recebidos & 5755520 & 6012160 & 6049600 & 6020480 \\
\hline & & Nro handovers & 24 & 5 & 14 & 14 \\
\hline & \multirow[t]{3}{*}{$400 \mathrm{k}$} & Valor pago & 105.64 & 96.49 & 113.39 & 132.85 \\
\hline & & Bytes recebidos & 4061120 & 5799520 & 5958400 & 5800800 \\
\hline & & Nro handovers & 4 & 8 & 18 & 13 \\
\hline \multirow{9}{*}{ MPEG1 } & \multirow[t]{3}{*}{$100 \mathrm{k}$} & Valor pago & 105.64 & 82.90 & 113.61 & 144.46 \\
\hline & & Bytes recebidos & 132289600 & 141011800 & 141924400 & 142090600 \\
\hline & & Nro handovers & 22 & 5 & 20 & 11 \\
\hline & \multirow[t]{3}{*}{$200 \mathrm{k}$} & Valor pago & 105.64 & 88.21 & 113.39 & 141.65 \\
\hline & & Bytes recebidos & 111333400 & 134665400 & 141289600 & 138697400 \\
\hline & & Nro handovers & 14 & 6 & 24 & 12 \\
\hline & \multirow[t]{3}{*}{$400 \mathrm{k}$} & Valor pago & 105.64 & 98.19 & 114.41 & 127.08 \\
\hline & & Bytes recebidos & 64136000 & 109188800 & 118051200 & 108851000 \\
\hline & & Nro handovers & 20 & 28 & 43 & 39 \\
\hline \multirow{9}{*}{ FTP } & \multirow[t]{3}{*}{$100 \mathrm{k}$} & Valor pago & 105.64 & 82.18 & 113.64 & 147.32 \\
\hline & & Bytes recebidos & 240574220 & 275267340 & 331226320 & 280121420 \\
\hline & & Nro handovers & 18 & 5 & 25 & 11 \\
\hline & \multirow[t]{3}{*}{$200 \mathrm{k}$} & Valor pago & 105.64 & 89.42 & 113.53 & 138.02 \\
\hline & & Bytes recebidos & 149812780 & 209697220 & 258164100 & 214364960 \\
\hline & & Nro handovers & 24 & 10 & 24 & 11 \\
\hline & \multirow[t]{3}{*}{$400 \mathrm{k}$} & Valor pago & 105.64 & 94.38 & 113.30 & 131.23 \\
\hline & & Bytes recebidos & 49521820 & 86374020 & 113342500 & 106791340 \\
\hline & & Nro handovers & 14 & 24 & 30 & 21 \\
\hline
\end{tabular}




\section{Apêndice C - Resultados do cenário mais povoado à $36 \mathrm{~km} / \mathrm{h}$}

\begin{tabular}{|c|c|c|c|c|c|c|}
\hline \multirow{2}{*}{$\begin{array}{c}\text { Aplicação } \\
\text { no móvel }\end{array}$} & \multirow{2}{*}{$\begin{array}{l}\text { Tráfego outros } \\
\text { usuários (bps) }\end{array}$} & \multirow[t]{2}{*}{ Medida } & \multirow{2}{*}{$\begin{array}{c}\text { Acesso } \\
\text { tradicional }\end{array}$} & \multicolumn{3}{|c|}{ Acesso sob demanda } \\
\hline & & & & PREÇO & RSSI & CARGA \\
\hline \multirow{9}{*}{ VoIP } & \multirow[t]{3}{*}{$100 \mathrm{k}$} & Valor pago & 15.29 & 9.53 & 16.88 & 21.30 \\
\hline & & Bytes recebidos & 869600 & 850080 & 861920 & 867360 \\
\hline & & Nro handovers & 3 & 3 & 12 & 5 \\
\hline & \multirow[t]{3}{*}{$200 \mathrm{k}$} & Valor pago & 15.29 & 9.64 & 16.71 & 21.30 \\
\hline & & Bytes recebidos & 840800 & 824960 & 861600 & 856480 \\
\hline & & Nro handovers & 7 & 3 & 12 & 5 \\
\hline & \multirow[t]{3}{*}{$400 \mathrm{k}$} & Valor pago & 15.29 & 11.81 & 16.43 & 20.91 \\
\hline & & Bytes recebidos & 530400 & 711360 & 760800 & 732640 \\
\hline & & Nro handovers & 5 & 14 & 17 & 8 \\
\hline \multirow{9}{*}{ MPEG1 } & \multirow[t]{3}{*}{$100 \mathrm{k}$} & Valor pago & 15.29 & 9.64 & 17.10 & 21.30 \\
\hline & & Bytes recebidos & 20004000 & 19260800 & 20201600 & 20333200 \\
\hline & & Nro handovers & 5 & 3 & 12 & 5 \\
\hline & \multirow[t]{3}{*}{$200 \mathrm{k}$} & Valor pago & 15.29 & 11.04 & 16.90 & 21.30 \\
\hline & & Bytes recebidos & 16769200 & 18846200 & 20018800 & 18760000 \\
\hline & & Nro handovers & 3 & 4 & 12 & 5 \\
\hline & \multirow[t]{3}{*}{$400 \mathrm{k}$} & Valor pago & 15.29 & 12.24 & 16.52 & 20.77 \\
\hline & & Bytes recebidos & 8447200 & 10537000 & 13159600 & 11780800 \\
\hline & & Nro handovers & 3 & 11 & 14 & 11 \\
\hline \multirow{9}{*}{ FTP } & \multirow[t]{3}{*}{$100 \mathrm{k}$} & Valor pago & 15.29 & 10.09 & 16.96 & 21.30 \\
\hline & & Bytes recebidos & 35931320 & 31888820 & 41881880 & 39809040 \\
\hline & & Nro handovers & 3 & 4 & 14 & 5 \\
\hline & \multirow[t]{3}{*}{$200 \mathrm{k}$} & Valor pago & 15.29 & 9.98 & 16.74 & 21.25 \\
\hline & & Bytes recebidos & 18969760 & 16093040 & 27559880 & 24219620 \\
\hline & & Nro handovers & 3 & 4 & 12 & 7 \\
\hline & \multirow[t]{3}{*}{$400 \mathrm{k}$} & Valor pago & 15.29 & 11.54 & 17.21 & 21.19 \\
\hline & & Bytes recebidos & 3592860 & 3483520 & 11177360 & 9329360 \\
\hline & & Nro handovers & 5 & 8 & 13 & 7 \\
\hline
\end{tabular}




\section{Apêndice D - Resultados do cenário mais povoado à $5 \mathrm{~km} / \mathrm{h}$}

\begin{tabular}{|c|c|c|c|c|c|c|}
\hline \multirow{2}{*}{$\begin{array}{c}\text { Aplicação } \\
\text { no móvel }\end{array}$} & \multirow{2}{*}{$\begin{array}{l}\text { Tráfego outros } \\
\text { usuários (bps) }\end{array}$} & \multirow[t]{2}{*}{ Medida } & \multirow{2}{*}{$\begin{array}{c}\text { Acesso } \\
\text { tradicional }\end{array}$} & \multicolumn{3}{|c|}{ Acesso sob demanda } \\
\hline & & & & PREÇO & RSSI & CARGA \\
\hline \multirow{9}{*}{ VoIP } & \multirow[t]{3}{*}{$100 \mathrm{k}$} & Valor pago & 105.64 & 68.49 & 116.76 & 147.40 \\
\hline & & Bytes recebidos & 6034720 & 6019840 & 6052480 & 6050080 \\
\hline & & Nro handovers & 17 & 12 & 24 & 17 \\
\hline & \multirow[t]{3}{*}{$200 \mathrm{k}$} & Valor pago & 105.64 & 74.99 & 115.62 & 147.12 \\
\hline & & Bytes recebidos & 5822720 & 5996480 & 6045440 & 6010880 \\
\hline & & Nro handovers & 23 & 5 & 20 & 23 \\
\hline & \multirow[t]{3}{*}{$400 \mathrm{k}$} & Valor pago & 105.64 & 86.30 & 115.07 & 144.01 \\
\hline & & Bytes recebidos & 4193120 & 5565760 & 5765920 & 5370080 \\
\hline & & Nro handovers & 11 & 39 & 38 & 59 \\
\hline \multirow{9}{*}{ MPEG1 } & \multirow[t]{3}{*}{$100 \mathrm{k}$} & Valor pago & 105.64 & 74.32 & 115.88 & 147.40 \\
\hline & & Bytes recebidos & 141603400 & 141461200 & 141699200 & 141936200 \\
\hline & & Nro handovers & 17 & 6 & 32 & 19 \\
\hline & \multirow[t]{3}{*}{$200 \mathrm{k}$} & Valor pago & 105.64 & 77.90 & 115.40 & 146.71 \\
\hline & & Bytes recebidos & 119316200 & 135819200 & 141193600 & 136009000 \\
\hline & & Nro handovers & 15 & 9 & 26 & 27 \\
\hline & \multirow[t]{3}{*}{$400 \mathrm{k}$} & Valor pago & 105.64 & 89.50 & 116.46 & 140.03 \\
\hline & & Bytes recebidos & 59423200 & 85155200 & 108808400 & 88059800 \\
\hline & & Nro handovers & 11 & 65 & 50 & 99 \\
\hline \multirow{9}{*}{ FTP } & \multirow[t]{3}{*}{$100 \mathrm{k}$} & Valor pago & 105.64 & 68.60 & 115.51 & 147.40 \\
\hline & & Bytes recebidos & 256340740 & 239716440 & 316574760 & 278484400 \\
\hline & & Nro handovers & 21 & 9 & 27 & 21 \\
\hline & \multirow[t]{3}{*}{$200 \mathrm{k}$} & Valor pago & 105.64 & 78.07 & 115.37 & 146.90 \\
\hline & & Bytes recebidos & 139305360 & 159847420 & 225502240 & 181071700 \\
\hline & & Nro handovers & 33 & 10 & 16 & 35 \\
\hline & \multirow[t]{3}{*}{$400 \mathrm{k}$} & Valor pago & 105.64 & 85.87 & 116.24 & 142.76 \\
\hline & & Bytes recebidos & 33213220 & 38915840 & 92783500 & 77167900 \\
\hline & & Nro handovers & 15 & 24 & 40 & 68 \\
\hline
\end{tabular}

